\title{
Radon Transport in Dry, \\ Cracked Soil: \\ Two-Dimensional, Finite \\ Element Model
}

D. J. Holford

S. D. Schery

J. L. Wilson

F. M. Phillips

December 1989

Prepared for the U.S. Department of Energy under Contract DE-AC06-76RLO 1830

Pacific Northwest Laboratory

Operated for the U.S. Department of Energy

by Battelle Memorial Institute

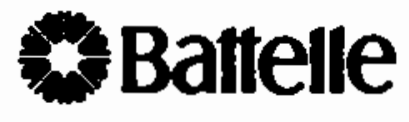




\title{
DISCLAIMER
}

This program was prepared as an account of work sponsored by an agency of the United States Government. Neither the United States Government nor any agency thereof, nor Battelle Memorial Institute, nor any or their employees, makes any warranty, expressed or implied, or assumes any legal ilability of responsibility for the accuracy, completeness, or usefulness of any information, apparatus, product, of process disclosed, of represents that its use woutd not infringe privately owned rights. Reference herein to any specific commercial product, process, or service by trade name, trademark, manuiacturer, of otherwise, does not necessarily constitute or imply its en. dorsement, recommendation, or favoring by the United States Covernment of any agency thereof, or Battelle Memorial Institute. The views and opinions of authors expressed herein do not necessarily state or reflect those of the United States Government or any agency thereof.

\author{
PACIFIC NORTHWEST LABORATORY \\ operated by \\ BATTELLE MEMORIAL INSTITUTE \\ for the \\ UNITED STATES DEPARTMENT OF ENERGY \\ under Contract DE-ACO6-76RLO 1830
}

Printed in the United States of America

Available to DOE and DOE contractors from the

Office of Scientific and Technical Information. P.O. Box 62, Oak Ridge, TN 37831; prices available from $\{615) 576-6401$. FTS 626-14401.

Availabie to the public from the National Technical Intormation Service, U.S. Department ot Commerce, 5285 Port Royal Rd., Springtield, VA 22167.

NTI5 Price Codes, Microfiche A01

\begin{tabular}{|c|c|}
\hline \multicolumn{2}{|c|}{ Printed Copy } \\
\hline Pages & $\begin{array}{l}\text { Price } \\
\text { Codes }\end{array}$ \\
\hline$\overline{001-025}$ & $\mathrm{A02}$ \\
\hline $026-050$ & $\mathrm{~A} 03$ \\
\hline $051-075$ & $A 04$ \\
\hline $076-100$ & $\mathrm{~A} 05$ \\
\hline $101-125$ & $A 06$ \\
\hline $126-150$ & $\mathrm{~A} 07$ \\
\hline 151.175 & $\mathrm{AOS}$ \\
\hline $176-200$ & $\mathrm{~A} 09$ \\
\hline $201-225$ & Ato \\
\hline $226-250$ & A11 \\
\hline $251-275$ & A12 \\
\hline $276-300$ & $\mathrm{~A} 13$ \\
\hline
\end{tabular}


D. J. Holford

S. D. Schery (a)

J. L. Wilson (a)

F. M. Phillips(a)

December 1989

Prepared for the U.S. Department of Energy under Contract DE-ACO6-76RLO 1830

Pacific Northwest Laboratory Richland, Washington 99352

(a) New Mexico Institute of Mining and Technology Socorro, NM 87801. 


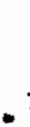




\section{ABSTRACT}

A two-dimensional finite element code, CRACK, simulates the effect of changes in surface air pressure on radon concentration in soil with parallel, partially penetrating cracks. A sensitivity analysis investigates the effect of changes in crack dimensions, soil characteristics, and surface air pressure on radon flux to the atmosphere from a dry, cracked, soil. Radon flux is found to be most sensitive to changes in soil properties: the diffusion coefficient is most important, followed by permeability and porosity. Radon flux is also sensitive to changes in barometric pressure. Cracks have a more significant effect on radon flux from soils of low permeability. The effects of moisture should be considered in future studies, because of moisture's importance to the effective air-filled porosity, air permeability, and diffusion coefficient of soils. 


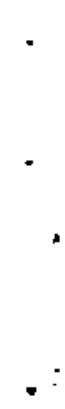




\section{SUMMARY}

A two-dimensional finite element code, CRACK, was created to simulate the effect of changes in surface air pressure on radon concentration in soil with parallel, partially penetrating cracks. The governing air flow equation assumes transient, compressible, ideal gas flow. The governing radon transport equation includes advection, diffusion, radioactive decay, and a source of radon in the soil.

A sensitivity analysis investigates the effect of changes in crack dimensions (width, depth, and spacing), soil characteristics (porosity, permeability, and diffusion coefficient), and surface air pressure changes (both constant and sinusoidal) on radon flux to the atmosphere from a dry, cracked soil.

\section{CRACK DIMENSIONS}

During decreasing atmospheric pressure, increasing the depth of a crack causes an increase in radon flux density up to an asymptotic value. This asymptotic value is approached because the velocity near the bottom of the crack is decreasing as the crack gets deeper and because the radon concentration reaches an asymptotic value with depth.

Decreasing crack spacing causes an increase in radon flux density for decreasing atmospheric pressure, if spacing is greater than depth. If spacing is less than depth, flux drops sharply with closer crack spacing. With close crack spacing, pressure decreases in adjacent cracks interfere with each other, resulting in reduced pressure gradients in the soil toward the surface and crack.

Increasing the width of a crack causes an increase in radon flux density for decreasing atmospheric pressure, up to some limit governed by the spacing and depth.

\section{SOIL CHARACTERISTICS}

Diffusive flux from the soil is proportional to soil porosity. The pressure gradient in the crack increases proportionally to the porosity of the 
soil, resulting in more advective flux out of the crack. Pressure gradients are directly proportional to porosity because increasing soil porosity increases the gas storage capacity of the soil for changes in pressure, and pressure decreases do not move as far down into the soil. Radon concentrations do not change with a change in porosity because the only term in the transport equation divided by the porosity is the specific discharge velocity, which is directly proportional to porosity.

For homogeneous soils, radon flux is proportional to soil permeability. However, for cracked soils, radon flux is higher from lower-permeability soils than from higher-permeability soils with the same size cracks. Stronger pressure gradients occur in the soil because decreased permeability does not allow pressure drops at the surface and crack to move into the soil. Stronger pressure gradients in the crack increase concentrations and surface flux.

The diffusive flux across the soil boundary is proportional to the diffusion coefficient in soil. Increasing the diffusion coefficient of the soil causes an increase in radon flux density, because the larger the value of diffusion, the shorter the diffusion path length through the soil, which enables radon to reach the surface faster without decaying.

\section{CONSTANT AND SINUSOIDAL PRESSURE VARIATIONS}

The decrease in flux density caused by rising pressure is not as great as the increase in flux density caused by dropping pressure of the same magnitude. Therefore, periods of alternately dropping and rising pressure (such as a sinusoidal variation) show a net enhancement of flux.

Decreasing the period of a sinusoidal variation in atmospheric pressure causes a small increase in mean radon flux densities but a large change in the deviation of flux about the mean. The changes are up to $70 \% 1$ arger for a soil with cracks than they are for a homogeneous soil.

Increasing the amplitude of a sinusoidal variation in atmospheric pressure causes an increase in mean radon flux densities and also in the deviation about the mean. The changes in mean flux and standard deviation are up to $100 \%$ larger for a soil with cracks than for a homogeneous soil. 


\section{COMPARISON OF MODEL RESULTS TO FIELD DATA}

While the two-dimensional model with cracks matches some of the observed peaks in radon flux better than a one-dimensional model, there are variations in the observed fluxes that do not correlate to the changes in atmospheric pressure.

Soil cracks and short-term variations in pressure attributed to wind are sufficient to explain the difference between a one-dimensional radon transport model driven by barometric pressure changes and observed radon fluxes.

\section{CONCLUSIONS}

Radon flux is sensitive to changes in soil properties, with the diffusion coefficient being most important, followed by the permeability and porosity. Radon flux is also very sensitive to changes in barometric pressure. Cracks have a more significant effect on the radon flux from low permeability soils. The effects of moisture should be considered in future modeling studies because of its influence on the effective air-filled porosity, air permeability, and effective diffusion coefficient of the soils. 
,

.

:

.

.

,

. 


\section{ACKNOWLEDGMENTS}

This study was conducted at the New Mexico Institute of Mining and Technology (NMIMT) in Socorro, New Mexico. The lead author received financial support as a research assistant in the Physics Department. This report is essentially the lead author's independent study paper, part of the requirements for her master's degree in Hydrology from the NMIMT. Dr. Stephen D. Schery, Physics Department, and Dr. John L. Wilson and Dr. Fred M. Phillips, Hydrology Section, Geoscience Department, served as independent study advisors. The technical advice of David Peterson and the editorial comments of Stephen Conrad are gratefully acknowledged.

This work was funded in part by U.S. Department of Energy under Contract DE-FG04-86ER60432. Funding for the computer simulations was also provided by the NMIMT Computer Center. Funding to publish this report has come from the Department of Energy's Office of Health and Environmental Research's Indoor Radon Program under the Radon Transport Modeling in Soils project at the Pacific Northwest Laboratory. 


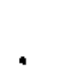

- :

.

.

$\because$

. 


\section{CONTENTS}

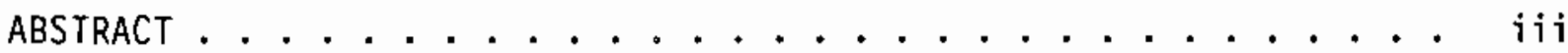

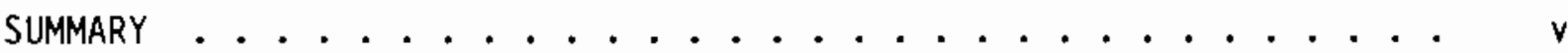

ACKNOWLEDGMENTS ......................... ix

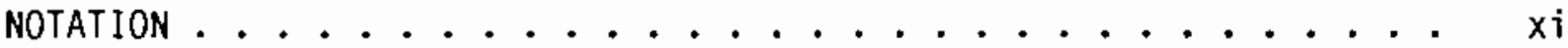

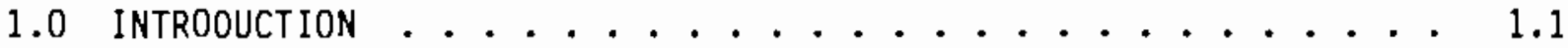

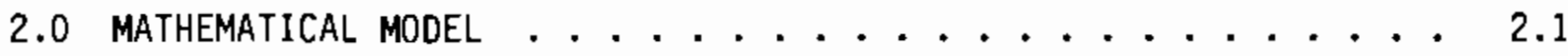

2.1 GENERAL CONSIDERATIONS AND ASSUMPTIONS ......... 2.1

2.2 RADON TRANSPORT . . . . . . . . . . . . . . 2.2

2.2.1 Derivation of Governing Equation ....... 2.2

2.2.2 Solution by Galerkin Finite Element Method . . . 2.4

2.3 AIR FLOW . . . . . . . . . . . . . . . 2.7

2.3.1 Derivation of Governing Equation . . . . . . 2.7

2.3.2 Solution by Galerkin Finite Element Method . . . 2.9

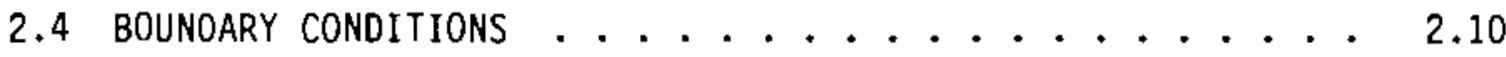

2.4.1 Boundary Conditions for Transport Equation . . . 2.10

2.4.2 Boundary Conditions for Flow Equation ...... 2.12

2.4.3 Numerical Treatment of Boundary Conditions .... 2.12

3.0 VERIFICATION OF NUMERICAL MODEL . . . . . . . . . 3.1

3.1 1-D ADVECTION, DISPERSION, DECAY, AND SOURCE $\ldots \ldots \ldots . . . . .3$

3.2 MATRIX DiffUSION FROM A SINGLE CRACK . . . . . . . 3.3

3.3 LINEARIZED GAS FLOW . . . . . . . . . . . . . . . . 3.4

3.4 LINEAR FLOW FROM INTERSECTING CONSTANT PRESSURE

BOUNDARIES ...................... 3.6 
4.0 SENSITIVITY ANALYSIS . . . . . . . . . . . . 4.1

4.1 CRACK DIMENSIONS . . . . . . . . . . . . . 4.3

4.1.1 Crack Depth ............... 4.4

4.1 .2 Crack Spacing . . . . . . . . . . . . 4.4

4.1 .3 Crack Width ............... 4.5

4.2 SOIL PROPERTIES . . . . . . . . . . . . . . . . . 4.6

4.2 .1 Porosity ................. 4.7

4.2 .2 Permeability ............. 4.7

4.2.3 Soil Diffusion Coefficient . . . . . . . 4.8

4.3 EFFECT OF PRESSURE VARIATIONS . . . . . . . . . . . 4.9

4.3.1 Linear Variations ............. 4.9

4.3.2 Sinusoidal Variations............ 4.10

5.0 COMPARISON OF MODEL RESULTS TO FIELD DATA . . . . . . . 5.1

6.0 CONCLUSIONS AND RECOMMENDATIONS . . . . . . . . . 6.1

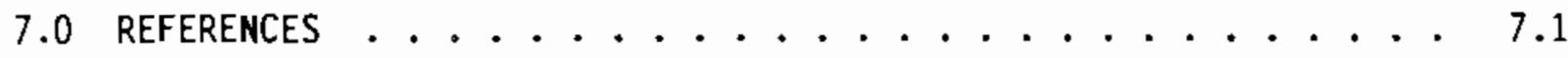




\section{FIGURES}

1.1 Uranium-238 Decay Series . . . . . . . . . . . 1.2

1.2 Schematic Diagram of Analytical Solution for Crack

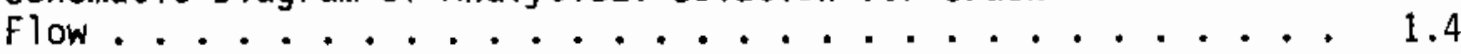

2.1 Two-Dimensional Cracked Soil Model . . . . . . . . . . 2.1

2.2 Boundary Conditions for Gas Flow and Radon Transport

Equations ........................ 2.11

3.1 Comparison of Galerkin Finite Element Solution

to Steady-State Analytical Solution for Advective-

Dispersive Equation with Decay and Source ........ . 3.2

3.2 Comparison of Galerkin Numerical Solution to a Steady-State

Analytical Solution for Matrix Diffusion from a Single

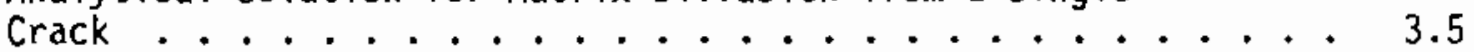

3.3 Comparison of Galerkin Numerical Solution for Pressure

Equation to a One-Dimensional Transient Analytical

Solution for Linear Flow ...............

3.4a Comparison of Numerical Solution for Pressure to a

Two-Dimensional Analytical Solution for Linear Flow

Between Two Intersecting Constant Pressure Boundaries:

Time Step $10 \ldots \ldots . \ldots . . . \ldots$

3.4b Comparison of Numerical Solution for Pressure to a

Two-Dimensional Analytical Solution for Linear Flow

Between Two Intersecting Constant Pressure Boundaries:

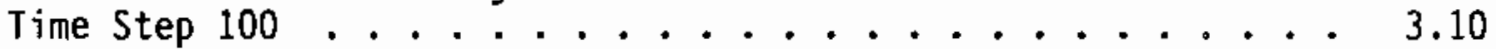

$3.4 \mathrm{c}$ Comparison of Numerical Solution for Pressure to a

Two-Dimensional Analytical Solution for Linear Flow

Between Two Intersecting Constant Pressure Boundaries:

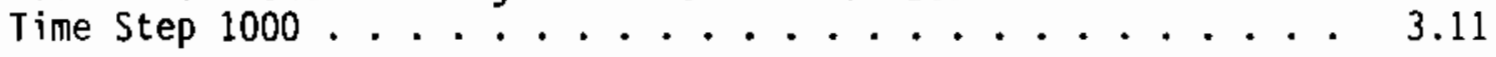

4.1 Diagram of Typical Finite Element Grid Used . . . . . . . 4.13

4.2 Steady-State Concentration Profile for Soil with Cracks

$400 \mathrm{~cm}$ Deep, $0.06 \mathrm{~cm}$ Wide, and $800 \mathrm{~cm}$ Apart ........ . 4.14

4.3a Effect of Decreasing Atmospheric Pressure with Time

at a Rate of $90 \mathrm{~Pa} / \mathrm{hr}$ on Gas Pressures in Soil with

Cracks $400 \mathrm{~cm}$ Deep, $0.06 \mathrm{~cm}$ Wide, and $800 \mathrm{~cm}$ Wide ...... 
4.3b Effect of Decreasing Atmospheric Pressure with Time at a Rate of $90 \mathrm{~Pa} / \mathrm{hr}$ on Radon Concentrations in Soil with Cracks $400 \mathrm{~cm}$ Deep, $0.06 \mathrm{~cm}$ Wide, and $800 \mathrm{~cm}$ Wide .... 4.16

4.3c Effect of Decreasing Atmospheric Pressure with Time at a Rate of $90 \mathrm{~Pa} / \mathrm{hr}$ on Radon Flux in Soil with Cracks $400 \mathrm{~cm}$ Deep, $0.06 \mathrm{~cm}$ Wide, and $800 \mathrm{~cm}$ Wide . . . . . 4.17

4.4a Effect of Crack Depth on Percent Difference in Flux Density Between Soil with Cracks Spaced $400 \mathrm{~cm}$ Apart and $0.06 \mathrm{~cm}$ Wide and Soil without Cracks After $6 \mathrm{~h}$ of Decreasing Atmospheric Pressure . . . . . . . . . . . 4.18

4.4b Effect of Crack Depth on Gas Pressures in Soil with Cracks $0.06 \mathrm{~cm}$ Wide and Spaced $400 \mathrm{~cm}$ Apart After $6 \mathrm{~h}$ of Decreasing Atmospheric Pressure . . . . . . . . .

4.4c Effect of Crack Depth on Radon Concentrations in Soil with Cracks $0.06 \mathrm{~cm}$ Wide and Spaced $400 \mathrm{~cm}$ Apart During $6 \mathrm{~h}$ of Decreasing Atmospheric Pressure . . . . . . . . . .

4.4d Effect of Crack Depth on Radon Flux Density From Soil with Cracks $0.06 \mathrm{~cm}$ Wide and Spaced $400 \mathrm{~cm}$ Apart After $6 \mathrm{~h}$ of Decreasing Atmospheric Pressure ............

4.5 Effect of Spacing and Crack Width on Percent Difference in Flux Density Between Soil With $30 \mathrm{~cm}$ Deep Cracks and Soil Without Cracks After $6 \mathrm{~h}$ of Decreasing Atmospheric Pressure ...................

4.6a Effect of Crack Spacing on Gas Pressures in Soil with Cracks $30 \mathrm{~cm}$ Deep and $0.1 \mathrm{~cm}$ Wide After $6 \mathrm{~h}$ of Decreasing Atmospheric Pressure .................

4.6b Effect of Crack Spacing on Radon Concentrations in Soil with Cracks $30 \mathrm{~cm}$ Deep and $0.1 \mathrm{~cm}$ Wide After $6 \mathrm{~h}$ of Decreasing Atmospheric Pressure ................

4.6c Effect of Crack Spacing on Radon Flux Density from Soil with Cracks $30 \mathrm{~cm}$ Deep and $0.1 \mathrm{~cm}$ Wide During $6 \mathrm{~h}$ of Decreasing Atmospheric Pressure . . . . . . . . . . . . .

4.7 Effect of Crack Width and Spacing on Percent Difference in Flux Density Between Soil with $400 \mathrm{~cm}$ Deep Cracks and Soil without Cracks After $6 \mathrm{~h}$ of Decreasing Pressure .......

4.8a Effect of Crack Spacing on Gas Pressures in Soil with Cracks $400 \mathrm{~cm}$ Deep and $0.06 \mathrm{~cm}$ Wide After $6 \mathrm{~h}$ of Decreasing Atmospheric Pressure .............. 
4.8b Effect of Crack Spacing on Radon Concentrations in Soil with Cracks $400 \mathrm{~cm}$ Deep and $0.06 \mathrm{~cm}$ Wide After $6 \mathrm{~h}$ of Decreasing Atmospheric Pressure . . . . . . . . . . . . . . .

4.8c Effect of Crack Spacing on Radon Flux Density from Soil with Cracks $400 \mathrm{~cm}$ Deep and $0.06 \mathrm{~cm}$ Wide During $6 \mathrm{~h}$ of Decreasing Atmospheric Pressure . . . . . . . . . . . . . . . . . . .

4.9a Effect of Crack Width on Gas Pressures in Soil with Cracks $30 \mathrm{~cm}$ Deep and Spaced $56 \mathrm{~cm}$ Apart After $6 \mathrm{~h}$ of Decreasing Atmospheric Pressure . . . . . . . . . . . . . . . . .

4.9b Effect of Crack Width on Radon Concentrations in Soil with Cracks $30 \mathrm{~cm}$ Deep and Spaced $56 \mathrm{~cm}$ Apart After $6 \mathrm{~h}$ of Decreasing Atmospheric Pressure . . . . . . . . . . .

4.9c Effect of Crack Width on Radon Flux Density from Soil with Cracks $30 \mathrm{~cm}$ Deep and Spaced $56 \mathrm{~cm}$ Apart During $6 \mathrm{~h}$ of Decreasing Atmospheric Pressure . . . . . . . . . . 4.32

4.10a Effect of Crack Width on Gas Pressures in Soil with Cracks $400 \mathrm{~cm}$ Deep and Spaced $800 \mathrm{~cm}$ Apart After $6 \mathrm{~h}$ of Decreasing Atmospheric Pressure....................

4.10b Effect of Crack Width on Radon Concentrations in Soil with Cracks $400 \mathrm{~cm}$ Deep and Spaced $800 \mathrm{~cm}$ Apart After $6 \mathrm{~h}$ of Decreasing Atmospheric Pressure

4.10c Effect of Crack Width on Radon Flux Density from Soil with Cracks $400 \mathrm{~cm}$ Deep and Spaced $800 \mathrm{~cm}$ Apart During $6 \mathrm{~h}$ of Decreasing Atmospheric Pressure . . . . . . . . . . .

4.11a Effect of Soil Porosity on Radon Flux Density from Homogeneous Soil During $6 \mathrm{~h}$ of Decreasing Atmospheric Pressure ......................

4.11b Effect of Soil Porosity on Radon Flux Density from Soil with Cracks $400 \mathrm{~cm}$ Deep, $0.06 \mathrm{~cm}$ Wide and Spaced $800 \mathrm{~cm}$ Apart During $6 \mathrm{~h}$ of Decreasing Atmospheric Pressure

4.11c Effect of Soil Porosity on Gas Pressures in Soil with Cracks $400 \mathrm{~cm}$ Deep, $0.06 \mathrm{~cm}$ Wide and Spaced $800 \mathrm{~cm}$ Apart After $6 \mathrm{~h}$ of Decreasing Atmospheric Pressure . . . . . . .

4.11d Effect of Soil Porosity on Radon Concentrations in Soil with Cracks $400 \mathrm{~cm}$ Deep, $0.06 \mathrm{~cm}$ Wide and Spaced $800 \mathrm{~cm}$ Apart After $6 \mathrm{~h}$ of Decreasing Atmospheric Pressure . . . . .

4.12a Effect of Soil Permeability on Radon Flux Density from Homogeneous Soil During $6 \mathrm{~h}$ of Decreasing Atmospheric Pressure 
4.12b Effect of SoiT Permeability on Radon Fiux Density from So 11 with Cracks $400 \mathrm{~cm}$ Deep, $0.06 \mathrm{~cm}$ Wide and Spaced $800 \mathrm{~cm}$ Apart During $6 \mathrm{~h}$ of Decreasing Atmospheric Pressure . . . . . . 4.41

4.12c Effect of Soil Permeability on Gas Pressures in Soil with Cracks $400 \mathrm{~cm}$ Deep, $0.06 \mathrm{~cm}$ Wide and Spaced $800 \mathrm{~cm}$ Apart After $6 \mathrm{~h}$ of Decreasing Atmospheric Pressure . . . . . 4.42

4.12d Effect of Soil Permeability on Radon Concentrations in Soil with Cracks $400 \mathrm{~cm}$ Deep, $0.06 \mathrm{~cm}$ Wide and Spaced $800 \mathrm{~cm}$ Apart After $6 \mathrm{~h}$ of Decreasing Atmospheric Pressure . . . . . . .

4.13a Effect of Soil Diffusion Coefficient on Radon Flux Density from Homogeneous Soil During $6 \mathrm{~h}$ of Decreasing Atmospheric Pressure

4.13b Effect of Soil Diffusion Coefficient on Radon Flux Density from Soil with Cracks $400 \mathrm{~cm}$ Deep, $0.06 \mathrm{~cm}$ Wide and Spaced $800 \mathrm{~cm}$ Apart During $6 \mathrm{~h}$ of Decreasing Atmospheric Pressure . . .

4.13c Effect of Soil Diffusion Coefficient on Radon Concentrations in Soil with Cracks $400 \mathrm{~cm}$ Deep, $0.06 \mathrm{~cm}$ Wide and Spaced $800 \mathrm{~cm}$ Apart After $6 \mathrm{~h}$ of Decreasing Atmospheric Pressure . .

4.14a Effect of Constantly Decreasing Atmospheric Pressure on Gas Pressures in Soil with Cracks $400 \mathrm{~cm}$ Deep, $0.06 \mathrm{~cm}$ Wide and Spaced $800 \mathrm{~cm}$ Apart After $6 \mathrm{~h}$...........

4.14b Effect of Constantly Decreasing Atmospheric Pressure on Radon Concentrations in Soil with Cracks $400 \mathrm{~cm}$ Deep, $0.06 \mathrm{~cm}$ Wide and Spaced $800 \mathrm{~cm}$ Apart After $6 \mathrm{~h}$.........

4.15a Effect of Constantly Rising Atmospheric Pressure on Gas Pressures in Soil with Cracks $400 \mathrm{~cm}$ Deep, $0.06 \mathrm{~cm}$ Wide and Spaced $800 \mathrm{~cm}$ Apart After $6 \mathrm{~h}$.............

4.15b Effect of Constantly Rising Atmospheric Pressure on Radon Concentrations in Soil with Cracks $400 \mathrm{~cm}$ Deep, $0.06 \mathrm{~cm}$ Wide and Spaced $800 \mathrm{~cm}$ Apart After $6 \mathrm{~h} \mathrm{..........}$

4.16 Effect of Constantly Changing Atmospheric Pressure on Radon Flux Density from Soil with Cracks $400 \mathrm{~cm}$ Deep, $0.06 \mathrm{~cm}$ Wide and Spaced $800 \mathrm{~cm}$ Apart During $6 \mathrm{~h}$...........

4.17a Effect of Sinusoidal Atmospheric Pressure Variation with Time of Period $=72 \mathrm{~s}$, Amplitude $=90 \mathrm{~Pa}$ on Gas Pressures in Soil with Cracks $400 \mathrm{~cm}$ Deep, $0.06 \mathrm{~cm}$ Wide and Spaced $800 \mathrm{~cm}$ Apart . . . . . . . . . . . . . . . . . . . 
4.17b Effect of Sinusoidal Atmospheric Pressure Variation with Time of Period $=72 \mathrm{~s}$, Amplitude $=90 \mathrm{~Pa}$ on Radon Concentrations in Soil with Cracks $400 \mathrm{~cm}$ Deep, $0.06 \mathrm{~cm}$ Wide and Spaced $800 \mathrm{~cm}$ Apart . . . . . . . . . . . . . . .

4.18 Effect of Sinusoidal Atmospheric Pressure Variation of Period $=7200 \mathrm{~s}$ and Amplitude $=90 \mathrm{~Pa}$ on Radon Flux Density from Soil with Cracks and Soil without Cracks . . . .

4.19 Effect of Sinusoidal Atmospheric Pressure Variation of Period $=720 \mathrm{~s}$ and Amplitude $=90 \mathrm{~Pa}$ on Radon Flux Density from Soil with Cracks and Soil without Cracks . . . . . . . .

4.20 Effect of Sinusoidal Atmospheric Pressure Variation of Period $=72 \mathrm{~s}$ and Amplitude $=90 \mathrm{~Pa}$ on Radon Flux Density from Soil with Cracks and Soil without Cracks . . . . . . .

4.21 Effect of Period of Sinusoidal Atmospheric Pressure Variation on Mean and Standard Deviation of Radon Flux Density from Soil with Cracks and Soil without Cracks ............

4.22a Effect of Period of Sinusoidal Atmospheric Pressure Variation on Gas Pressures in Soil with Cracks $400 \mathrm{~cm}$ Deep, $0.06 \mathrm{~cm}$ Wide and Spaced $800 \mathrm{~cm}$ Apart at 21600, 2160, and 216 Seconds, Respectively .....................

4.22b Effect of Period of Sinusoidal Atmospheric Pressure Variation on Radon Concentrations in Soil with Cracks $400 \mathrm{~cm}$ Deep, $0.06 \mathrm{~cm}$ Wide and Spaced $800 \mathrm{~cm}$ Apart at 21600, 2160, and 216 Seconds, Respectively .................

4.23 Effect of Sinusoidal Atmospheric Pressure Variation of Period $=720 \mathrm{~s}$ and Amplitude $=135 \mathrm{~Pa}$ on Radon Flux Density from Soil with Cracks and Soil without Cracks ........

4.24 Effect of Sinusoidal Atmospheric Pressure Variation of Period $=720 \mathrm{~s}$ and Amplitude $=180 \mathrm{~Pa}$ on Radon Flux Density from Soil with Cracks and Soil without Cracks. . . . . . . . .

4.25 Effect of Amplitude of Sinusoidal Atmospheric Pressure Variation on Mean and Standard Deviation of Radon Flux Density from Soil with Cracks and Soil without Cracks

4.26a Effect of Amplitude of Sinusoidal Atmospheric Pressure Variation with a Period of 720 Seconds on Gas Pressures in Soil with Cracks $400 \mathrm{~cm}$ Deep, $0.06 \mathrm{~cm}$ Wide and Spaced $800 \mathrm{~cm}$ Apart at 2160 Seconds 
4.26b Effect of Amplitude of Sinusoidal Atmospheric Pressure Variation with a Period of 720 Seconds on Radon Concentrations in Soil with Cracks $400 \mathrm{~cm}$ Deep, $0.06 \mathrm{~cm}$ Wide and Spaced $800 \mathrm{~cm}$ Apart at 2160 Seconds . . . . . . . . . 4.64

5.1 Atmospheric Pressure and Radon Flux Density Measurements at Field Site of Scherey et al. (1984) . . . . . . . . 5.2

5.2 Measurements of Subsurface Pressure Gradients, Barometric Pressure, and Wind Speed Taken at Field Site of Schery and Siegel (1986) Over a 32-h Period. . . . . . . . . . 5.3

\section{TABLES}

4.1 Base-Case Parameters for Sensitivity Analysis . . . . . . 4.2 


\subsection{INTRODUCTION}

Radon-222 gas is produced as a decay product of $226 \mathrm{Ra}$, which is found in soils that have weathered from rocks containing 238U (Figure 1.1). Exposure to the decay products of radon gas, when they are allowed to accumulate in a closed space such as a uranium mine, has been linked to lung cancer. There is a possibility that high concentrations in buildings may also pose a risk to health. Factors that may increase the flux of radon out of the soil are thus of great concern; cracks in soil are one of those factors.

Clements (1974) measured radon fluxes from soil at a site near the New Mexico Institute of Mining and Technology (NMIMT) campus in Socorro, New Mexico. Data collected over 12-h intervals were simulated satisfactorily by a onedimensional, homogeneous, and isotropic porous-media model that included a constant gas velocity, diffusion of radon in the soil, radioactive decay, and production of radon.

Schery, Gaeddert and Wilkening (1984) also measured radon fluxes from soil at another site near the NMIMT campus. Their data, collected over $2-h$ intervals, showed greater changes in surface radon flux density than in the subsurface concentration gradient. Fick's law [see Equation (2.1)] predicts that diffusive flux density should be proportional to the concentration gradient. They hypothesized that soil cracks might be causing the rapid changes in the flux observed, because cracks have a higher permeability and diffusion coefficient than the surrounding soil. Changes in radon concentrations would occur rapidly in the cracks, and would influence the surface fluxes recorded, but might not affect the subsurface concentration gradients significantly because the cracks would be small compared to the surrounding volume of soil. Experiments that involved forcing air up through the soil and pouring a thin film of water on top showed the presence of discrete points of rapid air exit. Polygonal cracks were observed on the surface of the soil at the site. The cracks were less than a millimeter wide, spaced 5 to $10 \mathrm{~cm}$ apart, and were probably not more than $10 \mathrm{~cm}$ deep. At an outcrop near the site, cracks and plant roots extending from the surface to at least $5 \mathrm{~m}$ were observed, but it was unclear whether the structures were connected from the surface to this depth. 


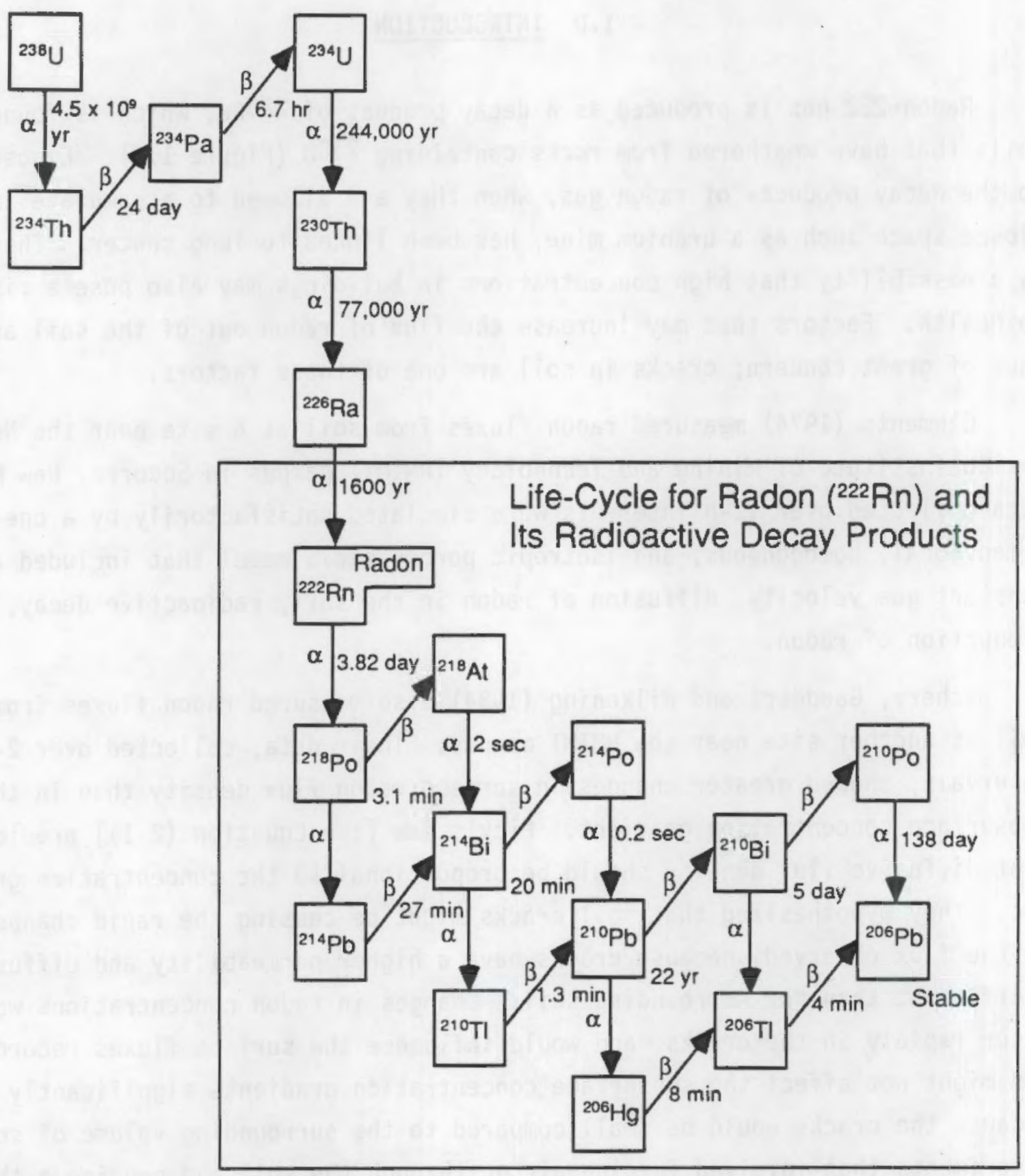

FIGURE 1.1. Uranium-238 Decay Series (showing half-lives and decay particle identities) 
Schery and Siegel (1986) estimated the effects of cracks in the soil by using simple analytical solutions for radon transport in porous media with cracks penetrating to fairly great depths where concentrations of radon have reached a maximum. However, from their results Schery and Siegel were convinced that cracks would affect surface fluxes proportionally more than they would affect the subsurface concentration gradients. Also, they concluded that cracks could cause a net enhancement of flux for sinusoidal variations in pressure such as those caused by fluctuations in wind speed or diurnal variations in atmospheric pressure. They described their calculations as "order of magnitude estimates for some limiting situations" and suggested that further modeling be done.

Analytical solutions for solute transport in ground water flowing in fractured rock have been derived by, among others, Neretnieks (1980) and Sudicky and Frind (1982). Typical assumptions for these models are illustrated in Figure 1.2. They assumed transport by advection and dispersion in the crack and by diffusion in the soil transverse to the crack. However, radon concentrations observed in the soil exhibit strong vertical gradients, which will cause diffusion parallel to vertical cracks. The analytical solutions also did not include advection in the porous media. However, Schery, Gaeddert and Wilkening (1984) showed, using a one-dimensional convective-dispersive model, that subsurface pressure gradients measured in field soil could cause significant changes in subsurface radon concentrations and, hence, in the radon surface flux. The analytical solutions also assumed the cracks penetrate fully to a constant concentration boundary at depth. This is a very limiting assumption, because the crack will have an effect on the radon flux that is proportional to its depth. Finally, the analytical solutions assume that at the top boundary, the concentration equals zero at a semi-infinite distance. Placing this boundary condition at the top of the crack is unrealistic, because as atmospheric pressure drops, the amount of radon transported out of the crack by advection is probably large enough to raise the concentration above zero.

The lack of appropriate analytical solutions led next to the possibility of using existing numerical solutions. Finite-element solutions by Huyakorn, Lester and Faust (1983), and Grisak and Pickens (1980a,b) illustrate the two main approaches to the numerical modeling of flow in cracked porous media. 


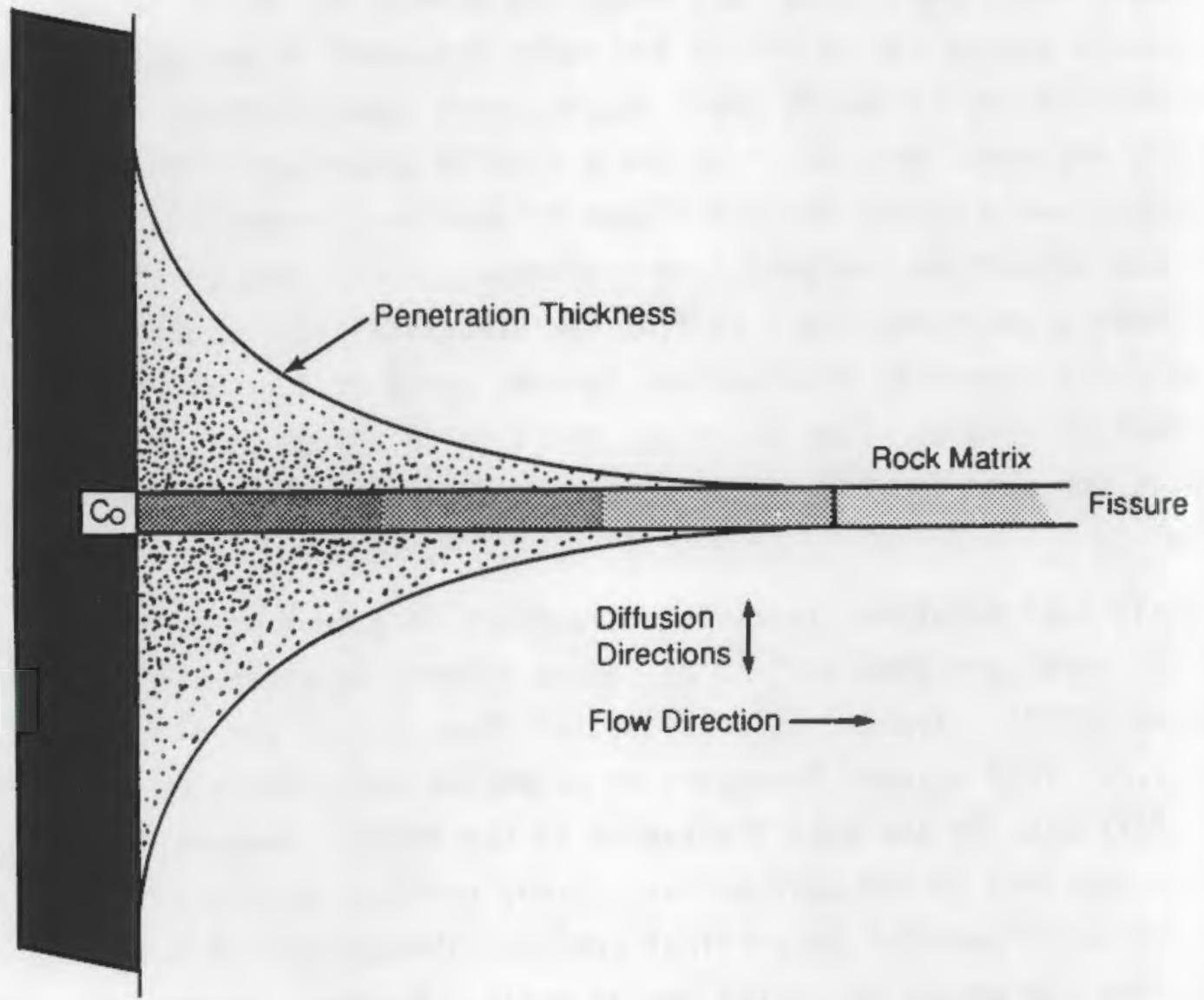

FIGURE 1.2. Schematic of Diagram of Analytical Solution for Crack Flow (Neretnieks 1980)

The first method Huyakorn called the "double porosity" approach. In this method, the crack and soil equations were solved separately. A leakage term was included in the crack equations to account for solute lost or gained across the crack/matrix interface. The leakage term was estimated at each time step, then the crack equation was solved. Concentrations in the crack were used as a boundary for the porous-media equations. After solving the porous-media equations, the leakage term was determined by back substitution. The process was repeated until the solution converged. The method used by Grisak andPickens has been called a "discrete fracture" approach by Huyakorn to distinguish it from his double porosity approach. The same convention will be used here. In this approach, the crack and porous media equations were solved simultaneously using a finite element approach simply by assigning different properties 
to the crack such as permeability, porosity, and diffusion coefficient. The crack was thus treated as an inhomogeneity in the porous media.

The use of available computer codes was considered, such as FTRANS (Intera 1985) which uses Huyakorn's approach. The available models used many of the limiting assumptions in the analytical solutions discussed previously. These were considered serious limitations and difficult ones to correct in an unfamiliar model. It seemed simpler to upgrade a finite-element model for two-dimensional advective-dispersive transport that the lead author had written. The discrete fracture approach was the easiest to include in the code because it only required giving different material properties to the crack, as opposed to Huyakorn's method, which would have necessitated a new and separate equation for the crack.

A two-dimensional finite element model, CRACK, has been developed that simulates the effects of surface pressure changes on radon flux from cracked soil. This report presents the theory and development of the finite element equations used in CRACK, a FORTRAN code. The sensitivity of the model to various soil and crack parameters and pressure perturbations is investigated. Suggestions made for further field and modeling studies complete the report. 


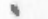

, 


\subsection{MATHEMATICAL MODEL}

\subsection{GENERAL CONSIDERATIONS AND ASSUMPTIONS}

CRACK simulates pressure gradients in the soil and cracks caused by pressure changes at the ground surface. The resulting air flow drives the advective transport of radon gas, affecting the flux density of radon across the soil/air boundary. The soil in the model may be heterogeneous and anisotropic, but it is isothermal and free of water down to the water table. The cracks in the model are evenly spaced, and of a uniform width and depth.

Figure 2.1 is a schematic diagram of the model, showing various components affecting transport. Flow and transport are two-dimensional in the soil, because the cracks do not extend all the way to the water table and pressure changes will result in a complex, nonuniform flow field. Flow and transport are effectively one-dimensional in the crack; because the cracks are narrow and diffusion is strong, we assume that the radon is evenly mixed across the width of the crack.

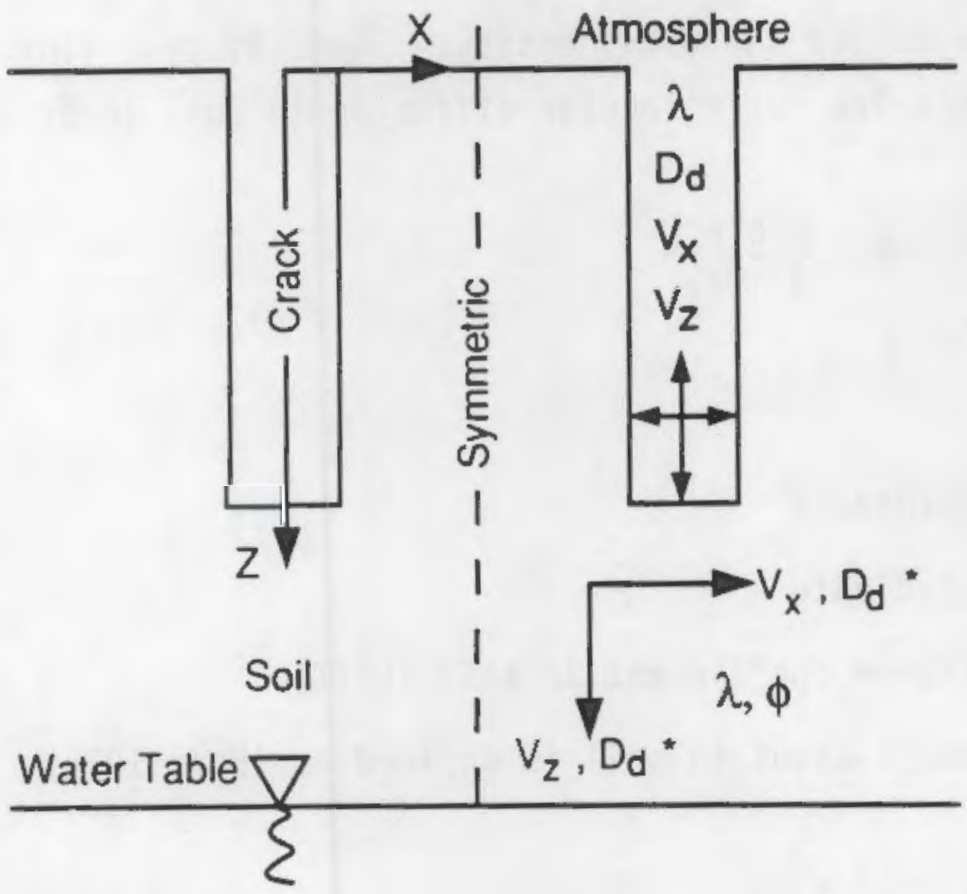

FIGURE 2.1. Two-Dimensional Cracked Soil Model 
The two-dimensional Cartesian coordinate system (in Figure 2.1) consists of the $x$ direction, which is parallel to the soil/atmosphere boundary, and the $z$ direction, which is perpendicular to the soil/atmosphere boundary.

Molecular diffusion $\left(D_{d}\right)$ of $222 R n$ is assumed to be governed by Fick's law. The flow of gas ( $v$ ) is governed by Darcy's law. Radon decays with a half-life of 3.8 days, represented by the decay constant, $\lambda$. A constant rate of production for radon, $\phi$, is ascribed to the soil, and we assume that radonproducing ${ }^{226} \mathrm{Ra}$ is evenly distributed in the soil.

\subsection{RADON TRANSPORT}

\subsubsection{Derivation of Governing Equation}

The concentration of $222 R n$ gas in air (C) is defined as the mass of radon per unit volume of air. The porosity of a soil $(n)$ is defined as the ratio of the volume of air space to the total volume of soil. Therefore, the concentration of radon gas in soil, or the mass of radon per unit bulk volume of soil, is equal to nc.

The mass of radon transported per unit time per unit bulk cross-sectional area of soil is called the flux density. The diffusive flux density $\left(F_{d}\right)$ is defined by Fick's law for molecular diffusion in soil (Bear 1979):

$$
F_{d_{i}}=-D_{d}{ }^{*}{ }_{i j} \frac{\partial(n C)}{\partial x_{j}}
$$

where $i=1,2$

$$
\begin{aligned}
x_{1} & =x \text { coordinate } \\
x_{2} & =z \text { coordinate } \\
D d^{*} & =\text { diffusion coefficient in soil }\left(L^{2} / T\right) .
\end{aligned}
$$

The diffusion coefficient in soil is defined as (Bear 1979)

$$
D_{d}{ }^{*}{ }_{i j}=D_{d} \tau^{*}{ }_{i j}
$$


where $D_{d}=$ diffusion coefficient in $\operatorname{air}(L 2 / T)$

$$
\tau^{*} i j=\text { tortuosity coefficient of soil. }
$$

The tortuosity can be defined as the ratio of the straight-line distance between two points to the distance by way of the connected pores. The tortuosity of a soil is a scalar for isotropic soils and has been empirically determined to be between 0.01 and 0.66 (Bear 1979). The smaller the value of tortuosity, the longer the diffusion path length through the soil.

The advective flux density $\left(\mathrm{F}_{\mathrm{a}}\right)$, or the mass of radon transported per unit time per unit bulk cross-sectional area of soil by gas flow, is defined as (Bear 1979)

$$
F_{a_{i}}=v_{i} c
$$

where $v_{j}=$ Darcy velocity of gas $(L / T)$.

The Darcy velocity is defined as the volume of gas flowing per unit bulk crosssectional area of soil per unit time.

The effects of mechanical dispersion are assumed to be negligible at the low flow velocities anticipated. According to Bear (1979), the condition for this assumption to be valid is that the Peclet number be less than one. The Peclet number is defined as $P e=v \times d \div D_{d}$, where $d$ is some characteristic length of the soil. This characteristic length may be calculated from an empirical formula for intrinsic permeability: $k=c x d^{2}$, where $c$ is an empirical constant. Bear (1979) claims that a common value for $c$ is 100 . When a permeability for the field soil is taken from Schery, Gaeddert and Wilkening (1984) of $2.7 \times 10^{-8} \mathrm{~cm}^{2}$, a value for $d$ of about $5 \times 10^{-5} \mathrm{~cm}$ is obtained. Assuming an average air velocity in the soil of about $1 \times 10^{-4} \mathrm{~cm} / \mathrm{s}$ and $D_{d}$ equal to $0.1 \mathrm{~cm} 2 / \mathrm{s}$ results in a Peclet number very much less than one, $1 \times 10-8$. Therefore, the assumption that molecular diffusion dominates over mechanical dispersion is a reasonable one.

Conservation of mass requires that the net mass transported into a unit volume of soil equal the change in the mass stored in the volume, minus the 
mass lost by radioactive decay, plus the mass of $222 \mathrm{Rn}$ produced by decay of $226 \mathrm{Ra}$ in the soil. The resulting continuity equation for the soil takes the form:

$$
-\frac{\partial(n C)}{\partial t}=\frac{\partial F_{i}}{\partial x_{i}}+\lambda(n C)-n \phi
$$

where $t=$ time

$$
\begin{aligned}
& \lambda=\ln (2) / \text { half-life of } 222 \mathrm{Rn}\left(T^{-1}\right) \\
& \phi=\underset{(M / L 3 / T)}{\operatorname{production}} \text { rate of radon per unit volume of soil pore space } \\
& F_{i}=F_{d i}+F_{a i}=\text { total flux density. }
\end{aligned}
$$

Substituting Equations (2.1) and (2.3) into (2.4) and dividing through by porosity gives

$$
\frac{\partial C}{\partial t}=\frac{\partial}{\partial x_{i}}\left(D d^{*}{ }_{i j} \frac{\partial C}{\partial x_{j}}\right)-\frac{\partial}{\partial x}\left(\frac{v i}{n} C\right)-\lambda C+\phi .
$$

For the results presented in this paper, the soil is assumed to be isotropic, with a scalar tortuosity $\left(\tau^{\star}\right)$, making $D_{d}{ }^{\star}$ a scalar. Perfect transverse mixing in the $x$ direction is assumed to occur in the crack, which is implemented by assigning a value for $V_{x}$ in the crack that is several orders of magnitude larger than $V_{Z}$ in the crack. Also, $D_{d}$ is substituted for $D_{d}{ }^{*}$, and a porosity of 1 is assumed in the crack.

\subsubsection{Solution by Galerkin Finite Element Method}

The governing equation for transport of radon gas (Equation 2.5) can be rewritten as

$$
L(C)=\frac{\partial C}{\partial t}-D d^{*} \frac{\partial C}{\partial x^{2}}+\frac{\partial}{\partial x_{i}}\left(\frac{N_{i}}{n} C\right)+\lambda C-\phi=0 .
$$


We introduce a trial function $\hat{C}$ for $C$ :

$$
\hat{c}\left(x_{i}, t\right)=\sum_{j=1}^{n n} N_{j}\left(x_{i}\right) c_{j}(t)
$$

where $N=$ weighting function

$$
\mathrm{nn}=\text { number } \text { of nodes. }
$$

Because $\hat{C}$ is only an approximation for $C$, substitution of $\hat{C}$ in Equation (2.6) results in some error such that $L(\hat{C}) \neq 0$.

The Galerkin method requires that the weighted integral of the error over the whole solution region, $R$, must be equal to zero (Huyakorn and Pinder 1983):

$$
\int_{R} N_{I} L(\hat{C}) d R=0
$$

This yields

$$
\int_{R} N_{I}\left[\frac{\partial \hat{C}}{\partial t}-D_{d} * \frac{\partial^{2} \hat{c}}{\partial x_{i}^{2}}+\frac{\partial}{\partial x_{i}}\left(\frac{v_{i}}{n} \hat{c}\right)+\lambda \hat{C}-\phi\right] d R=0
$$

Application of Green's theorem to the second derivative term gives

$$
\begin{aligned}
\int_{R}\left[\frac{\partial \hat{C}}{\partial t} N_{I}+D_{d}^{*} \frac{\partial \hat{C}}{\partial x_{i}} \frac{\partial N_{I}}{\partial x_{i}}+\frac{\partial}{\partial x_{i}}\left(\frac{N_{i}}{n} \hat{C}\right) N_{I}+\lambda \hat{C} N_{I}-\phi N_{I}\right] d R \\
-\int_{B}\left(D_{d}^{*} \frac{\partial \hat{C}}{\partial x_{i}} N_{I} \dot{n}_{i}\right) d B
\end{aligned}
$$

where $\vec{n}_{j}=$ unit normal vector to boundary $B$.

Because the boundary integral term in Equation (2.10) only applies at boundary nodes, it will be left out of the discussion until Section 2.4.3 on numerical treatment of boundary conditions. 
Substituting Equation (2.7) for $\hat{C}$ in Equation (2.10) gives

$$
\begin{aligned}
\int_{R}\left[\frac{\partial C_{J}}{\partial t} N_{I} N_{J}+\right. & D_{d}{ }^{*} C_{J} \frac{\partial N_{I}}{\partial x_{i}} \frac{\partial N_{J}}{\partial x_{i}}+C_{J} N_{I} \frac{\partial}{\partial x_{i}}\left(\frac{N_{i}}{n} N_{J}\right) \\
& \left.+\lambda C_{J} N_{I} N_{J}-\phi N_{I}\right] d R=0 .
\end{aligned}
$$

The time integral is solved using a standard implicit finite-difference approximation:

$$
\frac{\partial c_{j}}{\partial t}=\frac{c_{j}\left(t_{m+1}\right)-c_{j}\left(t_{m}\right)}{t_{m+1}-t_{m}}=\frac{c_{j}^{m+1}-c_{j}^{m}}{\Delta t}
$$

where $c^{m}=$ concentration at previous time step

$$
\begin{aligned}
c^{m+1} & =\text { concentration at current time step } \\
\Delta t & =\text { time increment. }
\end{aligned}
$$

Substituting Equation (2.12) into Equation (2.11) and gathering terms yields

$$
\begin{aligned}
\int_{R}\left\{\left[\frac{1}{\Delta t} N_{I} N_{J}\right.\right. & \left.\left.+D_{d}^{*} \frac{\partial N_{I}}{\partial x_{i}} \frac{\partial N_{J}}{\partial x_{i}}+N_{I} \frac{\partial}{\partial x_{i}}\left(\frac{N_{i}}{n} N_{J}\right)+\lambda N_{I} N_{J}\right] C_{J}^{m+1}\right\} d R \\
& =\int_{R}\left[\phi N_{I}+C_{J}^{m+1}\left(\frac{1}{\Delta t} N_{I} N_{J}\right)\right] d R
\end{aligned}
$$

or, in matrix form

$$
[\mathrm{LHS}]_{I J}\left\{\mathrm{C}^{\mathrm{m+1}}\right\}_{\mathrm{J}}=\{\mathrm{RHS}\}_{\mathrm{I}} \text {. }
$$

A fully implicit time-stepping scheme was used to ensure stability. The matrix equations are solved using Gaussian elimination in a banded storage mode by a subroutine named SLBNS (Brebbia and Ferrante 1978). 


\subsection{AIR FLOW}

\subsubsection{Derivation of Governing Equation.}

The radon transport equation [Equation (2.5)] and the air flow equation are coupled by Darcy's law (Bear 1979):

$$
v_{i}=-\frac{k_{i j}}{\mu}\left(\frac{\partial p}{\partial x_{j}}+\rho g \frac{\partial z}{\partial x_{j}}\right)
$$

where $v_{i}=$ Darcy velocity $(L / T)$

$$
\begin{aligned}
& i=1,2 ; x_{1}=x \text { coordinate, } x_{2}=z \text { coordinate } \\
& j=1,2 \\
& \left.k=\text { intrinsic permeability of soil ( } L^{2}\right) \\
& \mu=\text { dynamic viscosity of air }(M / L / T) \\
& P=\text { absolute gas pressure }(M / L 2 / T) \\
& \rho=\text { gas density }\left(M / L^{3}\right) \\
& g=\text { gravitational acceleration }\left(L / T^{2}\right) \\
& z=\text { depth below surface. }
\end{aligned}
$$

Conservation of mass requires that the net rate of fluid flow into a unit volume of soil equal the change of fluid mass stored within the volume. The continuity equation takes the form (Bear 1979)

$$
-\frac{\partial(n \rho)}{\partial t}=\frac{\partial\left(\rho v_{i}\right)}{\partial x_{i}}
$$

where $n$ = porosity.

Combining the continuity equation and Darcy's Law gives

$$
\frac{\partial}{\partial t}(n \rho)=\frac{\partial}{\partial x_{i}}\left[\frac{k_{i j}}{\mu} \rho\left(\frac{\partial P}{\partial x_{j}}+\rho g \frac{\partial z}{\partial x_{j}}\right)\right] .
$$


For an ideal gas, the equation of state is

$$
\rho=M P / R T
$$

where $M=$ molecular weight

$$
\begin{aligned}
& R=\text { universal gas constant } \\
& T=\text { absolute temperature. }
\end{aligned}
$$

For isothermal flow, then

$$
\frac{\partial \rho}{\partial t}=\frac{M}{R T} \frac{\partial P}{\partial t} .
$$

Substituting Equations (2.18) and (2.19) into (2.17) gives

$$
\frac{\partial(n P)}{\partial t}=\frac{\partial}{\partial x_{i}}\left(\frac{k_{i j}}{\mu} P \frac{\partial P}{\partial x_{j}}\right)+\frac{\partial}{\partial x_{i}}\left(\frac{k_{i j}}{\mu} P \rho g \frac{\partial z}{\partial x_{j}}\right) .
$$

Because the density of air is so small, the effect of gravity is assumed to be negligible. Also, $n$ is assumed to be uniform in space and time because the soil is assumed to be homogeneous, isotropic, and incompressible, so the equation reduces to

$$
n \frac{\partial P}{\partial t}=\frac{\partial}{\partial x_{i}}\left(\frac{k_{i j}}{\mu} P \frac{\partial P}{\partial x_{j}}\right)
$$

which, using the chain rule, can be rearranged to

$$
\frac{n}{p} \frac{\partial p^{2}}{\partial t}=\frac{\partial}{\partial x_{i}}\left(\frac{k_{i j}}{\mu} \frac{\partial p^{2}}{\partial x_{j}}\right) .
$$


In the crack, we assume the porosity equals 1.0 and the permeability equals (Bear 1979)

$$
k_{c}=\frac{w^{2}}{12}
$$

where $w=$ width of crack.

\subsubsection{Solution by Galerkin Finite Element Method}

The solution of the flow equation by the Galerkin finite element method is similar to that for the transport equation, except that there are fewer terms in the flow equation, and it is weakly non-linear.

The governing equation for compressible, ideal gas flow may be rewritten as

$$
L(P)=\frac{n}{P} \frac{\partial P^{2}}{\partial t}-\frac{\partial}{\partial x_{i}}\left(\frac{k_{i j}}{\mu} \frac{\partial P^{2}}{\partial x_{i}}\right)=0
$$

Using the same techniques as in Equations (2.7) through (2.10) gives

$$
\int_{R}\left(\frac{n}{P} \frac{\partial P_{J}^{2}}{\partial t} N_{I} N_{J}+\frac{k_{i j}}{\mu} P_{J}^{2} \frac{\partial N_{I}}{\partial x_{i}} \frac{\partial N_{J}}{\partial x_{i}}\right) d R=0 .
$$

Equation (2.25) is solved in terms of $\mathrm{P}^{2} ;$ the $P$ in the coefficient of the nonlinear time term is treated as the average pressure for all the nodes in an element.

Applying an implicit finite-difference technique to the time derivative as was done in Equation (2.12) yields

$$
\begin{aligned}
& \int_{R}\left[\left(\frac{n}{p^{m+1}} \frac{1}{\Delta t} N_{I} N_{J}+\frac{k_{i j}}{\mu} \frac{\partial N_{I}}{\partial x_{i}} \frac{\partial N_{J}}{\partial x_{i}}\right)\left(p_{J}^{m+1}\right)^{2}\right] d R= \\
& =\int_{R}\left[\left(p_{J}^{m}\right)^{2} \frac{n}{p^{m+1}} \frac{1}{\Delta t} N_{I} N_{J}\right] d R
\end{aligned}
$$


or, in matrix form:

$$
\left[\operatorname{LHS}\left(P^{m+1}\right)\right]_{I J}\left\{P^{2}\right\}_{J}^{m+1}=\left\{R H S\left(P^{m}, P^{m+1}\right)\right\}_{I} \cdot
$$

The flow equation is nonlinear because the $[L H S]_{I J}$ and $\{R H S\}_{I}$ are functions of $\mathrm{p}^{\mathrm{m}+1}$, the pressure at the current time step, which is unknown. Therefore, $\mathrm{P}^{\mathrm{m}+1}$ must be solved for iteratively. A very simple method of iteration, called Picard iteration, was used. For the first iteration, $\mathrm{p}^{\mathrm{m}+1}$ was set equal to $\mathrm{p}^{\mathrm{m}}$, the pressure at the last time step. The equation was solved for $\mathrm{p}^{\mathrm{m}+1}$, and this value was used to solve the equation over and over until the maximum normalized difference between values for two subsequent iterations was less than some prescribed tolerance (Huyakorn and Pinder 1983):

$$
\frac{\left(p_{J}^{k+1}-p_{j}^{k}\right)_{\max }}{\left(p_{J}^{k+1}\right)_{\max }}
$$

where $p^{k+1}=$ pressure at current iteration

$$
\mathrm{p}^{\mathrm{k}}=\text { pressure at previous iteration. }
$$

\subsection{BOUNDARY CONDITIONS}

\subsubsection{Boundary Conditions for Transport Equation}

The boundary conditions for the transport equation are shown schematically in Figure 2.2. At the top of the soil a first-type, or Dirichlet, boundary condition of $C=0$ is imposed because the concentration of radon in the atmosphere is assumed to be zero. This boundary condition further implies that there is no advective flux [Equation (2.1)] across the top boundary.

At the top of the crack a second-type, or Neumann, boundary condition of $\partial C / \partial z=0$ is imposed because advective transport is assumed to dominate and is strong enough to cause concentrations to rise above zero directly above the crack. This boundary condition implies that there is no diffusive flux [Equation (2.2)] modeled across this boundary. The sides of the model are 


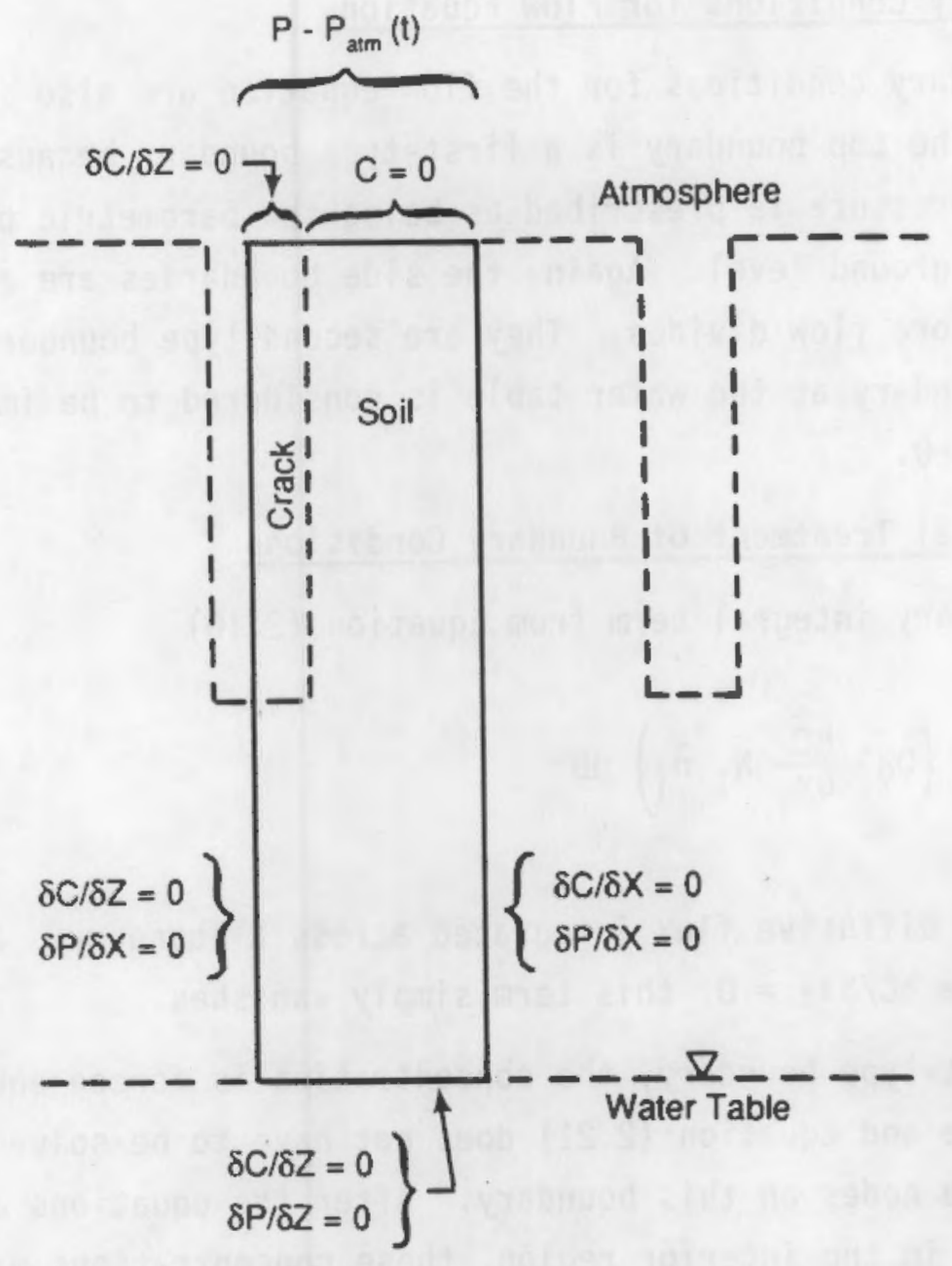

FIGURE 2.2. Boundary Conditions for Gas Flow and Radon Transport Equations

second-type boundaries, $\partial C / \partial x=0$, because they are axes of symmetry, either in the center of a crack or halfway between two evenly spaced and equally sized cracks.

The bottom boundary represents the water table, which is assumed to be an impermeable barrier to air flow and radon transport. Therefore, the diffusive flux is set equal to zero using a second-type boundary condition, $\partial C / \partial z=0$. The advective flux is also zero on this boundary because the flow velocity is zero. 


\subsubsection{Boundary Conditions for Flow Equation}

The boundary conditions for the flow equation are also illustrated in Figure 2.2. The top boundary is a first-type boundary because it is at the soil surface; the pressure is prescribed as being the barometric pressure of the atmosphere at ground level. Again, the side boundaries are axes of symmetry and are therefore flow divides. They are second-type boundaries, $\partial P / \partial x=0$. The bottom boundary at the water table is considered to be impermeable to gas flow, so $\partial P / \partial z=0$.

\subsubsection{Numerical Treatment of Boundary Conditions}

The boundary integral term from Equation (2.10)

$$
-\int_{B}\left(D_{d}^{*} \frac{\partial \hat{C}}{\partial x_{i}} N_{I} \vec{n}_{i}\right) d B
$$

represents the diffusive flux integrated across a boundary. At a second-type boundary, where $\partial C / \partial x_{i}=0$, this term simply vanishes.

At a first-type boundary, the concentration is forced equal to some specified value and Equation (2.21) does not have to be solved for concentrations at the nodes on this boundary. After the equations are solved for concentrations in the interior region, these concentrations may be substituted back into Equation (2.20) at the boundary nodes to determine the diffusive flux boundary integral term, Equation (2.29). The advective flux across the top boundary of the crack may be calculated by integrating Equation (2.3) across the boundary:

$$
\int_{B}\left(v_{i} c_{J} N_{I} \vec{n}_{i}\right) d B .
$$

The total radon flux density across the top boundary of the model may be calculated by adding the advective flux integral from the top boundary of the crack and the diffusive flux integral from the top boundary of the soil and dividing by the total length of the top boundary. The total radon flux density is used as the performance measure for the sensitivity analysis in the next section. 
There is one node situated on the top boundary at the interface between the soil and the crack. The node at this point is difficult to deal with numerically because it is located at the interface between a prescribed concentration $(C=0)$ and a prescribed diffusive flux $(\partial C / \partial X=0)$ boundary. Two test cases were run (with the base case parameters in Table 4.1) and it was noted that the difference between making this node a prescribed concentration boundary and making it a prescribed diffusive flux boundary was less than $0.1 \%$. This result is probably due to the grid being very fine at this interface.

First and second-type boundaries are applied in the flow equation exactly as they are in transport equation. 
•

.

. 


\subsection{VERIFICATION OF NUMERICAL MODEL}

Four test cases were run to verify the accuracy of the numerical model, CRACK, by comparing it to analytical solutions found in the literature. The model consists of two main parts, a flow code and a transport code. The first two test cases verify the transport code and the last two verify the flow code.

\subsection{1-D ADVECTION, DISPERSION, DECAY, AND SOURCE}

The solute transport code was compared to a one-dimensional analytical solution of the advection-dispersion equation with radioactive decay and a linear source term. The governing equation is

$$
\frac{\partial C}{\partial t}=D_{d} * \frac{\partial^{2} C}{\partial z^{2}}-\frac{v z}{n} \frac{\partial C}{\partial z}-\lambda C+\phi
$$

where $C=$ concentration of radon $\left(M / L^{3}\right)$

$$
\begin{aligned}
D_{d}{ }^{*} & =\text { coefficient of diffusion of radon in soil }\left(L^{2} / T\right) \\
V_{z} & =\text { discharge velocity of air in soil }(L / T) \\
n & =\text { porosity of soil } \\
\lambda & =\text { radioactive decay constant of radon }\left(T^{-1}\right) \\
\phi & =\text { rate of radon production in soil }\left(M / L^{3} / T\right) .
\end{aligned}
$$

The steady-state analytical solution was taken from Clements (1974)

$$
c=C^{\infty}\left(1-\exp \left\{\left[\frac{v_{z} / n}{2 D_{d^{*}}}+\left(\frac{\left(v_{z} / n\right)^{2}}{4\left(D_{d^{*}}\right)^{2}}+\frac{\lambda}{D_{d^{*}}}\right)^{1 / 2}\right] z\right\}\right)
$$

where $C^{\infty}=$ concentration of radon at depth $\left(M / L^{3}\right)$.

The numerical model was compared to the analytical solution with the data shown in Figure 3.1. The model ran 288 simulation hours before it reached steady state. There is excellent agreement between the two solutions. 


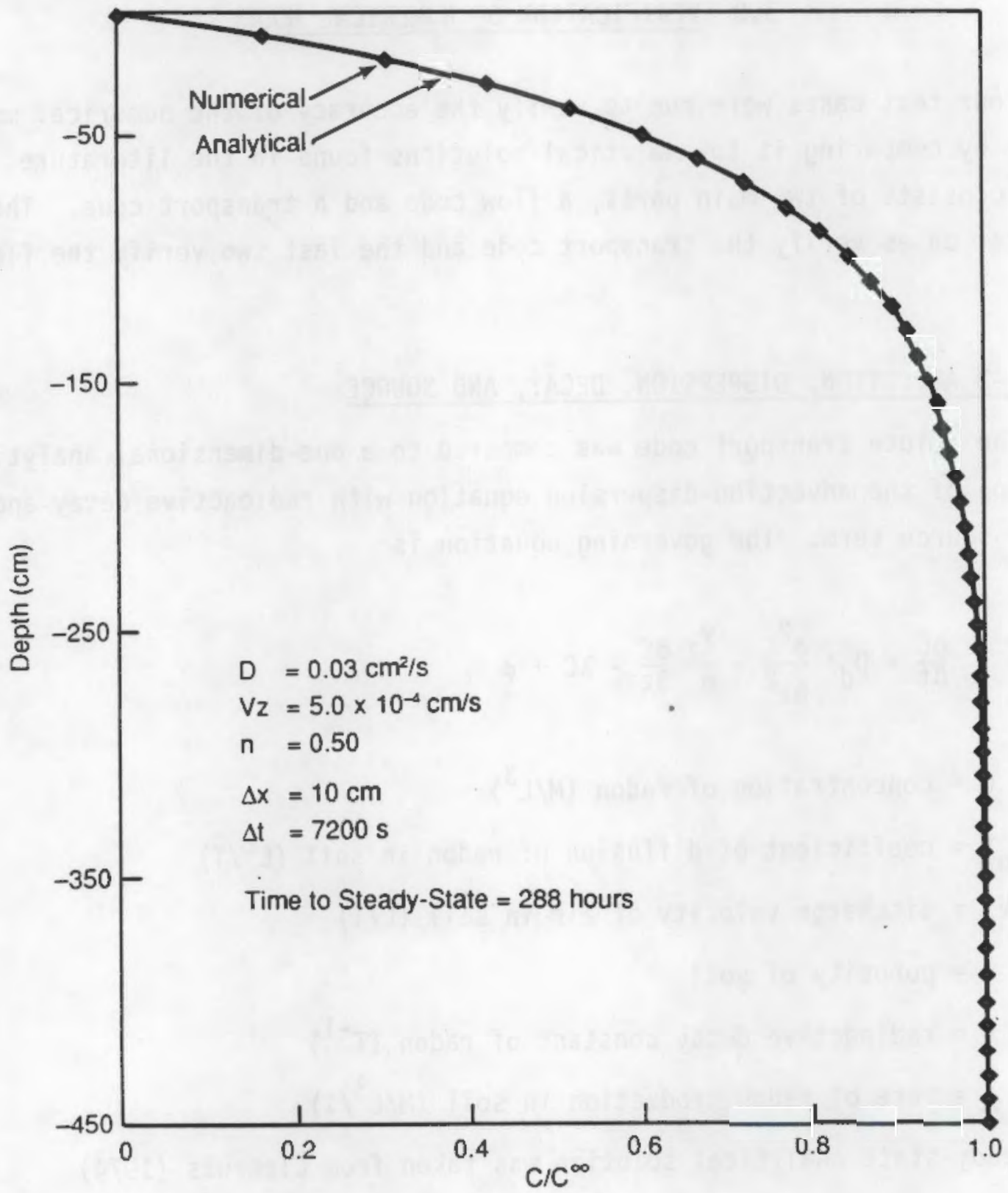

FIGURE 3.1. Comparison of Galerkin Finite Element Solution to Steady-State Analytical Solution for AdvectiveDispersive Equation with Decay and Source

Stability of the solution was ensured by using a time-weighting factor, $\theta$, of D.5. Using this time-weighting factor is termed the Crank-Nicholson scheme; it weights the solution by half towards the solution at the previous time step. This time-weighting factor is unconditionally stable. Accurate time steps were chosen using the formulas of Huyakorn and Pinder (1983) 


$$
\begin{aligned}
& \frac{\left(v_{z} / n\right) z}{2} \leq 0_{d}^{*} \\
& \Delta t \leq\left[\frac{\left(v_{z} / n\right)}{2 \Delta z}+\frac{D_{d}^{*}}{\Delta z^{2}}\right]
\end{aligned}
$$

where $\Delta z=$ smallest element dimension.

\subsection{MATRIX DIFFUSION FROM A SINGLE CRACK}

The transport code was tested in two dimensions for the case of a single, vertical crack with vertical advection, dispersion, and decay. The crack is contained in a soil matrix block with horizontal dispersion and decay. The governing equation for the crack is

$$
\frac{\partial C}{\partial t}=D_{d} * \frac{\partial^{2} C}{\partial z^{2}}-\frac{v z}{n} \frac{\partial C}{\partial z}-\lambda C+\left.\frac{n D_{d}^{*}}{b} \frac{\partial C}{\partial x}\right|_{x=b}
$$

where $b=$ boundary between soil and crack.

The governing equation for transport in the soil matrix is

$$
\frac{\partial C}{\partial t}=D_{d} * \frac{\partial^{2} C}{\partial x^{2}}-\lambda C
$$

A steady-state analytical solution by Sudicky and Frind (1982) was used for comparison. The solution for transport in the crack is

$$
C_{C}=C^{\infty} \exp \left[\frac{\left(v_{z} / n\right) z}{2 D_{z z}}\left(1-\left[1+\frac{4}{\gamma}(1+\beta)\right]^{1 / 2}\right)\right]
$$

where $\beta=n D_{x x} 1 / 2 / \lambda^{1 / 2} b \cdot \tanh \left(\sigma \lambda^{1 / 2}\right)$

$$
\gamma=(v / n)^{2} / \lambda D_{z z} \text {. }
$$


The analytical solution for transport in the soil matrix is

$$
C_{S}=C_{C}\left[\frac{\cosh \left(G \lambda^{1 / 2}(B-x)\right.}{\cosh \left(\sigma \lambda^{1 / 2}\right)}\right]
$$

where $G=D_{x x}{ }^{-1 / 2}$

$$
\begin{aligned}
& \sigma=G(B-b) \\
& B=1 / 2 \text { of crack spacing. }
\end{aligned}
$$

A steady-state solution was obtained by using one large time step of
$10^{35} \mathrm{~s}$. Close agreement can be seen in Figure 3.2 for various profiles in the $x$ and $z$ directions.

\subsection{LINEARIZED GAS FLOW}

The governing equation for one-dimensional gas flow is (Huyakorn and Pinder 1983)

$$
\frac{\partial}{\partial x}\left(\frac{k}{\mu} P \frac{\partial P}{\partial x}\right)=n \frac{\partial P}{\partial t}
$$

where $P=$ absolute pressure

$$
\begin{aligned}
& k=\text { intrinsic permeability }\left(L^{2}\right) \\
& \mu=\text { dynamic viscosity of air. }
\end{aligned}
$$

The solution is linearized by assuming that $P$ on the left-hand side of the equation equals the pressure at the last time step, yielding

$$
\frac{\partial^{2} p}{\partial x^{2}}=\frac{n \mu}{P} \frac{\partial p}{\partial t}
$$

where $P_{p}=$ pressure at previous time step. 

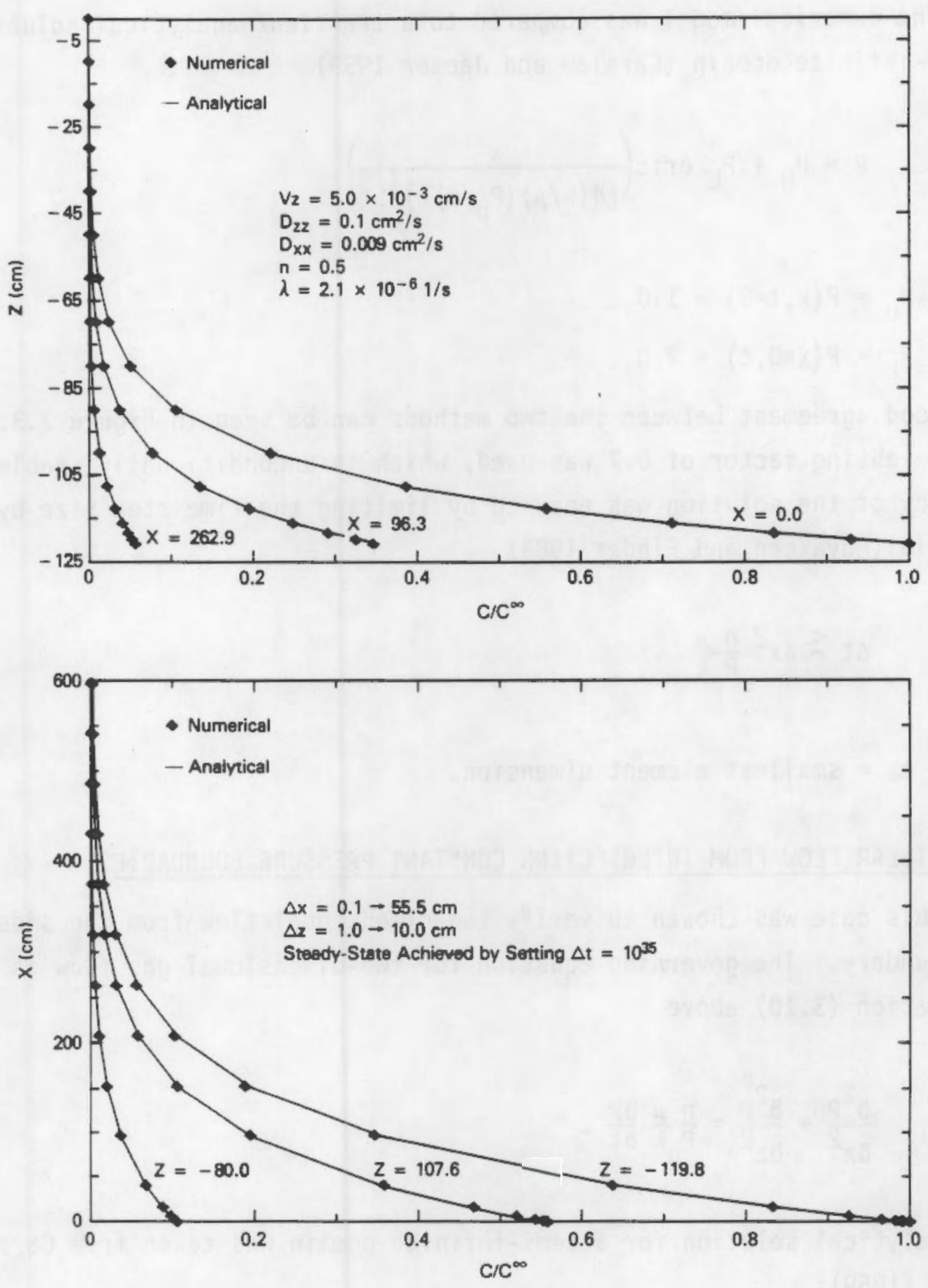

FIGURE 3.2. Comparison of Galerkin Numerical Solution to a SteadyState Analytical Solution for Matrix Diffusion from a Single Crack (analytical solution is calculated only at same points as numerical solution) 
The numerical model was compared to a transient analytical solution for a semi-infinite domain (Carslaw and Jaeger 1959)

$$
P=P_{0}+P_{L} \operatorname{erfc}\left(\frac{x}{\left[4(k / \mu)\left(P_{p} / n\right) t\right]^{1 / 2}}\right)
$$

where $P_{0}=P(x, t=0)=1.0$

$$
P_{L}=P(x=0, t)=2.0 \text {. }
$$

Good agreement between the two methods can be seen in Figure 3.3. A time-weighting factor of 0.7 was used, which is unconditionally stable. Accuracy of the solution was ensured by limiting the time step size by the criteria (Huyakorn and Pinder 1983)

$$
\Delta t \leq \Delta x^{2} \frac{n \mu}{P_{p} k}
$$

where $\Delta x=$ smallest element dimension.

\subsection{LINEAR FLOW FROM INTERSECTING CONSTANT PRESSURE BOUNDARIES}

This case was chosen to verify two-dimensional flow from the side and top boundary. The governing equation for two-dimensional gas flow is similar to Equation (3.10) above

$$
\frac{\partial^{2} p}{\partial x^{2}}+\frac{\partial^{2} p}{\partial z^{2}}=\frac{n}{P_{p} k} \frac{\partial p}{\partial t} .
$$

The analytical solution for a semi-infinite domain was taken from Carslaw and Jaeger (1959):

$$
P=P_{0}+P_{L}\left[1-\operatorname{erf}\left(\frac{x}{\left[4(k / \mu)\left(P_{p} / n\right) t\right]^{1 / 2}}\right) \operatorname{erf}\left(\frac{z}{\left[4(k / \mu)\left(P_{p} / n\right) t\right]^{1 / 2}}\right)\right]
$$




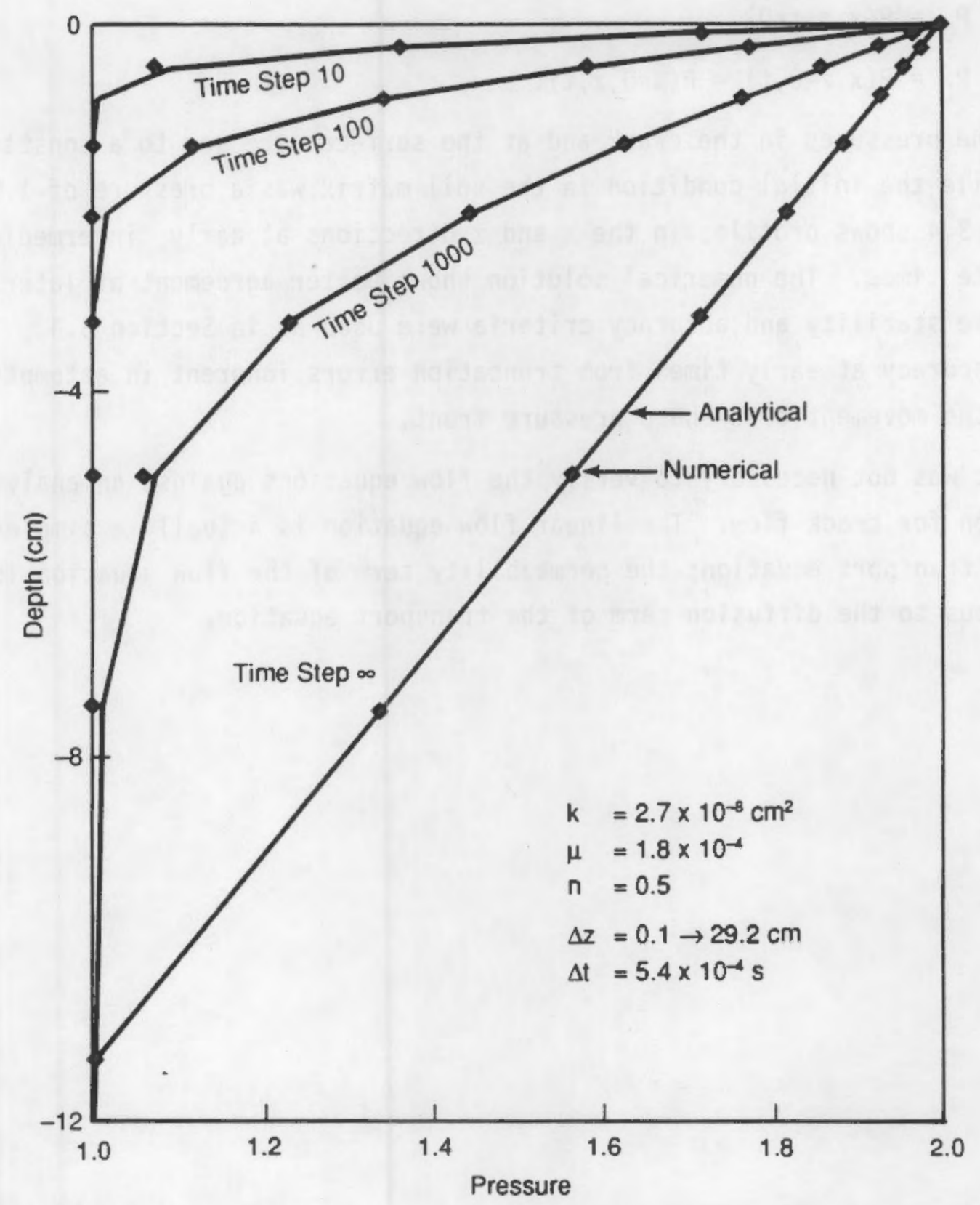

FIGURE 3.3. Comparison of Galerkin Numerical Solution for Pressure Equation to a One-Dimensional Transient Analytical Solution for Linear Flow (analytical solution is calclulated only at same points as numerical solution) 
where $P_{0}=P(x, z, t=0)$

$$
P_{L}=P(x, z=0, t)=P(x=0, z, t) \text {. }
$$

The pressures in the crack and at the surface were set to a constant of 2.0 while the initial condition in the soil matrix was a pressure of 1.0 . Figure 3.4 shows profiles in the $x$ and $z$ directions at early, intermediate, and late times. The numerical solution shows better agreement at later times. The same stability and accuracy criteria were used as in Section 3.3. There is inaccuracy at early times from truncation errors inherent in attempting to model the movement of a sharp pressure front.

It was not necessary to verify the flow equations against an analytical solution for crack flow. The linear flow equation is actually a simpler version of the transport equation; the permeability term of the flow equation is analogous to the diffusion term of the transport equation. 

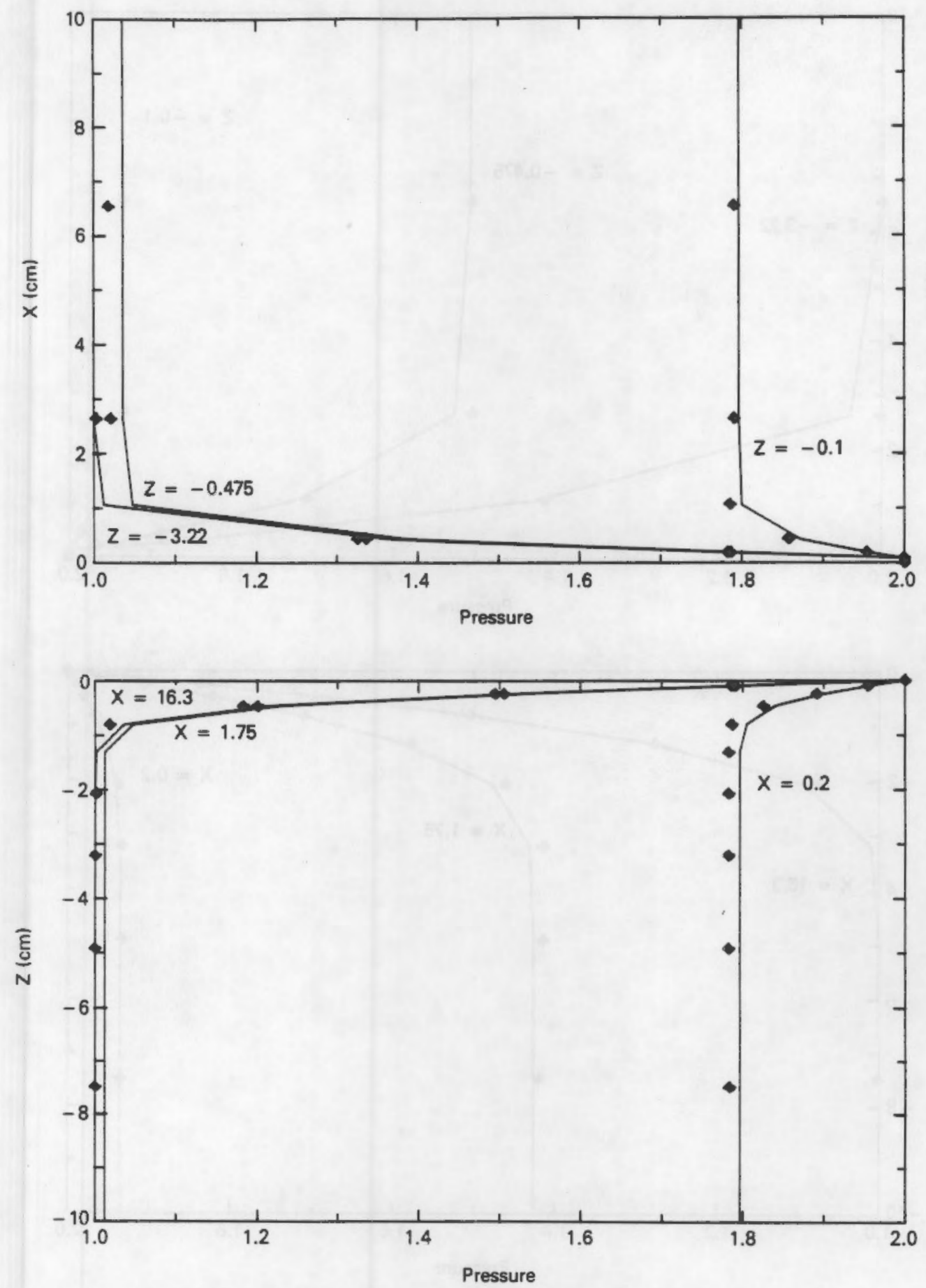

FIGURE 3.4a. Comparison of Numerical Solution for Pressure to a Two-Dimensional Analytical Solution for Linear Flow Between Two Intersecting Constant Pressure Boundaries: Time Step 10 

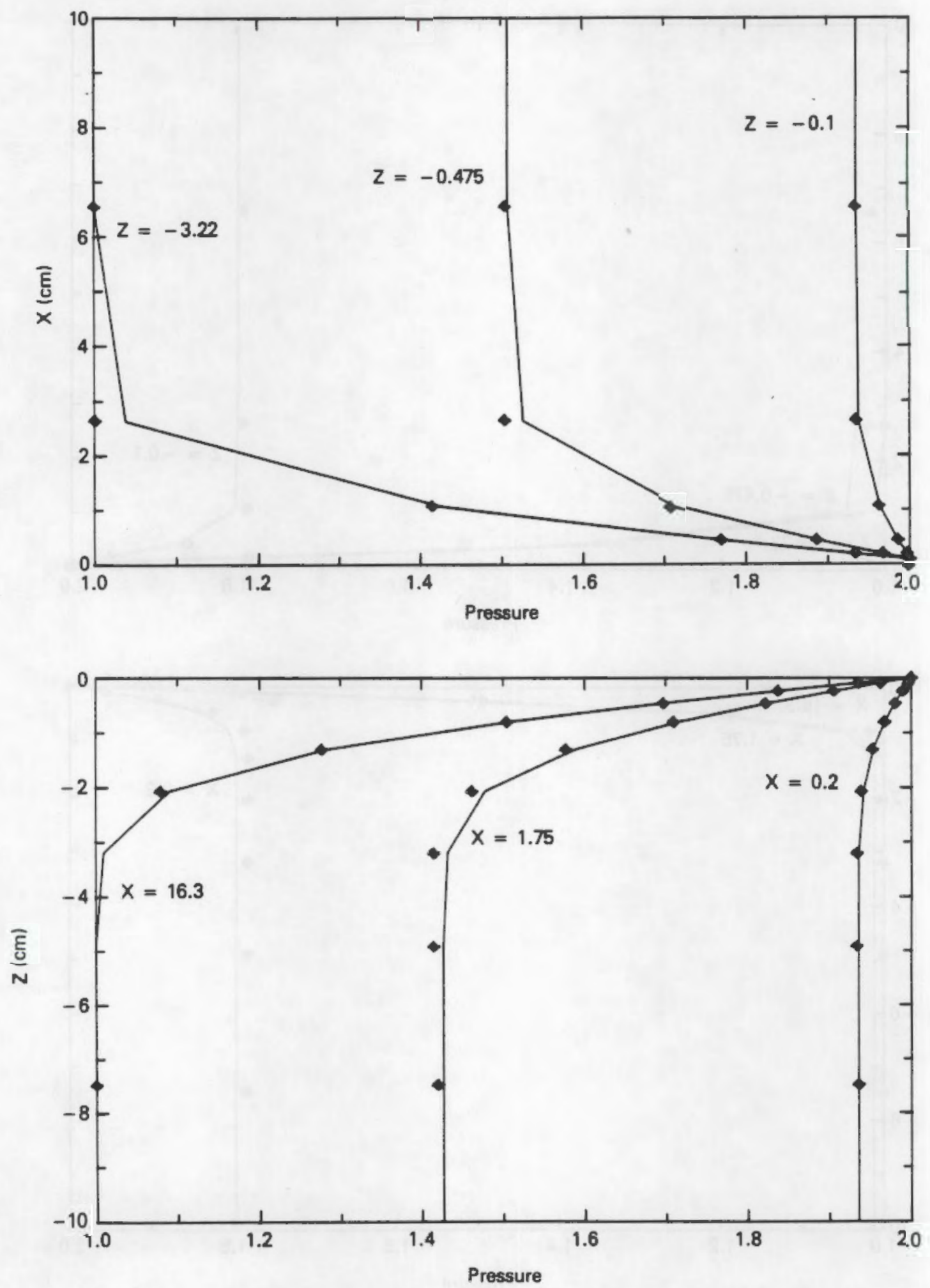

FIGURE 3.4b. Comparison of Numerical Solution for Pressure to a Two-Dimensional Analytical Solution for Linear Flow Between Two Intersecting Constant Pressure Boundaries: Time Step 100 

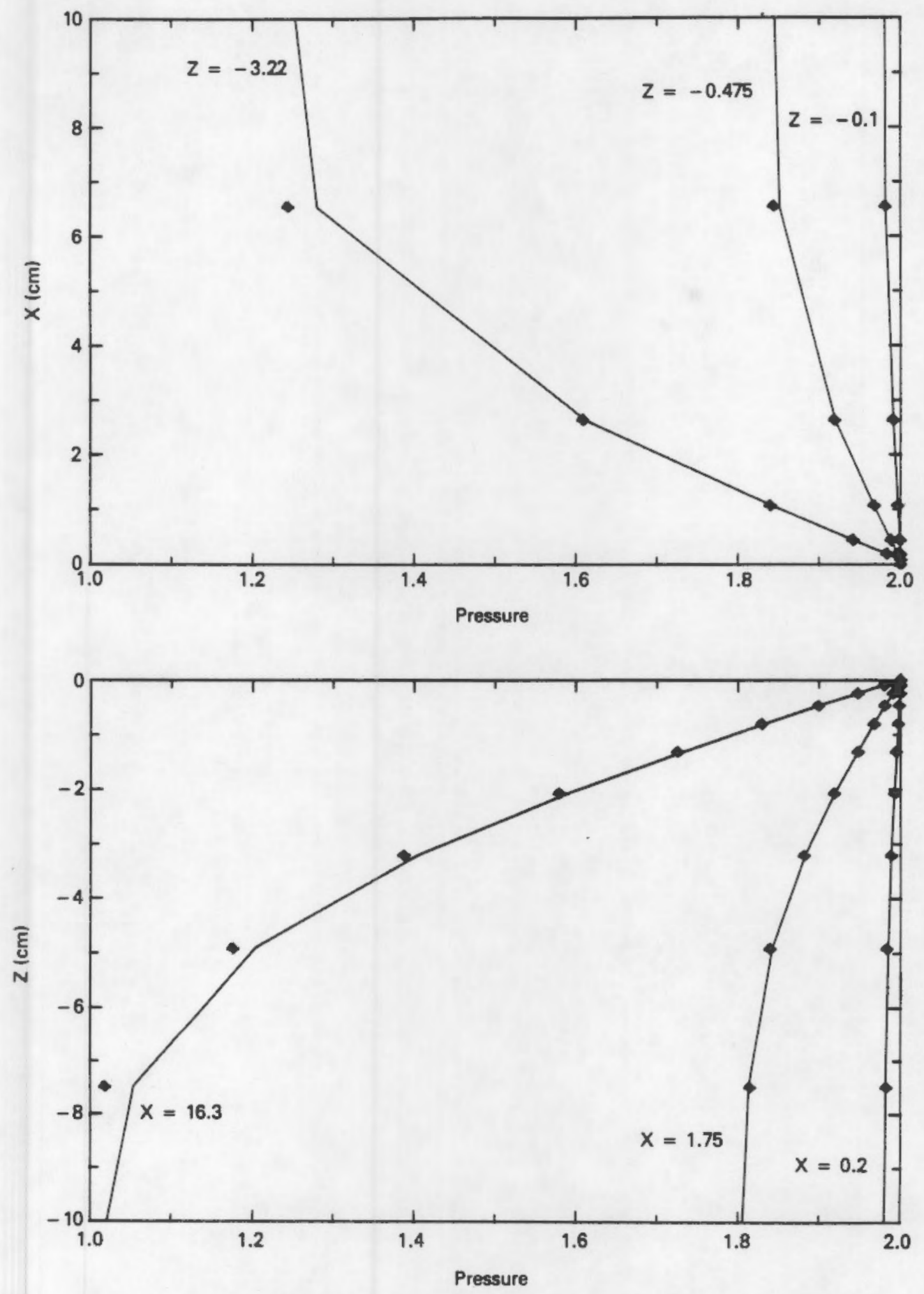

FIGURE 3.4c. Comparison of Numerical Solution for Pressure to a Two-Dimensional Analytical Solution for Linear Flow Between Two Intersecting Constant Pressure Boundaries: Time Step 1000 



\subsection{SENSIIIVITY ANALYSIS}

The objective of the sensitivity analysis described here is to vary the input parameters of the model to better understand their effect on radon flux densities from soil. First the crack dimensions, including crack depth, width, and spacing, are varied. Next, the soil properties, including porosity, intrinsic permeability, and soil diffusion coefficient, are perturbed for homogeneous and cracked soil. Finally, the effects of decreasing, increasing, and sinusoidally varying the atmospheric pressure conditions with time are tested.

The base-case parameters for the sensitivity analysis were taken from Schery, Gaeddert and Wilkening (1984). The depth to the water table is an estimate for Schery's field site, which is located at an elevation of $4500 \mathrm{ft}$ above mean sea level. The initial atmospheric pressure is a common one for the field site. The production rate of radon per unit volume of soil pore space, $\phi$, was determined for the soil at the field site by observing that the radon concentrations asymptotically reach a maximum value of 25,000 atoms $/ \mathrm{cm}^{3}$ $(1,420 \mathrm{pCi} / 1)$ with depth. Far below the surface, where $222 \mathrm{Rn}$ escape is negligible, the rate of radioactive decay must be balanced by the production rate. This requires that $c^{\infty}=\phi / \lambda$, where $C^{\infty}$ is the $222 R n$ concentration deep in the soil. The decay constant for radon, $\lambda$, equal to $2.1 \times 10^{-6} \mathrm{~s}^{-1}$ yields a value of $5.25 \times 10^{-2}\left(3.0 \times 10^{-3} \mathrm{pCi} / 1 / \mathrm{s}\right)$ for the production rate.

Figure 4.1 illustrates a typical finite element grid used for the simulations in this report. Note that the grid is very fine near the crack in the $x$ direction and near the surface in the $z$ direction. This fine grid is necessary because concentration gradients are likely to be strong in those areas.

All simulations were started from constant pressure and steady-state concentration conditions. Initially, the soil and cracks are at atmospheric pressure. The steady-state concentration profile incorporates the equilibrium effects of diffusion, decay, production, and boundary conditions. Equilibrium conditions will vary slightly based on the width and depth of the crack. Figure 4.2 shows a steady-state diffusive profile calculated using the base case parameters in Table 4.1. The concentration gradient is strongest near 
TABLE 4.1. Base-Case Parameters for Sensitivity Analys is

\begin{tabular}{|c|c|}
\hline Parameter & Value \\
\hline Air dynamic viscosity $(\mu)$ & $1.8 \times 10^{-4} \mathrm{~g} / \mathrm{cm} / \mathrm{s}$ \\
\hline Radon diffusion coefficient in air $\left(D_{d}\right)$ & $0.1 \mathrm{~cm}^{2} / \mathrm{s}$ \\
\hline Radon decay constant $(\lambda)$ & $2.1 \times 10^{-6} \mathrm{~s}^{-1}$ \\
\hline Radon production rate $(\phi)$ & $5.25 \times 10^{-2}$ atoms $/ \mathrm{cm}^{3} / \mathrm{s}$ \\
\hline Depth to water table & $10 \mathrm{~m}$ \\
\hline Crack depth & $400 \mathrm{~cm}$ \\
\hline Crack spacing & $800 \mathrm{~cm}$ \\
\hline Crack width & $0.06 \mathrm{~cm}$ \\
\hline Soil porosity (n) & 0.35 \\
\hline Soil intrinsic permeability (k) & $2.7 \times 10^{-8} \mathrm{~cm}^{2}$ \\
\hline Tortuosity $\left(\tau^{\star}\right)$ & 0.26 \\
\hline Radon diffusion coefficient in soil $\left(\mathrm{Dd}^{*}\right)$ & $2.6 \times 10^{-2} \mathrm{~cm}^{2} / \mathrm{s}$ \\
\hline Initial atmospheric pressure $\left(P_{0}\right)$ & 85. $\mathrm{kPa}$ \\
\hline \multicolumn{2}{|l|}{ Change in atmospheric pressure } \\
\hline per unit time $\left(\Delta P_{a t m} / \Delta t\right)$ & $-0.09 \mathrm{kPa} / \mathrm{h}$ \\
\hline Time increment $(\Delta t)$ & $900 \mathrm{~s}$ \\
\hline
\end{tabular}

the surface. Notice that the concentration profile reaches an asymptotic value of 25,000 atoms $/ \mathrm{cm}^{3}(1,420 \mathrm{pCi} / 1)$ with depth.

As an introduction, a generic simulation is presented to show the effects of atmospheric pressure changes over time. Showing the transient effects is important because all other runs discussed in this paper are illustrated at the last time step only. This simulation uses the parameters in Table 4.1.

Figure 4.3a shows that the subsurface pressure gradients generally slope toward the surface and crack, but are strongest near the bot tom of the crack. Radon is driven into the crack, where velocities are higher due to the crack's higher permeability. The pressure gradients around the bottom of the crack increase with time, causing radon concentrations to increase steadily with time in the crack (Figure $4.3 \mathrm{~b}$ ). The difference in concentrations is much greater between $0.5 \mathrm{~h}$ and $1.0 \mathrm{~h}$ than between $1.0 \mathrm{~h}$ and $2.0 \mathrm{~h}$. This indicates that changes in pressure gradients and radon concentrations are rapid at first, eventually reaching some equilibrium. Figure $4.3 \mathrm{c}$ shows that the total radon 
flux density increases with time as the atmospheric pressure decreases. The increase in flux is nonlinear for the first hour or two, while radon concentrations are still increasing. Thereafter, once radon concentrations have reached equilibrium, the increase in flux per unit time is constant, proportional to the decrease in atmospheric pressure.

The portion of flux from the crack and the portion from the soil are also shown in Figure 4.3c. The portion of flux from the crack is much smaller because the cracks are very small compared to the surrounding soil. The portion of flux density from the crack was calculated by dividing the advective flux integral [Equation (2.30)] by the crack width.

\subsection{CRACK DIMENSIONS}

Cracks of different depths, widths, and spacings were modeled to see how much total flux density could be enhanced in comparison to flux predicted by a homogeneous soil model without cracks. All other parameters are the same as in Table 4.1 .

The results of the cracked soil model and a homogeneous soil model were compared after $6 \mathrm{~h}$ of decreasing atmospheric pressure. The homogeneous soil model uses the same governing equations and boundary conditions developed in Chapter 2, except that no cracks are present in the soil. The formula used for calculating the difference between the flux predicted by the cracked soil model and the homogeneous soil model is

$$
\text { Percent increase in flux }=\frac{\mathrm{F}_{\mathrm{C}}-\mathrm{F}_{\mathrm{H}}}{\mathrm{F}_{\mathrm{H}}} \times 100
$$

where $F_{C}=$ radon flux predicted by cracked soil model (after $6 \mathrm{~h}$ of

$F_{H}=$ radon flux predicted by homogeneous soil model (after $6 \mathrm{~h}$ of decreasing atmospheric pressure).

After $6 \mathrm{~h}$, flux densities predicted by the model seemed to be increasing at a fairly constant rate; therefore, the percent increase in flux had reached a maximum. 


\subsubsection{Crack Depth}

The effect of increasing crack depth is shown in Figure $4.4 a$, where an increase in depth results in an increase in flux density compared to a homogeneous soil model. However, the increase in flux density is not proportional to crack depth but approaches an asymptotic value.

As the crack deepens, pressures decrease in the crack and pressure gradients in the soil curve towards the crack (Figure 4.4b). Note that the highest gradients in the soil towards the crack are near the bottom of the crack. Most radon will be driven into the crack near its bottom. Also, the velocities in the crack decrease towards the bottom. As the crack deepens, lower velocities are found at the bottom.

The crack brings up radon with higher concentrations from depth; the radon concentrations near the surface increase (Figure $4.4 \mathrm{c}$ ) and so do the radon fluxes (Figure 4.4d). However, the velocities at the bottom of the crack are becoming slower with depth. Therefore, even though the bottom of the crack may be intercepting higher radon concentrations, the rate at which the radon is brought to the surface is decreasing. As a result, the radon flux density becomes larger with increasing crack depth, but reaches an asymptotic value. This effect is also partially due to radon concentrations approaching an asymptotic value with depth.

\subsubsection{Crack Spacing}

The effect of crack spacing on a relatively shallow crack $(30 \mathrm{~cm})$ can be seen in Figure 4.5. As cracks are spaced closer together, the flux density increases. The increases in flux in comparison to a homogeneous soil model are very small, up to $1.5 \%$. A shallow crack does not penetrate far enough into the soil to pump up the higher radon concentrations at depth.

Close crack spacing results in the reduction in pressure gradients toward the surface and crack (Figure 4.6a), yielding lower velocities and hence less advective transport of radon into the crack. As a result, as cracks are more closely spaced, concentrations in the crack decrease (Figure 4.6b). However, Figure 4.6c shows that flux density increases as cracks are more closely spaced. A) though concentrations in the crack are decreasing, having a greater number of cracks per unit area causes an increase in flux. 
Figure 4.7 shows that effects of spacing for a relatively deep crack $(400 \mathrm{~cm})$ are different from those for a shallow crack. The increases in flux are much larger for a deep crack than for a shallow one; however, closer spacing causes an increase in flux density until pressure drawdowns between the cracks interfere, then flux density decreases sharply. It appears that if spacing is greater than depth, then fluxes increase with closer crack spacing. This is the same result seen for a shallow crack. However, if spacing is approximately less than depth, fluxes decrease with closer crack spacing. Figure 4.8a shows again that the closer cracks are spaced, the weaker are the pressure gradients towards the crack. Also, in Figure $4.8 \mathrm{~b}$ closer spacing again results in lower concentration gradients near the crack and surface. Lower pressure and concentration gradients oppose the effect of closer crack spacing, which is to increase the flux density. In Figure $4.8 \mathrm{c}$ instead of the flux density for cracks spaced at $200 \mathrm{~cm}$ being greater than that for $400 \mathrm{~cm}$, it is actually less than the flux density for $800 \mathrm{~cm}$. A limit is reached when crack spacing is less than crack depth $(400 \mathrm{~cm})$, and the effects of reduced pressure and concentration gradients cause the flux density to decrease.

\subsubsection{Crack Width}

Figure 4.5 showed the effects of crack width on the percent increase in flux density in comparison to the homogeneous soil model for a relatively shallow crack $(30 \mathrm{~cm})$. As the crack width increases, so does the flux density. There seems to be a logarithmic dependence on width. The increase in flux becomes more nonlinear as the crack width increases; the permeability of the crack is equal to the square of crack width divided by 12 , according to Equation (2.23). As seen in Figure $4.9 \mathrm{a}$, a crack $0.01 \mathrm{~cm}$ wide $\left(k_{c}=8.3 \times\right.$ $10^{-6} \mathrm{~cm}^{2}$ ) has almost no effect on the pressure gradients, while a crack 0.03 $\mathrm{cm}$ wide $\left(\mathrm{k}_{\mathrm{c}}=7.5 \times 10^{-5} \mathrm{~cm}^{2}\right)$ al lows surface pressures to drop nearly to the bottom of the crack. Pressure contours in soil with a $1.0-\mathrm{cm}-$ wide crack $\left(\mathrm{k}_{\mathrm{c}}=\right.$ $8.3 \times 10^{-2} \mathrm{~cm}^{2}$ ) look similar to those for a $0.03-\mathrm{cm}$ crack; once the crack is wide enough to allow surface pressure to drop essentially to the bottom, increasing the crack width further will make little difference in the pressure contours in the soil. 
Increasing the width from 0.01 to $0.03 \mathrm{~cm}$ causes concentrations to increase slightly in the crack (Figure $4.9 \mathrm{~b}$ ) because of the increase in pressure gradients toward the crack. However, a $1.0-\mathrm{cm}$-wide crack causes concentrations to actually decrease towards the crack. The diffusion coefficient in the crack is four times greater than the diffusion coefficient in the soil. The larger crack diffusion coefficient moves radon more quickly to the surface, lowering concentrations in the crack and adjacent soil. A $0.01-\mathrm{cm}$ crack, which did not affect the pressure and concentration profiles, also does not increase the radon flux density in comparison to a homogeneous soil model (Figure 4.9c). Even though the crack permeability for a width of $0.01 \mathrm{~cm}$ is 300 times greater than that of the surrounding soil, a $0.01-\mathrm{cm}$ crack is essentially part of the soil. A $0.03-\mathrm{cm}$ crack shows a slight increase in flux density, and a $1.0-\mathrm{cm}$ crack shows a significant increase in flux density, largely because wider cracks cover more area with a larger diffusion coefficient.

In Figure 4.7 , it was seen that increasing the width of a relatively deep crack $(400 \mathrm{~cm})$ caused an increase in percent change in flux density compared to a homogeneous soil model. Figure 4.10a shows that as crack width increases, pressures in the crack decrease, approaching surface pressure, because the permeability of the crack increases with the square of the crack width. The gradients in the soil toward the crack become stronger, causing concentrations around the crack to increase (Figure 4.10b). However, this effect is counteracted by the vertical pressure gradient in the crack, which becomes weaker with increasing width. The flux density becomes larger with an increase in width (Figure 4.10c), mediated by the opposing affects of stronger gradients in the soil towards the crack and weaker gradients in the crack.

\subsection{SOIL PROPERTIES}

Soil parameters used in the previous section were taken from Schery, Gaeddert and Wilkening (1984). The effect of choosing different parameters contributes to an understanding of the effect of cracks in different types of soils. All other parameters for these simulations are the same as in Table 4.1. 


\subsubsection{Porosity}

The porosity of the soil (n) was varied while keeping the permeability (k) equal to $2.7 \times 10^{-8} \mathrm{~cm}^{2}$ and the diffusion coefficient in soil ( $\mathrm{Od}^{\star}$ ) equal to $2.6 \times 10^{-2} \mathrm{~cm}^{2} / \mathrm{s}$. In Figure $4.11 \mathrm{c}$, it can be seen that the pressure gradient is directly proportional to the porosity. Increasing soil porosity increases the gas storage capacity of the soil for changes in pressure, from the continuity equation (2.16), and pressure changes do not move as far down into the soil.

Moreover, from Darcy's Law [Equation (2.9)] the specific discharge velocity is directly proportional to the pressure gradient. Therefore, the specific discharge velocity is directly proportional to the porosity. However, in the governing equation for transport [Equation (2.5)], the specific discharge velocity $(v)$ is the only term divided by the porosity. Therefore, changing porosity has no effect on the concentration maps (Figure 4.11d).

Figures $4.11 \mathrm{a}$ and $4.11 \mathrm{~b}$ show radon flux from homogeneous and cracked soils of varying porosity. Because the diffusive flux density [Equation (2.1)] is proportional to the porosity, the flux density from both homogeneous and cracked soils increases with an increase in porosity. Also, the larger the porosity, the more the flux density increases per unit time. This effect is more pronounced in cracked soils. The pressure gradient in the crack increases proportionally to the porosity of the soil, resulting in more advective flux out of the crack.

\subsubsection{Permeability}

The permeability of the soil was varied while the porosity was held at 0.35 and the diffusion coefficient in soil at $2.6 \times 10^{-2} \mathrm{~cm}^{2} / \mathrm{s}$. The permeabilities were taken from Schery and Siegel (1986). The different permeabilities are for the same soil but determined by different experimental methods.

For the homogeneous soils shown in Figure 4.12a, radon flux is higher from higher-permeability soils. This result is to be expected, since soil air velocities, and hence advective flux in the soil, are proportional to the permeability. However, for the cracked soils shown in Figure 4.12b, radon flux is higher from lower-permeability soils. This result can be explained by examining the pressure and concentration contours for each case. 
In Figure 4.12c, decreasing soil permeability prevents pressure decreases from propagating into the soil, increasing the pressure gradients in the soil and crack. Soil velocities are not changed much by a change in permeability, because velocities are proportional to the pressure gradient and the permeability, and as one increases the other decreases. Therefore, the concentrations in the soil show little change with a change in permeability (Figure 4.12d). However, pressure gradients increase in the crack as the soil permeability decreases. The crack permeability remains the same, so the crack velocities increase with a decrease in soil permeability. As a result, the concentrations close to the crack increase significantly with a decrease in soil permeability. This causes a nonlinear increase in flux density because the increase is due almost entirely to an increase in flux density from the crack while the flux density from the soil remains the same.

\subsubsection{Soil Diffusion Coefficient}

The diffusion coefficient in soil $\left(D d^{\star}\right)$ was varied while the porosity (n) was held at 0.35 and the permeability $(\mathrm{k})$ at $2.7 \times 10^{-8} \mathrm{~cm}^{2}$. The two values of soil diffusion coefficient chosen were simply five times greater and five times less than the one used in previous simulations.

For homogeneous soils of varying diffusion coefficient, it can be seen in Figure 4.13a that radon flux, as expected, is proportional to the soil diffusion coefficient. The curves all have roughly the same slope at all times.

However, the radon flux curves for cracked soils with different values of diffusion coefficient have the same slope at late times (Figure 4.13c), but at early times the slope is higher for the soil with a small diffusion coefficient. The early-time nonlinear increase in flux results from a rapid buildup of radon concentrations in the crack. At later times, the concentrations in the crack have reached equilibrium and the increase in flux is steady.

As shown in Figure 4.13c, a smaller soil diffusion coefficient results in an increase in concentrations in the crack and soil. With a longer diffusion path length in the soil, the radon cannot escape quickly to the surface and concentrations increase in the soil. Also, the crack brings radon up that 
cannot diffuse rapidly into the soil, and concentrations build up in the crack. Conversely, a shorter diffusion path allows more radon to escape across the soil/air interface, so the flux density increases as the soil diffusion coefficient of the soil is increased (Figure $4.13 \mathrm{~b}$ ).

\subsection{EFFECT OF PRESSURE VARIATIONS}

This section examines the effect of increasing and decreasing atmospheric pressure, consistent with rates measured in the field by Schery, Gaeddert and Wilkening (1984). Also, the effects of short-term sinusoidal fluctuations in surface pressure are examined. All other parameters for these simulations are the same as in Table 4.1 .

\subsubsection{Linear Variations}

The effect of decreasing atmospheric pressure at the top of the soil at different rates is shown in Figure $4.14 \mathrm{a}$. As the rate of pressure decrease increases, the subsurface pressure gradients in the soil and crack increase by the same proportion. The velocities in the soil and crack increase, bringing up radon from zones of greater concentration at depth, causing an increase in concentrations (Figure 4.14b). The faster the radon moves, the less radon is lost to radioactive decay before it reaches the surface.

A similar effect on pressures is seen when the surface pressure is increased at a constant rate (Figure 4.15a). The increase in subsurface gradient is proportional to the increase in the rate of pressure change. Increasing surface pressures cause the direction of gas flow to reverse; air now flows from the surface down into the crack and into the soil. This causes concentrations to decrease in the soil and crack (Figure $4.15 \mathrm{~b}$ ).

Interestingly, figure 4.16 shows that the decrease in flux density for a certain rate of increasing pressure is not as great as the increase in flux density for a decrease in pressure of the same magnitude. Although the pressure gradients are downward for the case of increasing atmospheric pressure, the concentration gradients in the soil and crack are still upward. The diffusive transport of radon is still toward the surface, because the concentration of radon in the atmosphere is zero. 


\subsubsection{Sinusoidal Variations}

In this section, sinusoidal variations in atmospheric pressure about a mean value of $85 \mathrm{kPa}$ were applied at the upper boundary of the model. The period and amplitude of the sine function were varied.

Figure 4.17a shows the effect of a sinusoidal atmospheric pressure variation over time on gas pressures in the soil. The first frame was taken when the surface pressure was at the bottom of a pressure decrease. The gradient is very strong towards the surface and crack. The second frame was taken when the pressure is increasing and is at the mean value of the sinusoidal variation. Pressures have begun to rise near the surface and near the crack, but gradients are still upward in most of the soil. The third frame was taken at the peak of a rise in pressure, and the gradient is predominantly downward.

Figure $4.17 \mathrm{~b}$ shows the effect of a sinusoidal pressure variation over time on radon concentrations. These results were recorded after two complete periods of sinusoidal atmospheric pressure variation. Since the first frame was taken at the end of a pressure decrease, concentrations are very high in the crack. The second frame was taken when pressures had been increasing; concentrations had begun to decrease near the crack. The third frame is at the end of a rise in pressure; concentrations are mostly decreasing, but still rise near the surface. This is the origin of the wiggles in concentration contours near the crack. The contour wiggles are manifestations of the increases and decreases that have occurred in the crack and have moved out into the soil, becoming damped out as they go.

Figure 4.18 shows the effect that a sinusoidal pressure variation with a long period $(2 \mathrm{~h})$ has on radon flux density. Soil with cracks shows a greater variation in flux than a homogeneous soil, and the mean flux increases slightly. Decreasing the period of the pressure change by 10 times, and then 100 times but keeping the amplitude the same (Figures 4.19 and 4.20), causes a small increase in the mean flux but a large change in the deviation about the mean (Figure 4.21). Standard deviation is used as a comparative measure rather than amplitude, since the flux curves are sinusoidally asymmetric. The standard deviation is, in most cases, about $75 \%$ of the amplitude of the radon flux density with time. 
The increase in the mean flux can be explained by the results of the previous section, where a decrease in pressure caused a greater change in flux than a rise in pressure of the same magnitude. The increase in flux deviation with a decrease in period results from the amplitude being kept constant, so that the variation in atmospheric pressure per unit time is larger.

Notably, there appears to be very little phase lag between a change in surface pressure and the response of the radon flux density in Figures 4.18 through 4.20. This is because the flux is calculated from the concentrations of nodes near the surface; the lag time between changes in surface pressure and changes in concentrations near the surface is very short.

It may also be observed that the response of surface flux to changes in pressure equilibrates rapidly. In other words, the standard deviations of the fluxes in Figures 4.18 through 4.20 increase only slightly with time. This situation is not surprising, because pressures and concentrations were observed to reach equilibrium quickly for constant changes in pressures (see discussion related to Figure 4.3 a).

Decreasing the period of the sinusoidal fluctuation allows less time for subsurface pressures in the soil and crack to equilibrate (Figure 4.22a). With a period of $7200 \mathrm{~s}$, when the pressure has been decreasing at the surface, the gradient curves smoothly toward the crack and surface. Decreasing the period to $720 \mathrm{~s}$ does not allow the pressure decrease to move completely into the soil, and the gradient is still upward in the portion of the soil farthest from the surface and crack. Decreasing the period to $72 \mathrm{~s}$ keeps the pressure decrease from moving into the soil except close to the surface and crack. Upward gradients near the surface and crack are very strong, while the gradient is downward everywhere else in the soil.

Decreasing the period of the sinusoidal variation also allows less time for changes in concentration to occur in the crack and move into the soil (Figure 4.22b). Concentration contours wiggle up and down near the crack, remnants of previous fluctuations in the crack that have moved into the soil. These variations are most clearly seen for a period of $7200 \mathrm{~s}$, and become less distinct for smaller periods. For a period of $7200 \mathrm{~s}$, concentrations rise consistently near the crack because pressure has been decreasing for the last few time steps. However, for shorter periods, the concentrations still 
decrease near the crack because pressure gradients in the crack are either weakly upward $(720 \mathrm{~s})$ or downward $(72 \mathrm{~s})$.

Increasing the amplitude of the sinusoidal variation in surface pressure while keeping the period constant (Figures 4.23 and 4.24 ) effectively increases the change in pressure per unit time. This causes a much greater change in flux from cracked soil than from soil with no cracks. With an increase in amplitude, the mean and deviation of radon flux density from cracked soil increase rapidly compared to soil with no cracks (Figure 4.25).

The increase in mean and deviation of flux for soil with cracks is almost linear, relating to the linear increase in subsurface pressure gradient with an increase in amplitude (Figure 4.26a). Of course these increases in subsurface pressure are probably linear only for fairly small changes in amplitude; the ones shown here are for 50 and $100 \%$ increases.

In Figure 4.26b, an increase in amplitude of the sinusoidal pressure variation causes concentrations in and near the crack to increase, but has less of an effect on concentrations in the soil. This situation illustrates why fluxes from a soil with cracks change more with a change in amplitude than homogeneous soil. 


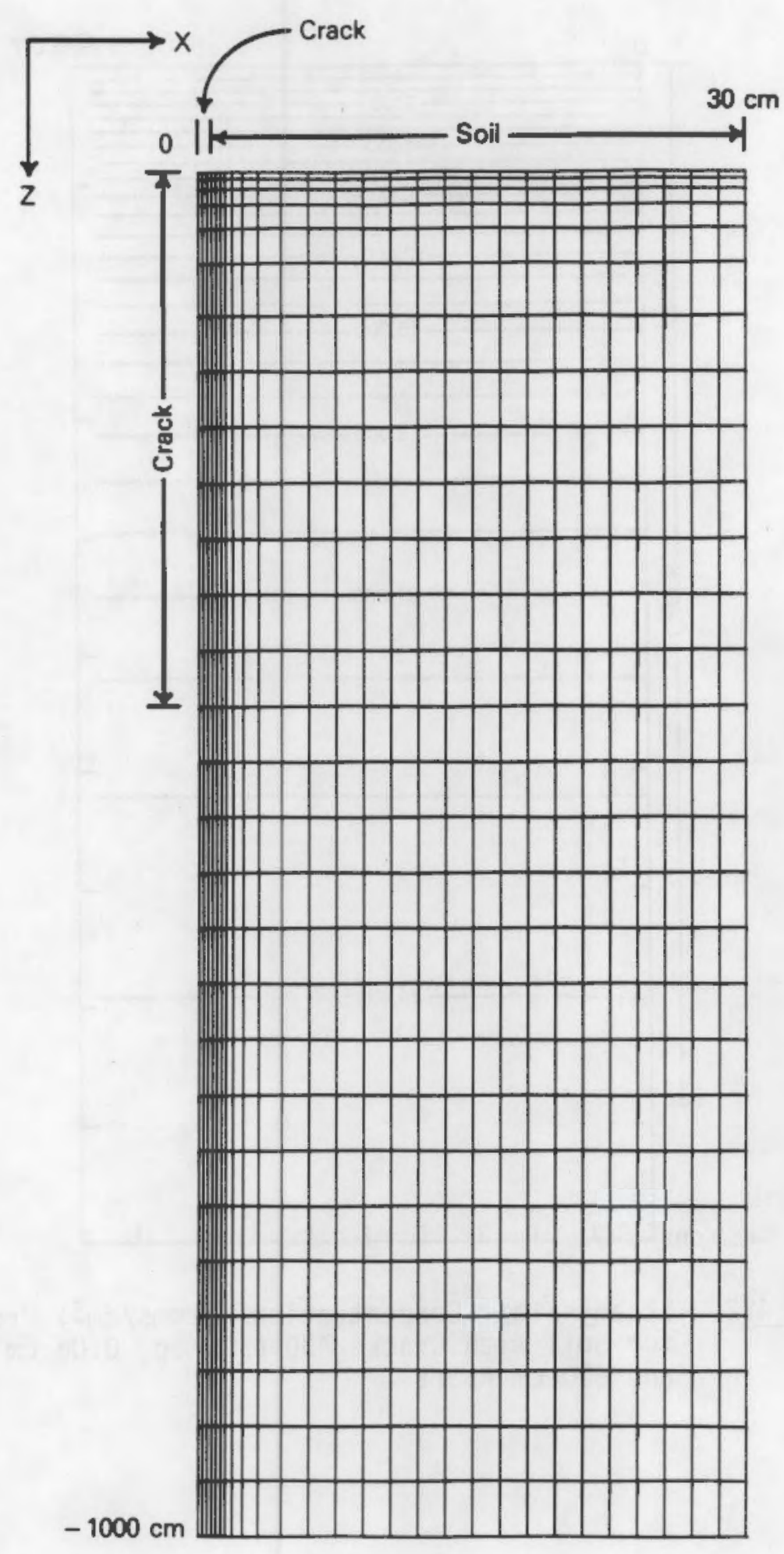

FIGURE 4.1. Diagram of Typical Finite Element Grid Used 


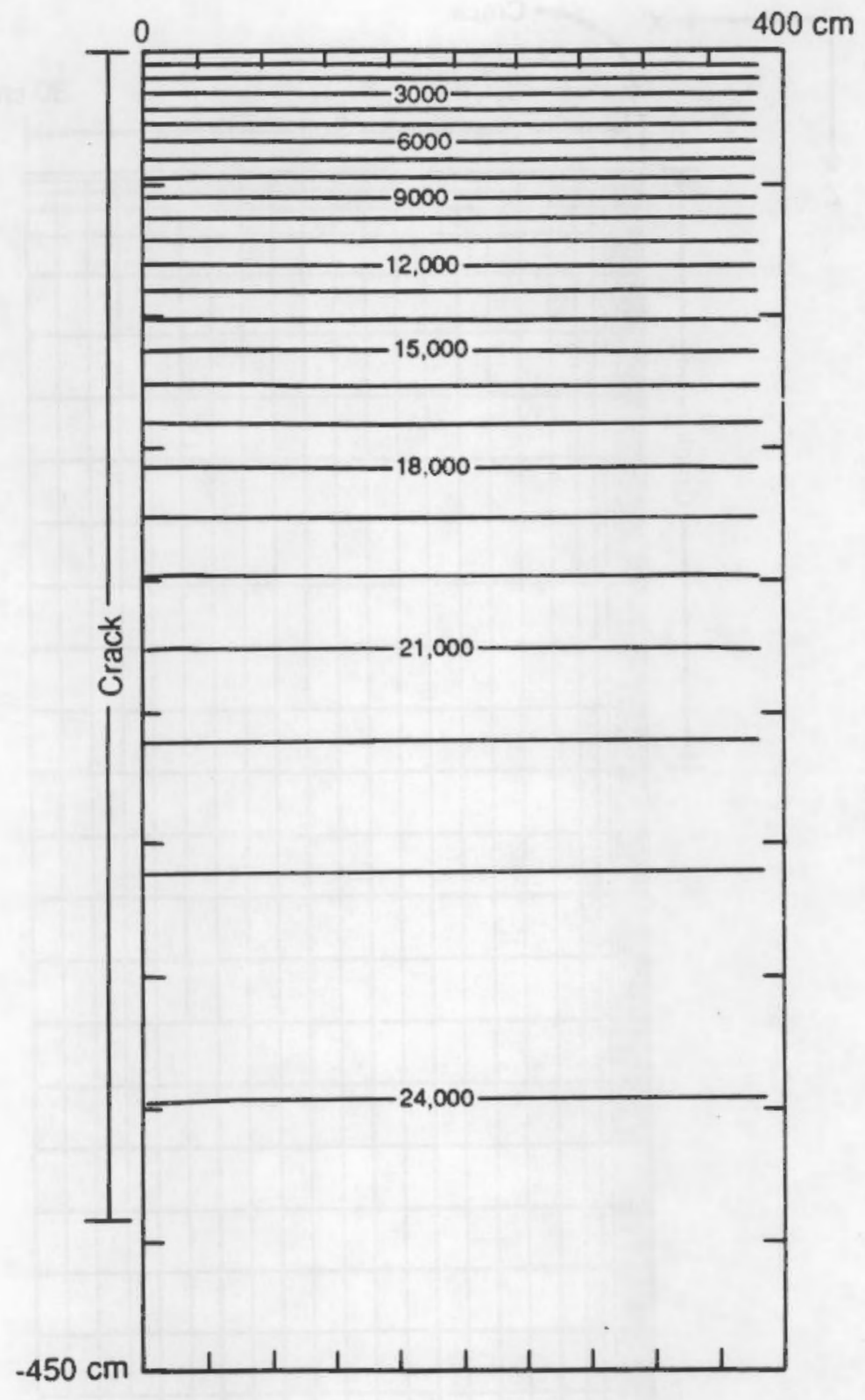

FIGURE 4.2. Steady-State Concentration (atoms $/ \mathrm{cm}^{3}$ ) Profile for Soil with Cracks $400 \mathrm{~cm}$ Deep, $0.06 \mathrm{~cm}$ Wide, and $800 \mathrm{~cm}$ Apart 

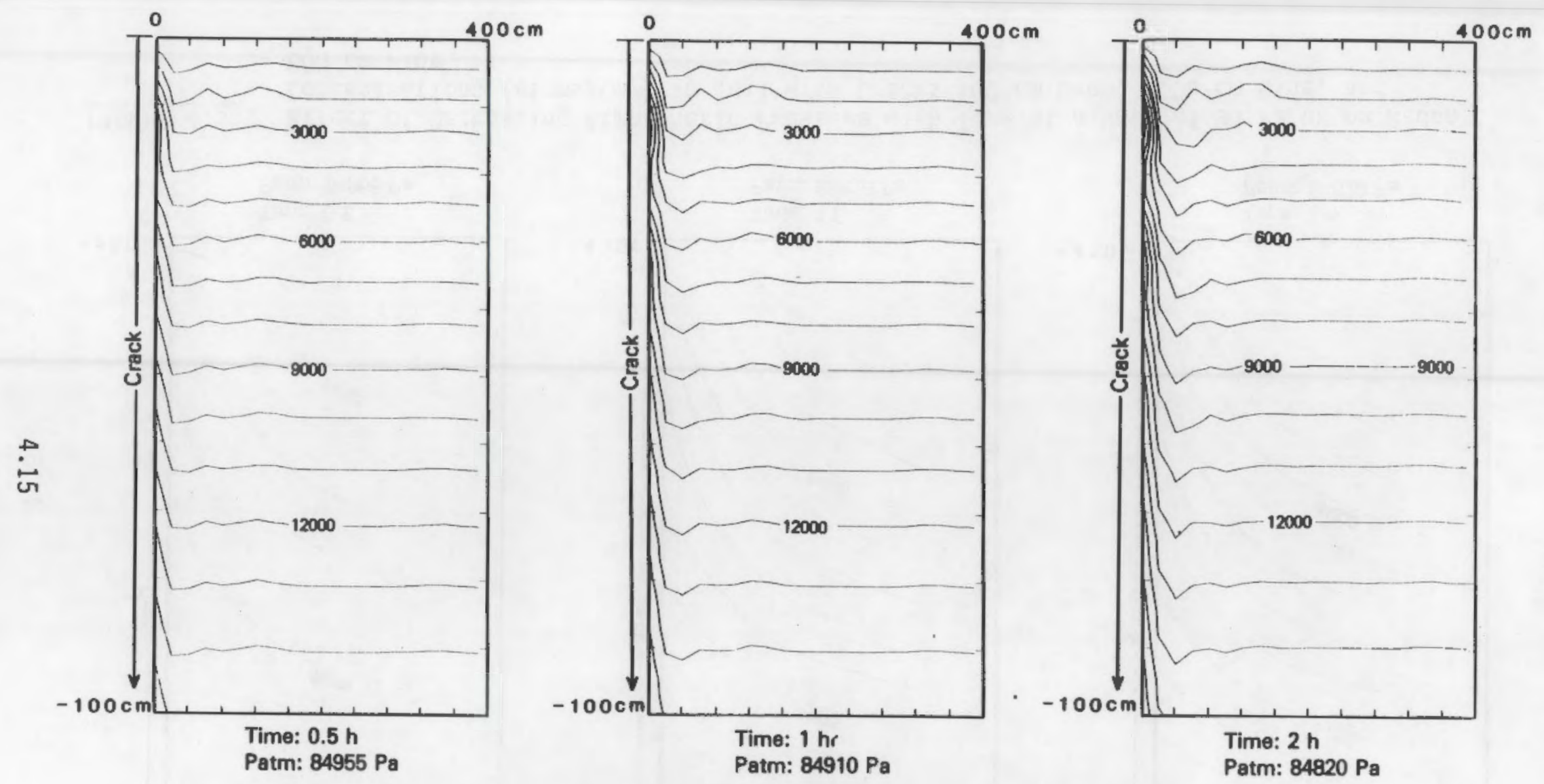

FIGURE 4.3a. Effect of Decreasing Atmospheric Pressure With Time at a Rate of $90 \mathrm{~Pa} / \mathrm{hr}$ on Gas Pressures (Pascals) in Soil with Cracks $400 \mathrm{~cm}$ Deep, $0.06 \mathrm{~cm}$ Wide, and $800 \mathrm{~cm}$ Wide 

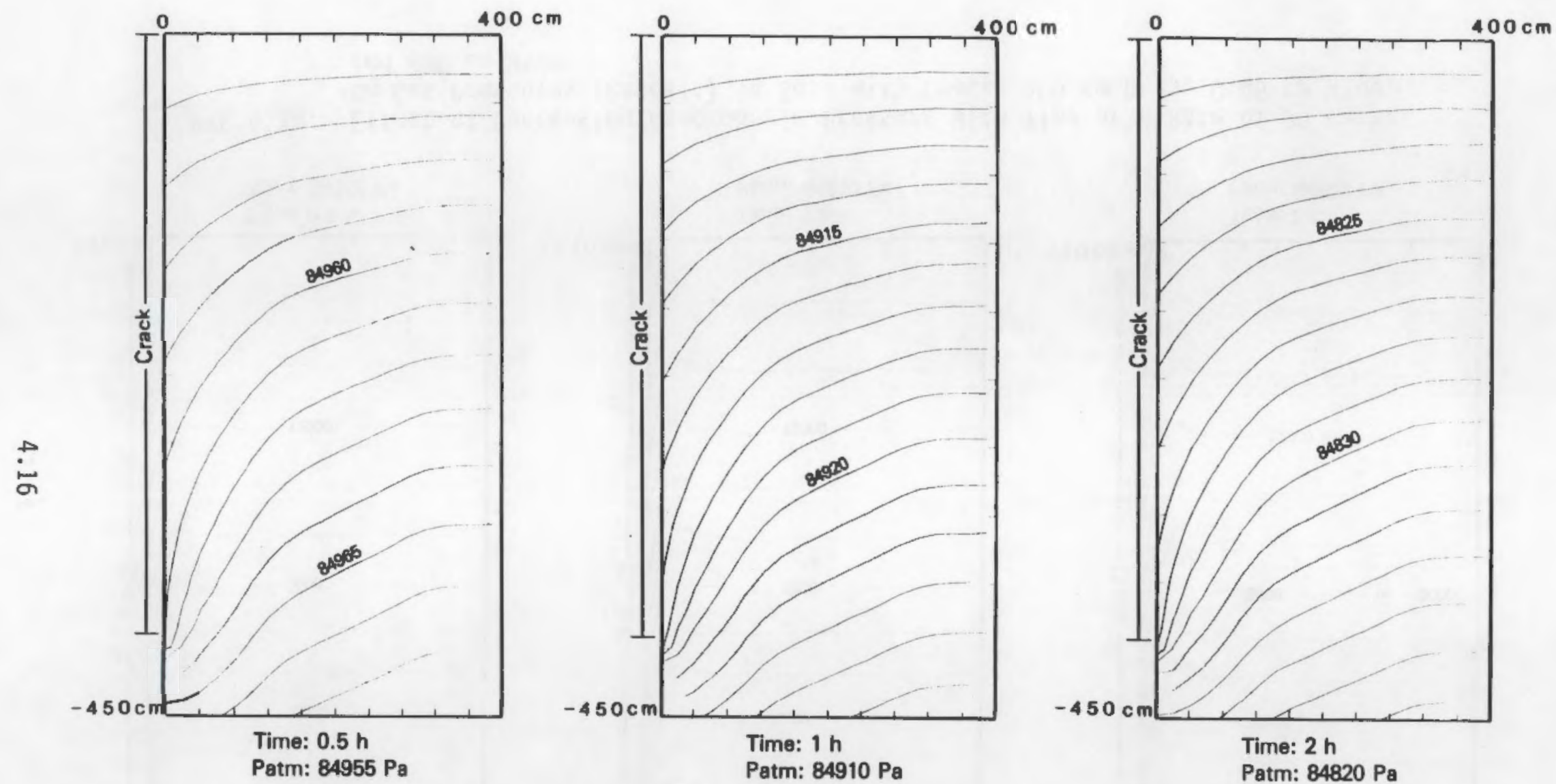

FIGURE 4.3b. Effect of Decreasing Atmospheric Pressure with Time at a Rate of $90 \mathrm{~Pa} / \mathrm{hr}$ on Radon Concentrations (atoms $/ \mathrm{cm}^{3}$ ) in Soil with Cracks $400 \mathrm{~cm}$ Deep, $0.06 \mathrm{~cm}$ Wide, and $800 \mathrm{~cm}$ Wide 


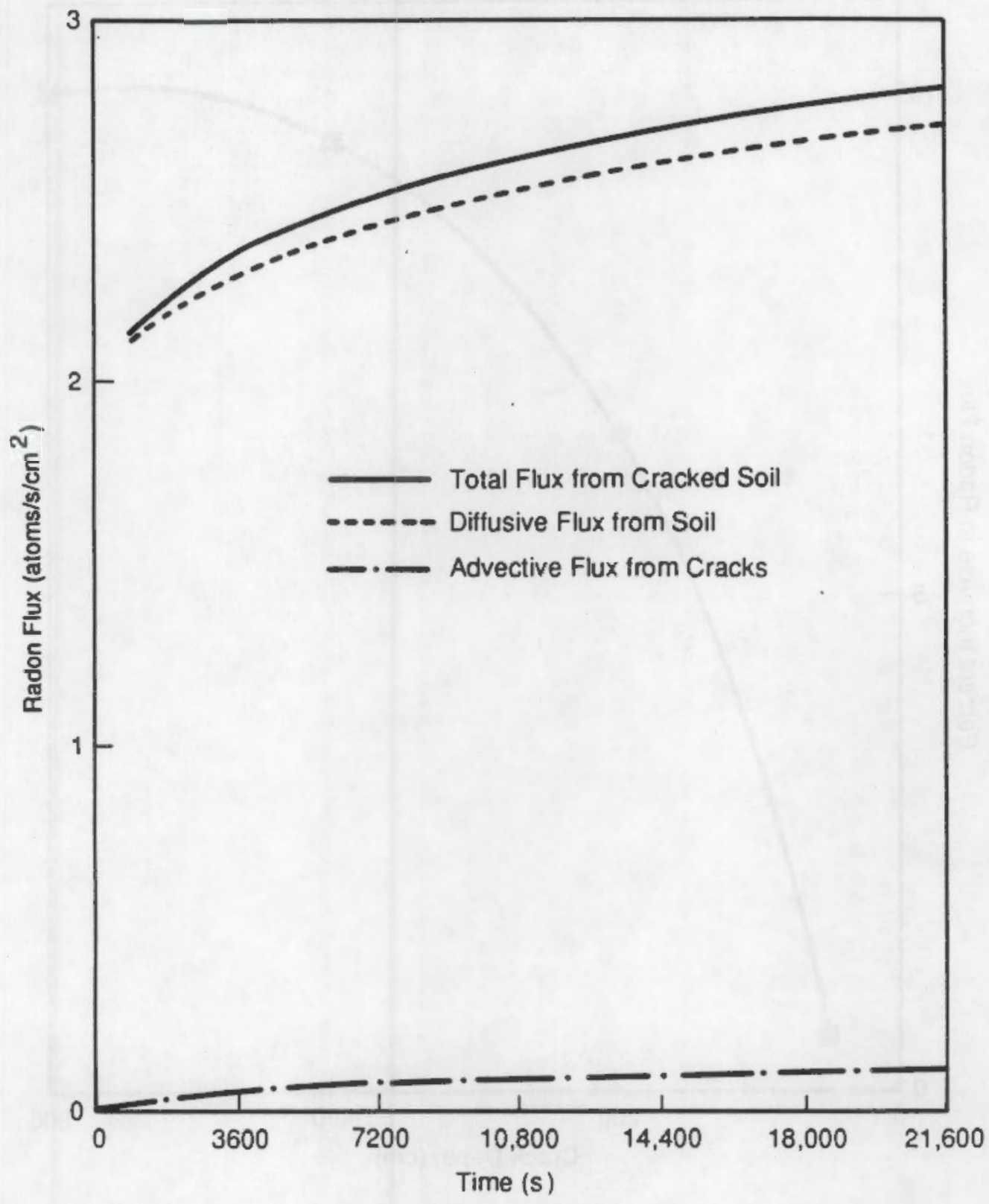

FIGURE 4.3c. Effect of Decreasing Atmospheric Pressure with Time at a Rate of $90 \mathrm{~Pa} / \mathrm{h}$ on Radon Flux from Soil with Cracks $400 \mathrm{~cm}$ Deep, $0.06 \mathrm{~cm}$ Wide, and $800 \mathrm{~cm}$ Wide 


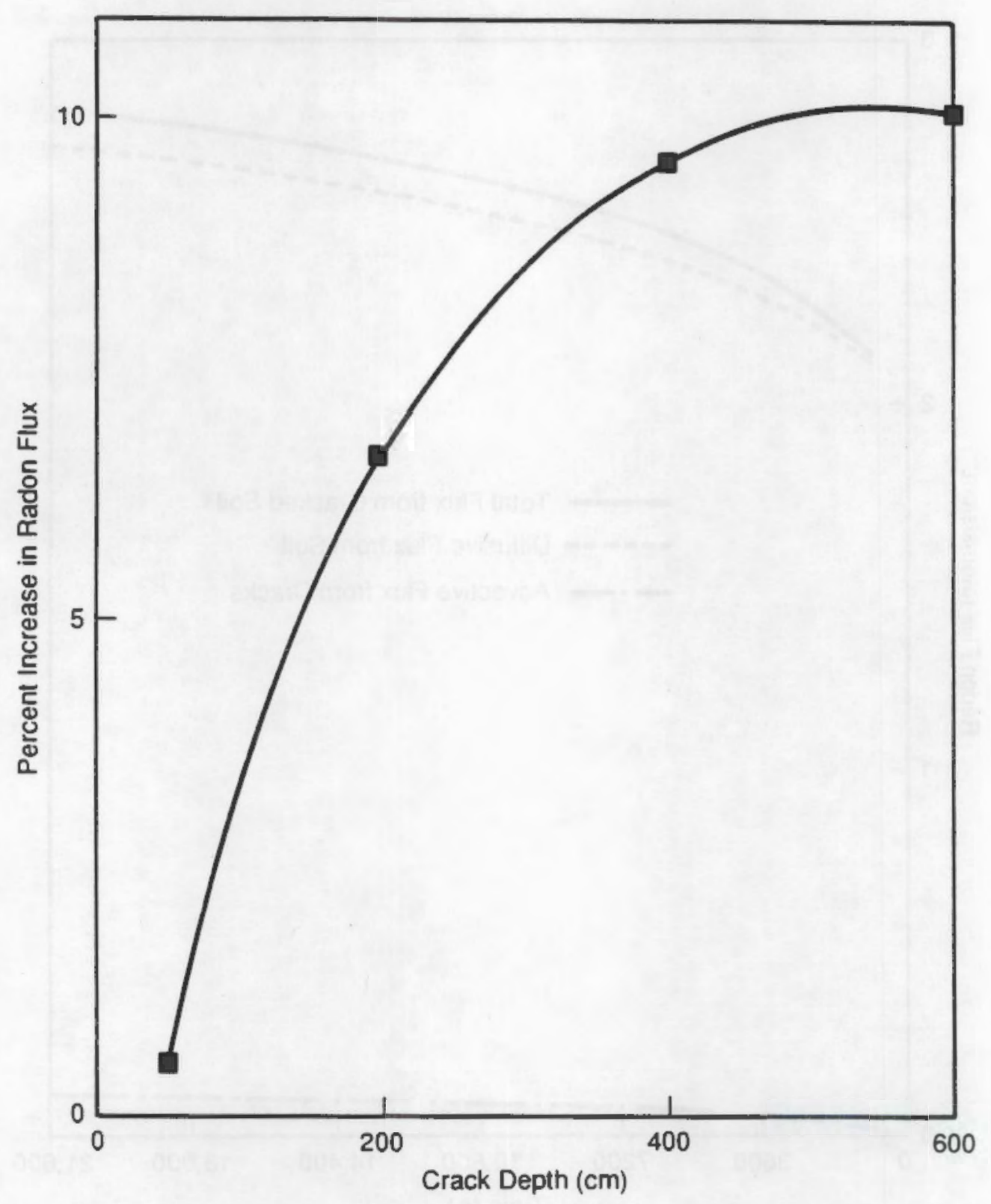

FIGURE 4.4a. Effect of Crack Depth on Percent Difference in Flux Density Between Soil with Cracks Spaced $400 \mathrm{~cm}$ Apart and $0.06 \mathrm{~cm}$ Wide and Soil without Cracks After $6 \mathrm{~h}$ of Decreasing Pressure 


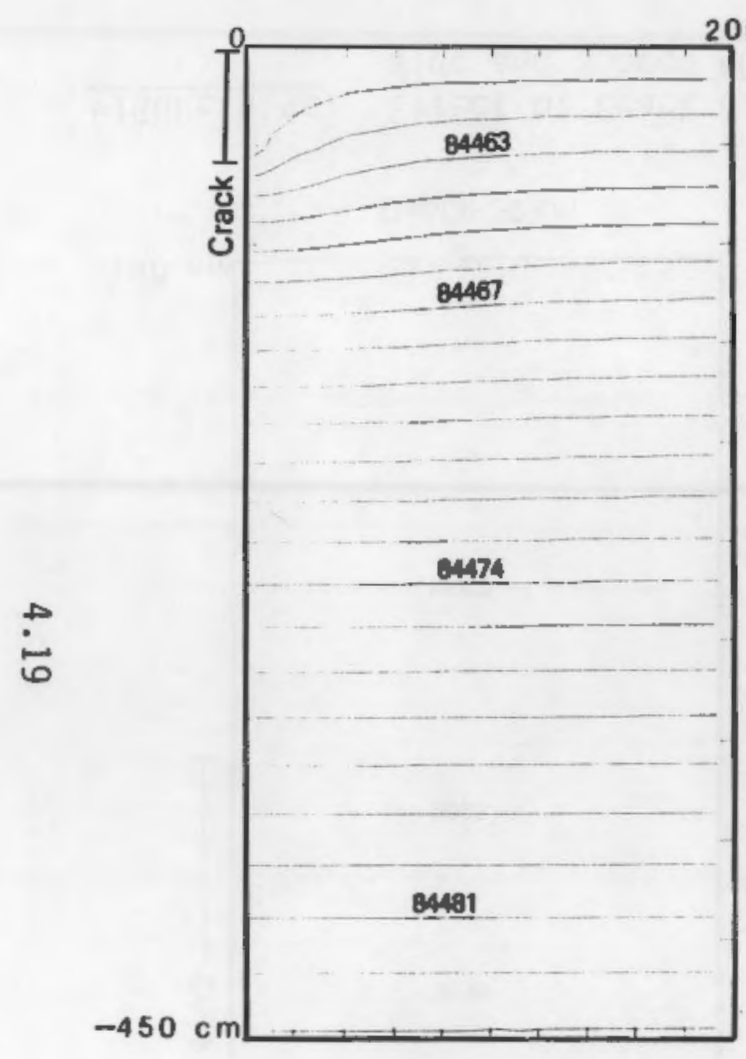

Depth: $50 \mathrm{~cm}$

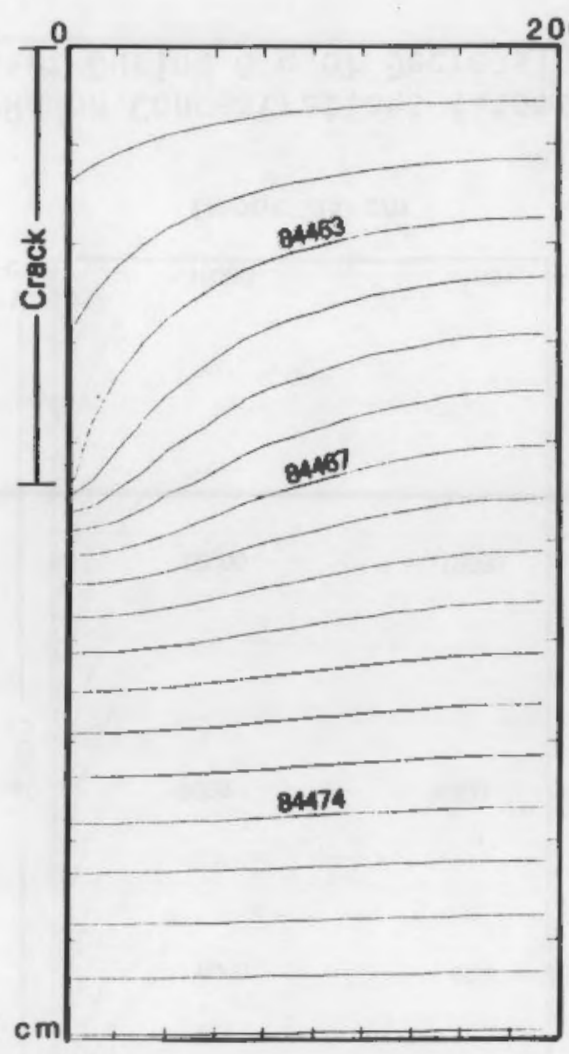

Depth: $200 \mathrm{~cm}$

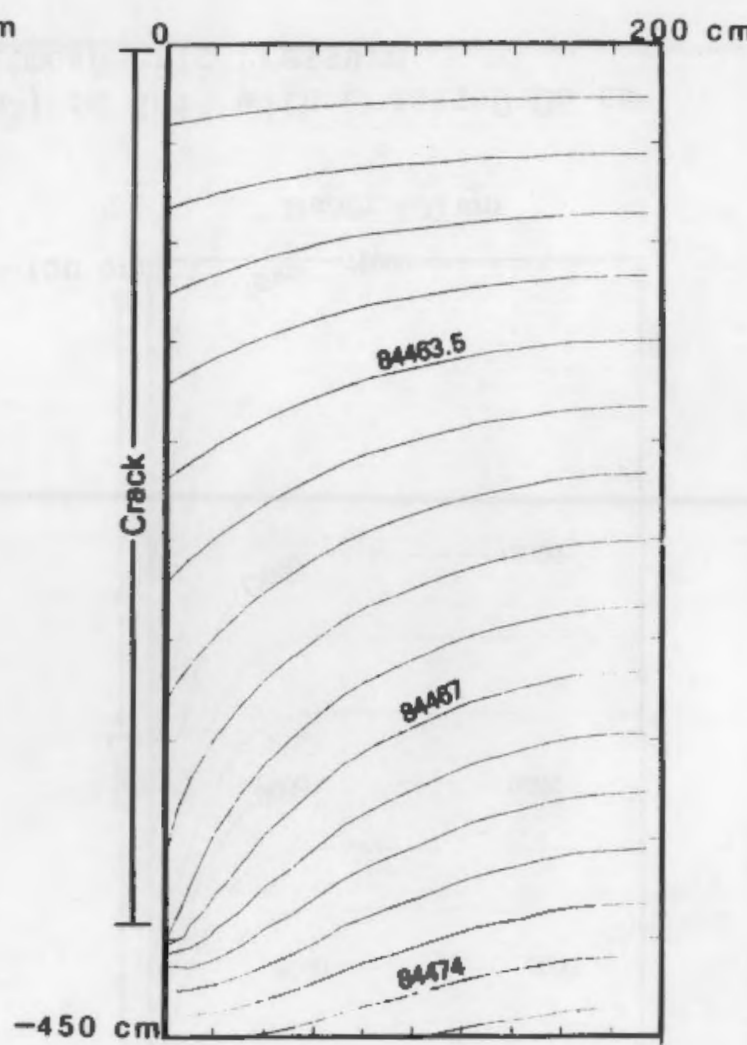

Depth: $400 \mathrm{~cm}$

FIGURE 4.4b. Effect of Crack Depth on Gas Pressures (Pascals) in Soil with Cracks $0.06 \mathrm{~cm}$ Wide and Spaced $400 \mathrm{~cm}$ Apart After $6 \mathrm{~h}$ of Decreasing Atmospheric Pressure 

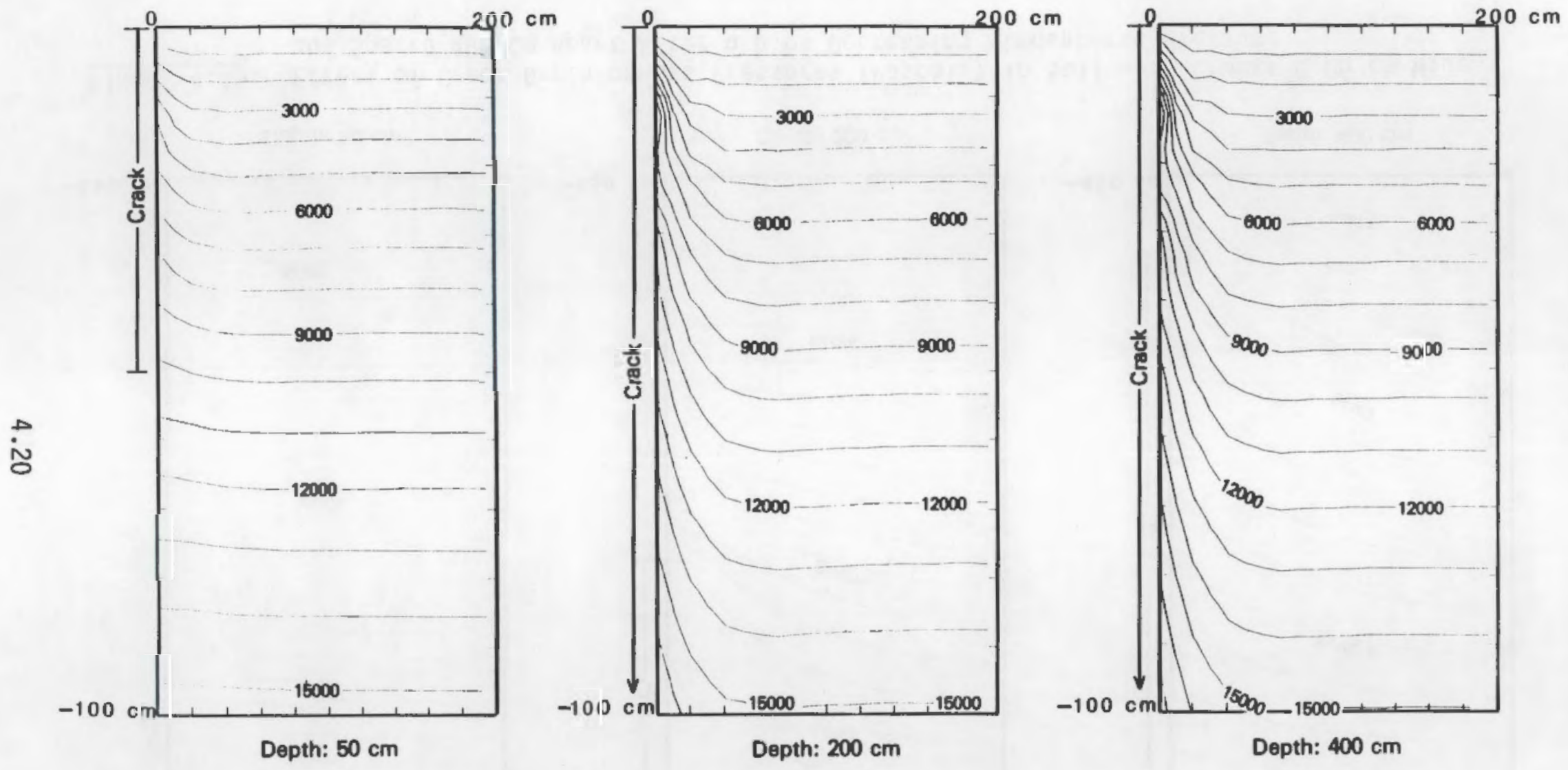

FIGURE 4.4c. Effect of Crack 0epth on Radon Concentrations (atoms $/ \mathrm{cm}^{3}$ ) in Soil with Cracks $0.06 \mathrm{~cm}$ Wide and Spaced $400 \mathrm{~cm}$ Apart During $6 \mathrm{~h}$ of Decreasing Atmospheric Pressure 


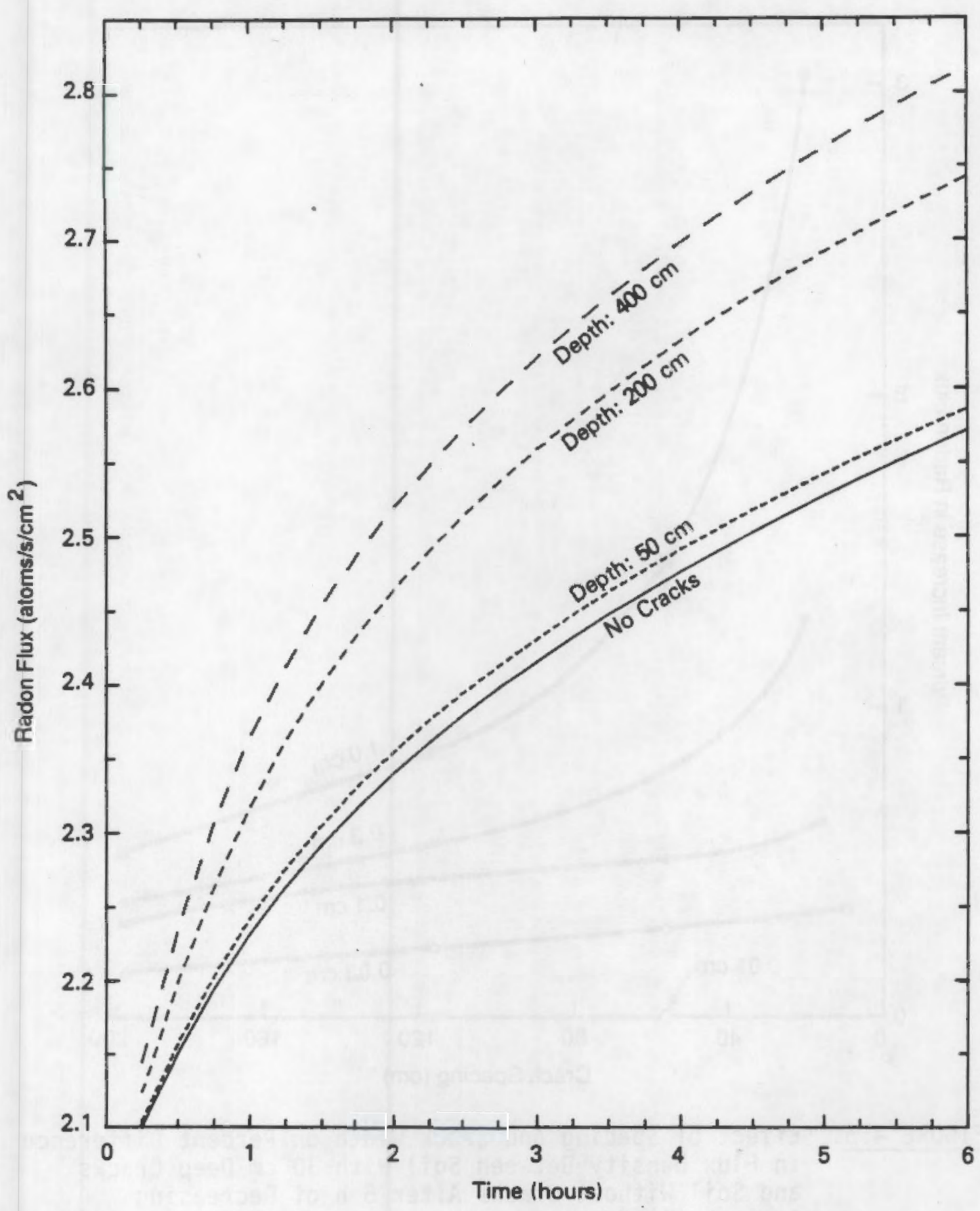

FIGURE 4.4d. Effect of Crack Depth on Radon Flux Density from Soil with Cracks $0.06 \mathrm{~cm}$ Wide and Spaced $400 \mathrm{~cm}$ Apart After 6 hours of Decreasing Atmospheric Pressure 


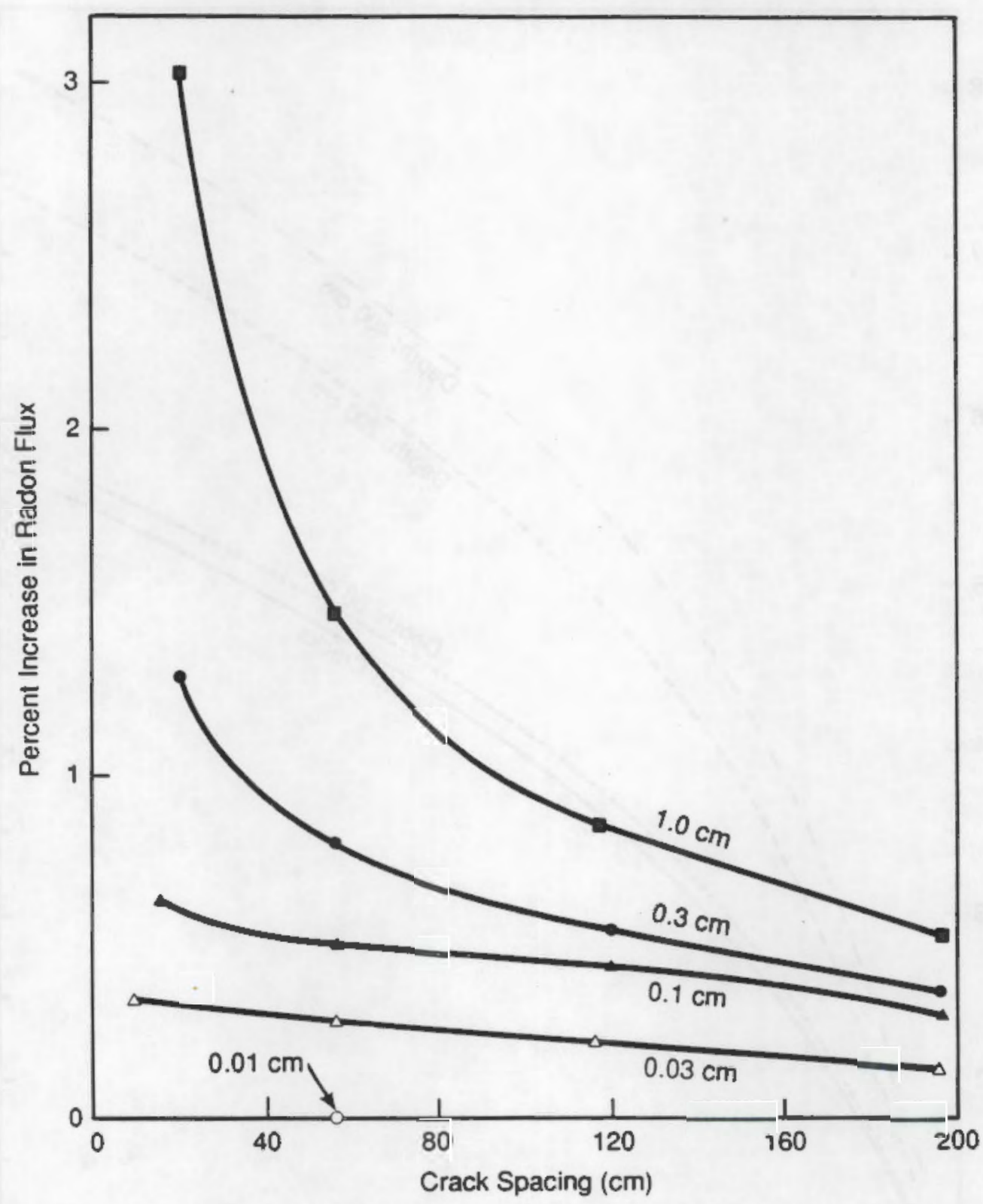

FIGURE 4.5. Effect of Spacing and Crack Width on Percent Difference in Flux Density Between Soil With $30 \mathrm{~cm}$ Deep Cracks and Soil Without Cracks After $6 \mathrm{~h}$ of Decreasing Atmospheric Pressure 


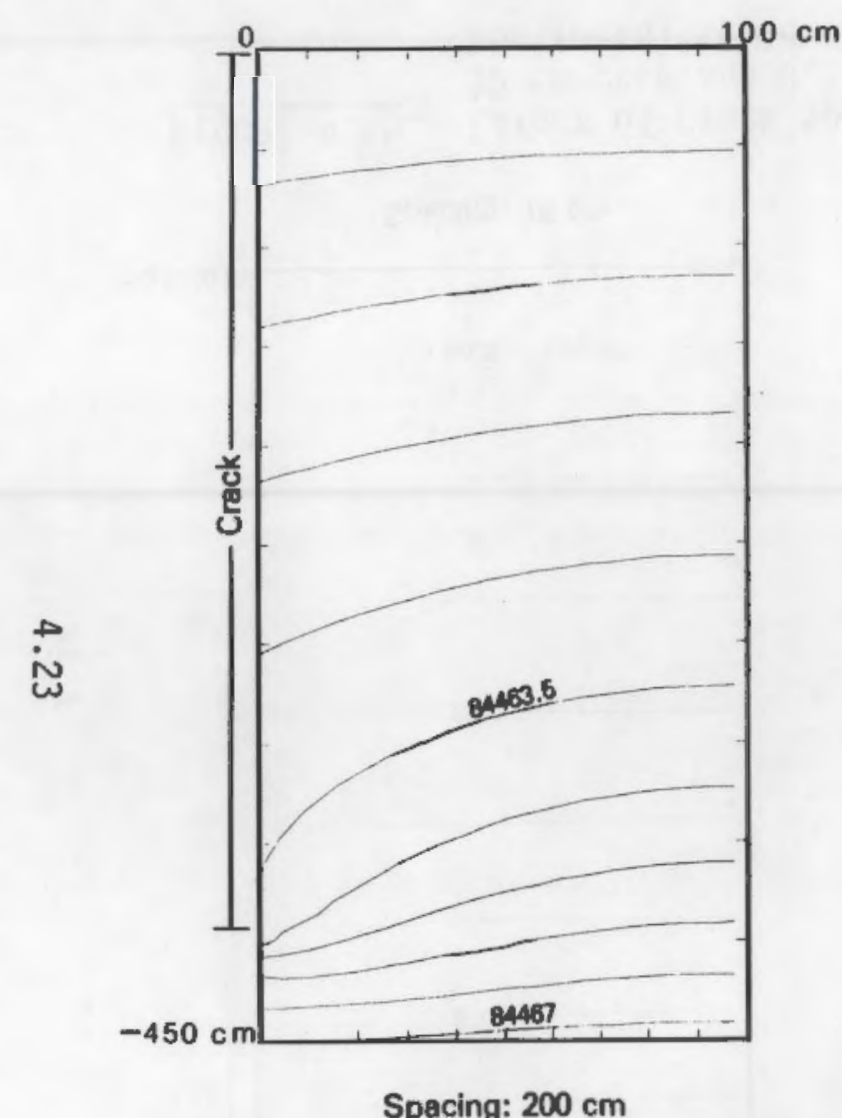

Spacing: $200 \mathrm{~cm}$

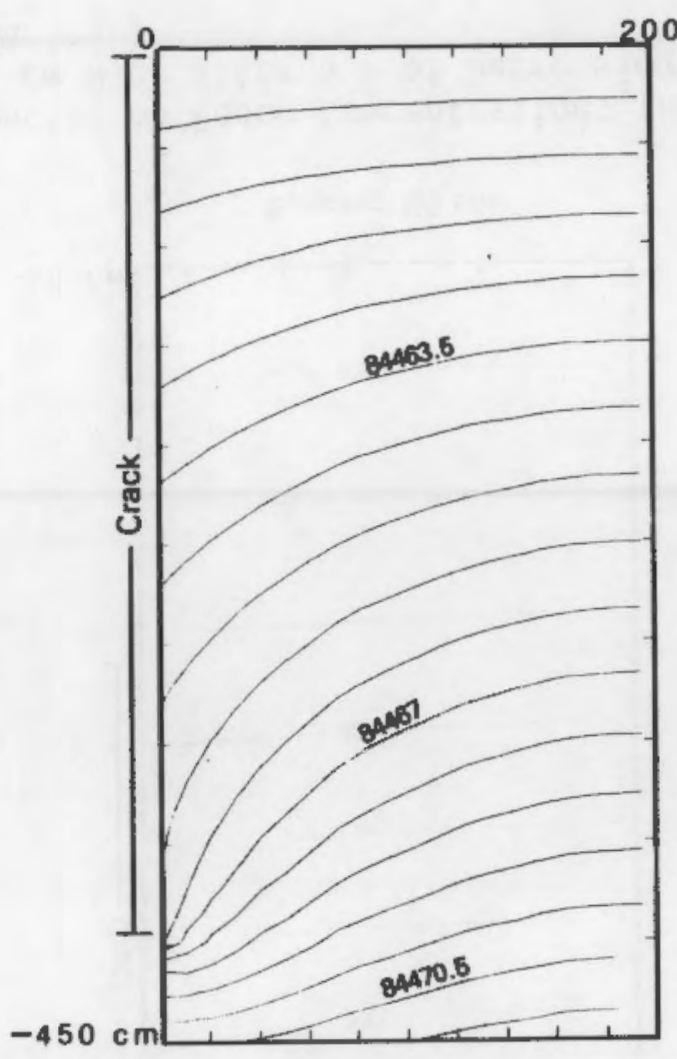

Spacing: $400 \mathrm{~cm}$

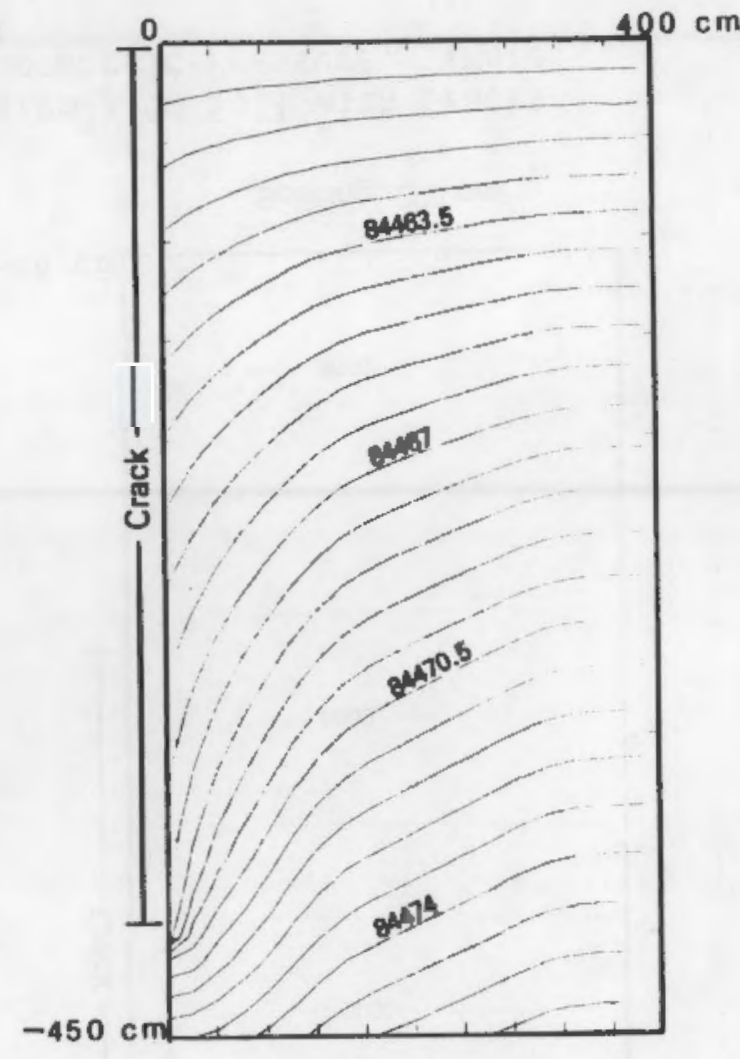

Spacing: $800 \mathrm{~cm}$

FIGURE 4.6a. Effect of Crack Spacing on Gas Pressures (Pascals) in Soil with Cracks $30 \mathrm{~cm}$ Deep and $0.1 \mathrm{~cm}$ Wide After $6 \mathrm{~h}$ of Decreasing Atmospheric Pressure. (Note: horizontal scale varies.) 


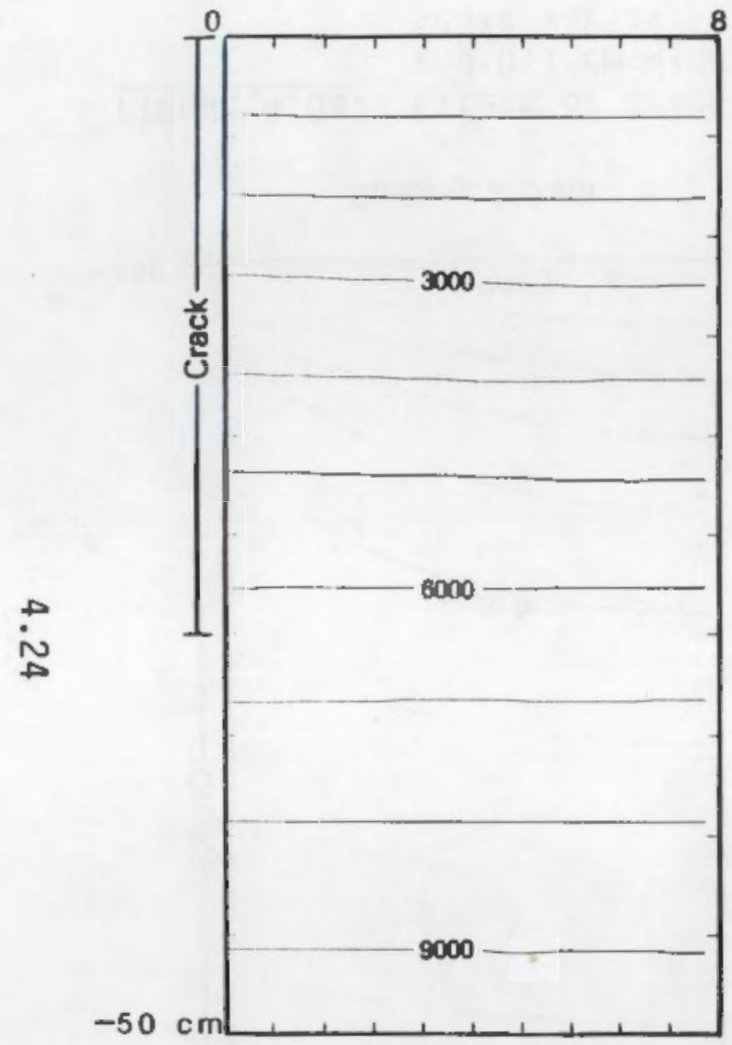

Spacing: $16 \mathrm{~cm}$
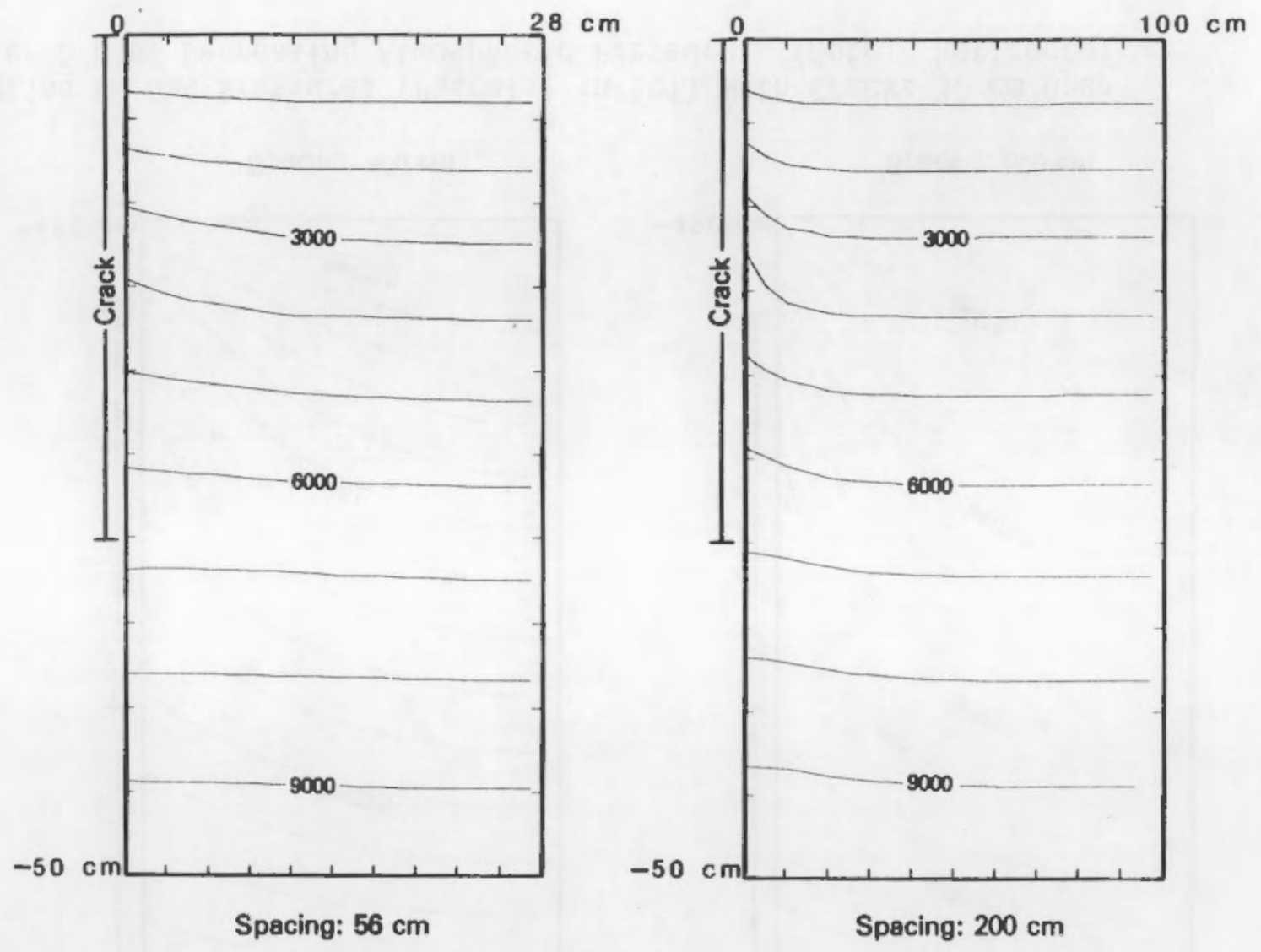

FIGURE 4.6b. Effect of Crack Spacing on Radon Concentrations (atoms $/ \mathrm{cm}^{3}$ ) in Soil with Cracks $30 \mathrm{~cm}$ Deep and $0.1 \mathrm{~cm}$ Wide After $6 \mathrm{~h}$ of Decreasing Atmospheric Pressure. (Note: horizontal scale varies.) 


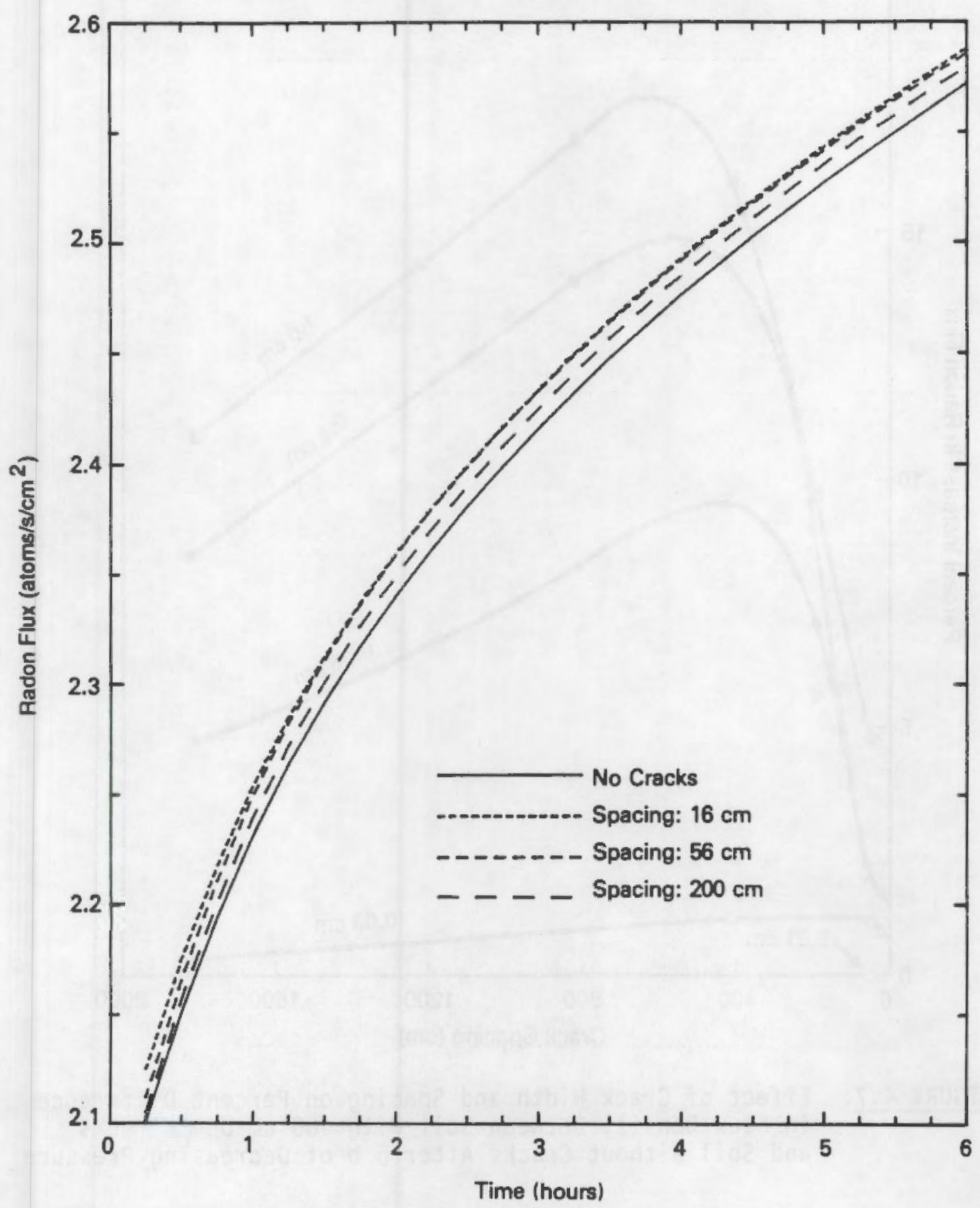

FIGURE 4.6c. Effect of Crack Spacing on Radon Flux Density from Soil with Cracks $30 \mathrm{~cm}$ Deep and $0.1 \mathrm{~cm}$ Wide During $6 \mathrm{~h}$ of Decreasing Atmospheric Pressure 


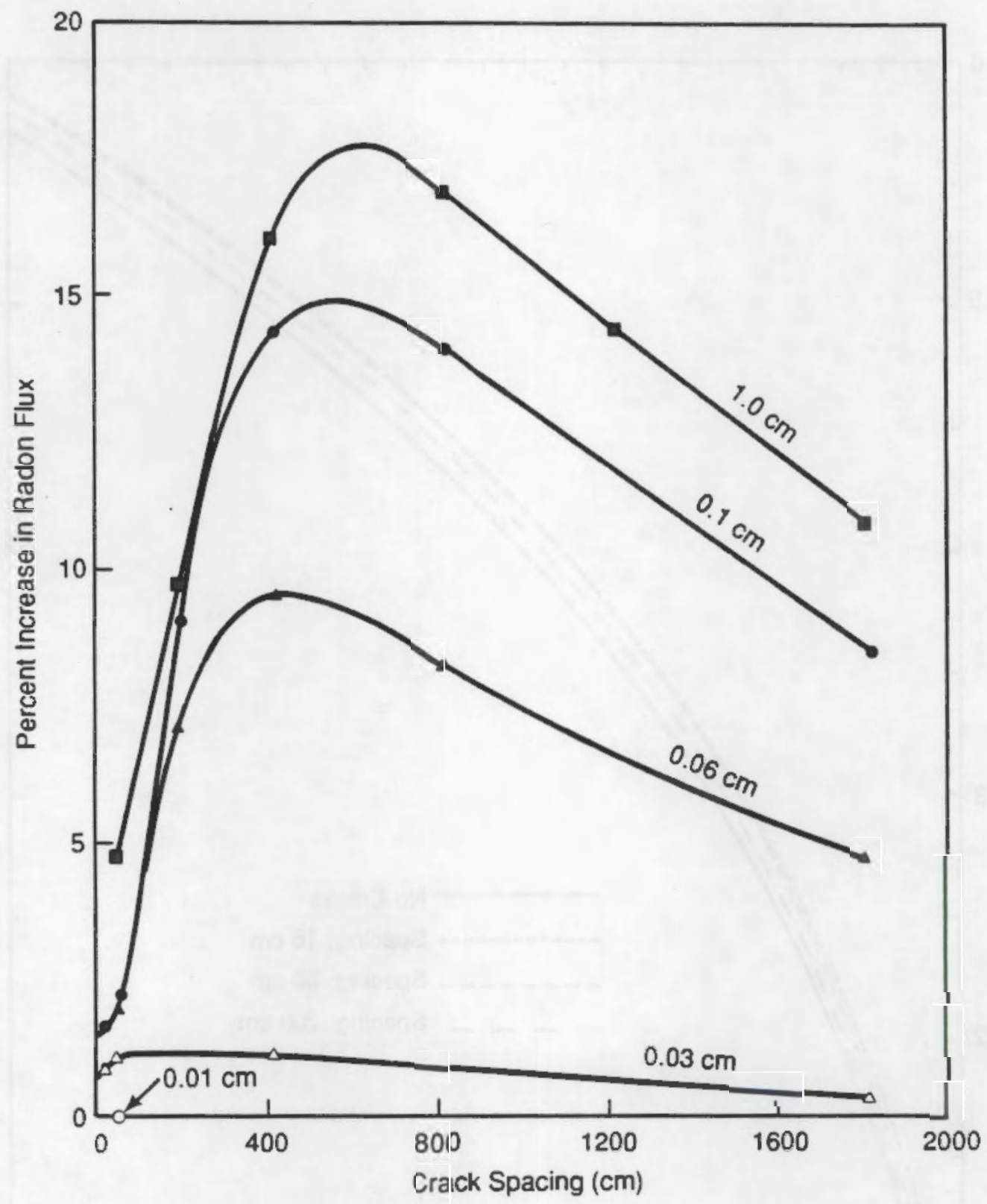

FIGURE 4.7. Effect of Crack Width and Spacing on Percent Difference in Flux Density Between Soil With $400 \mathrm{~cm}$ Deep Cracks and Soil Without Cracks After $6 \mathrm{~h}$ of Decreasing Pressure 


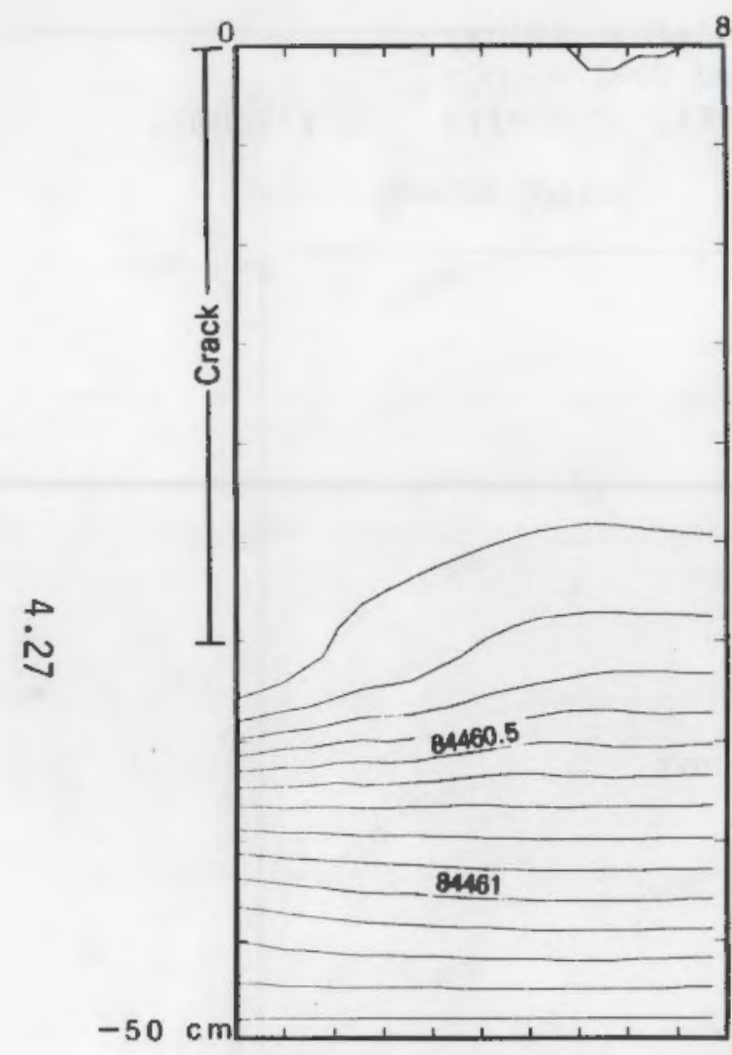

Spacing: $16 \mathrm{~cm}$
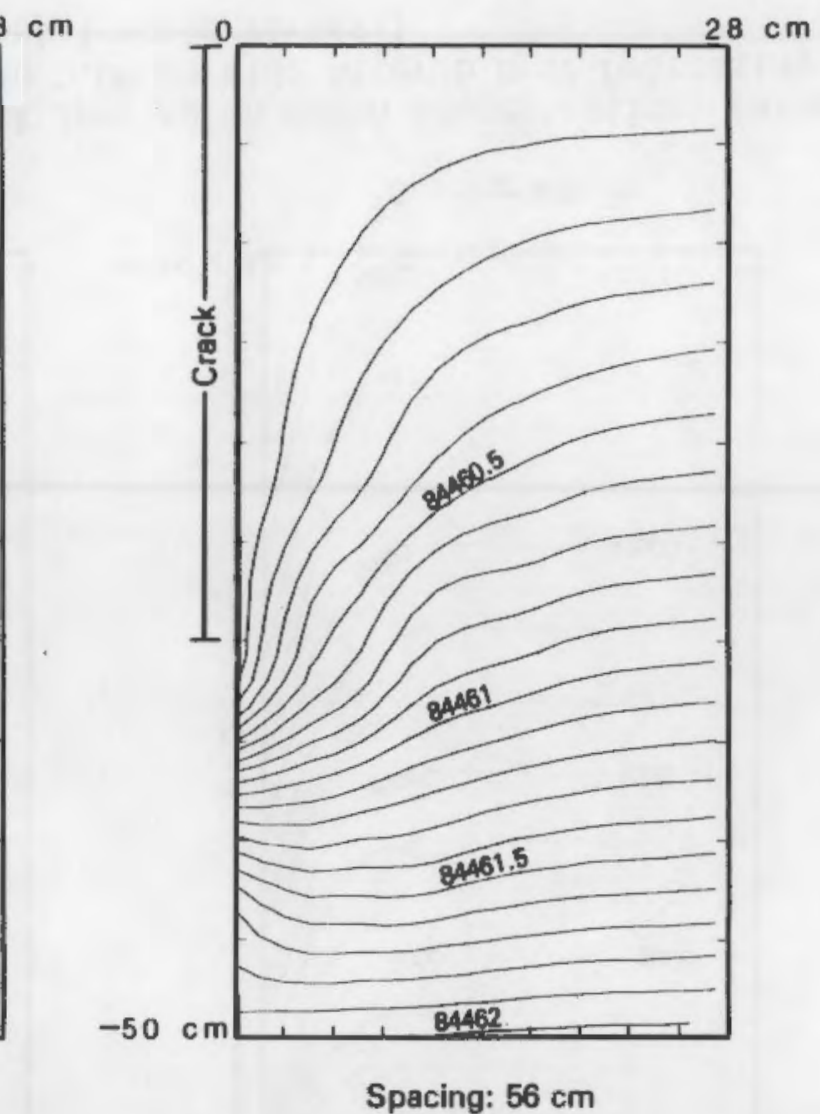

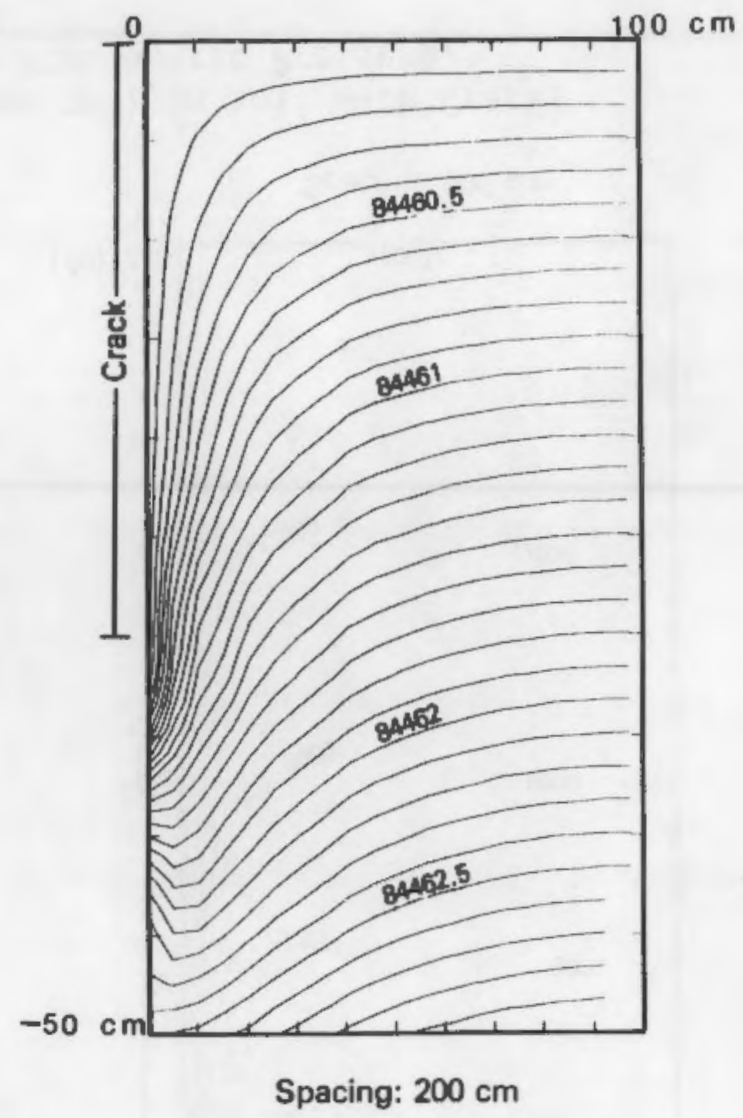

FIGURE 4.8a. Effect of Crack Spacing on Gas Pressures (Pascals) in Soil with Cracks $400 \mathrm{~cm}$ Deep and $0.06 \mathrm{~cm}$ Wide After $6 \mathrm{~h}$ of Decreasing Atmospheric Pressure. (Note: horizontal scale varies.) 

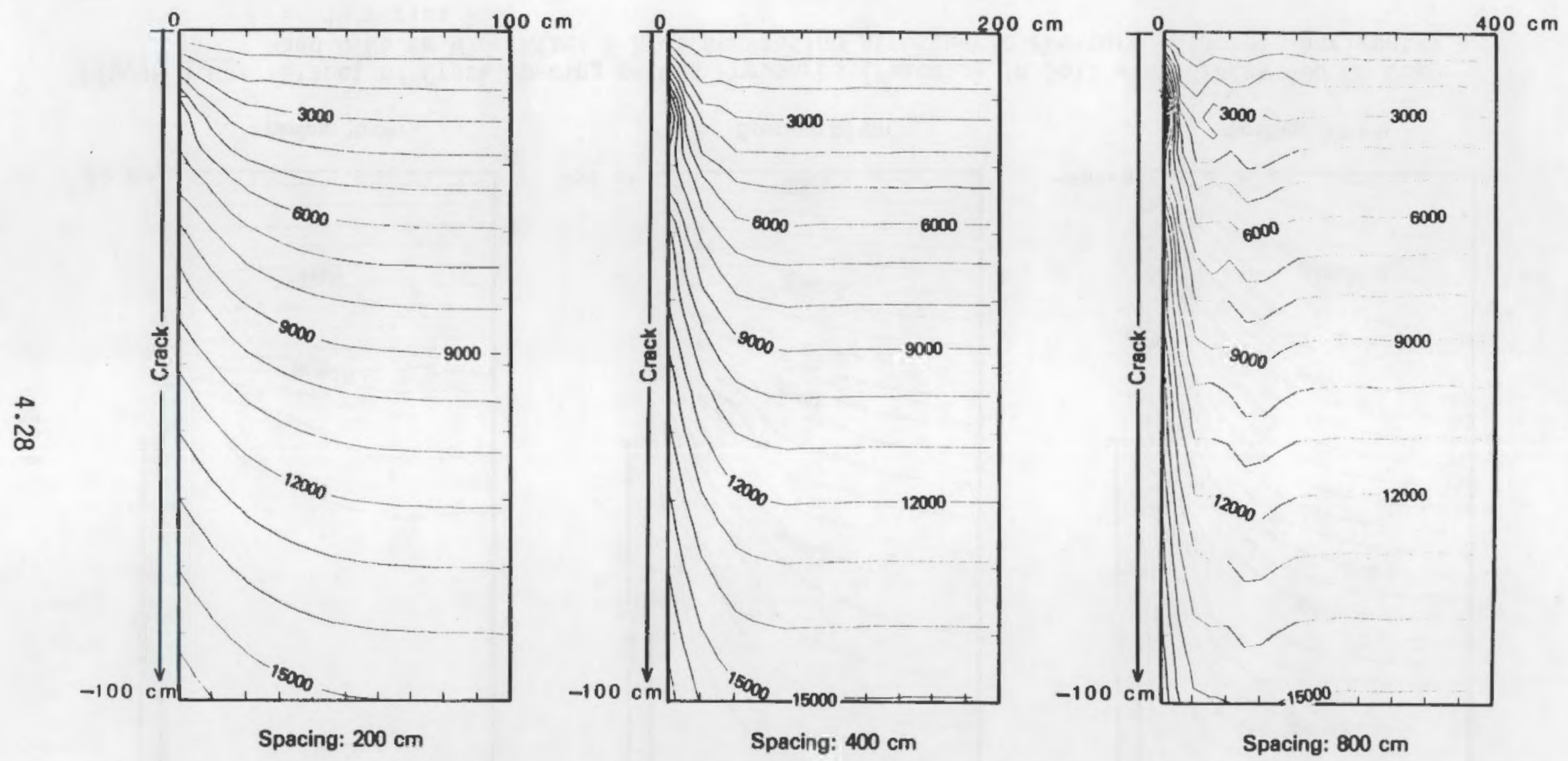

FIGURE 4.8b. Effect of Crack Spacing on Radon Concentrations (atoms $/ \mathrm{cm}^{3}$ ) in Soil with Cracks $400 \mathrm{~cm}$ Deep and $0.06 \mathrm{~cm}$ Wide After $6 \mathrm{~h}$ of Decreasing Atmospheric Pressure. (Note: horizontal scale varies.) 


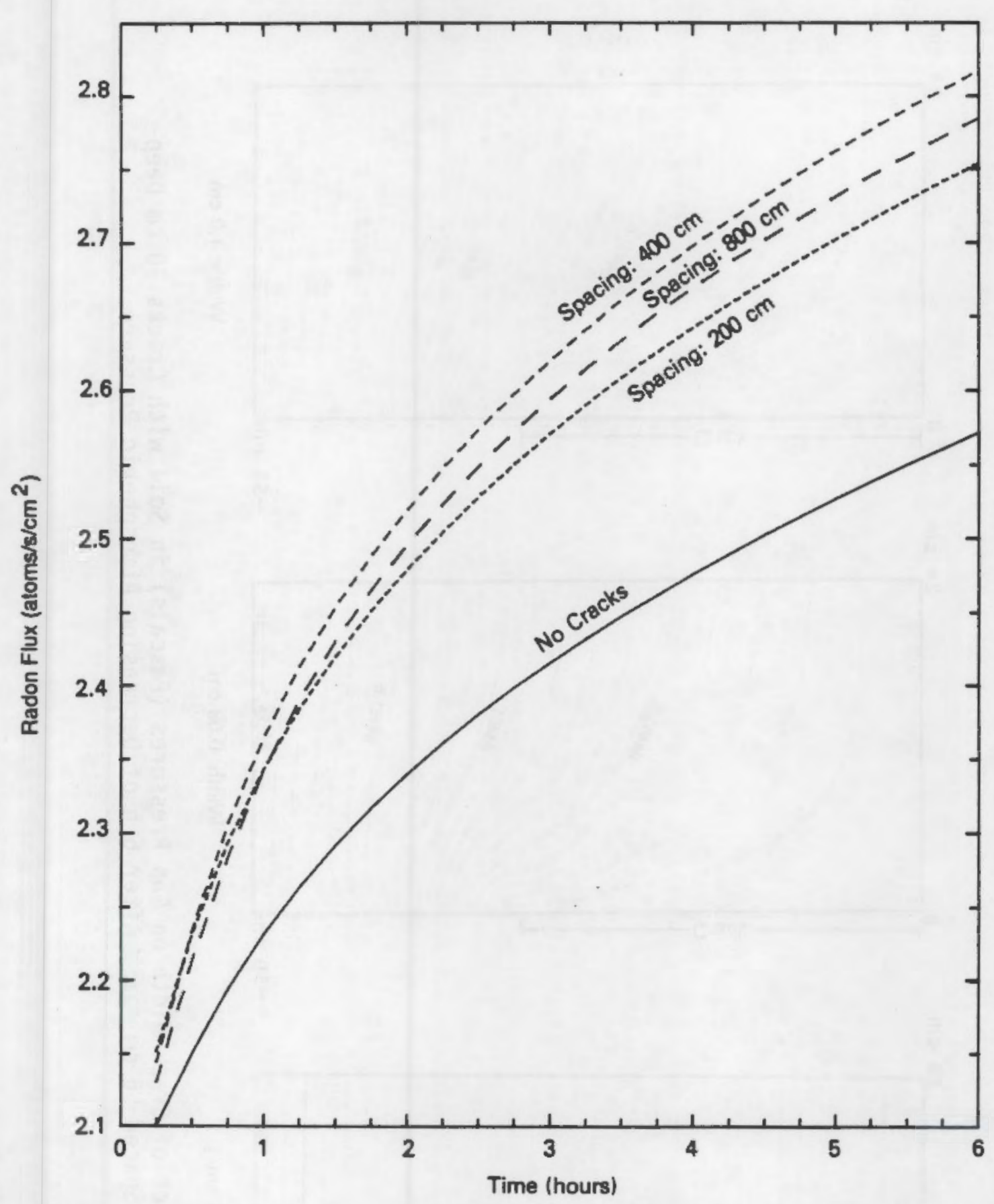

FIGURE 4.8c. Effect of Crack Spacing on Radon Flux Density from Soil with Cracks $400 \mathrm{~cm}$ Deep and $0.06 \mathrm{~cm}$ Wide During $6 \mathrm{~h}$ of Decreasing Atmospheric Pressure 


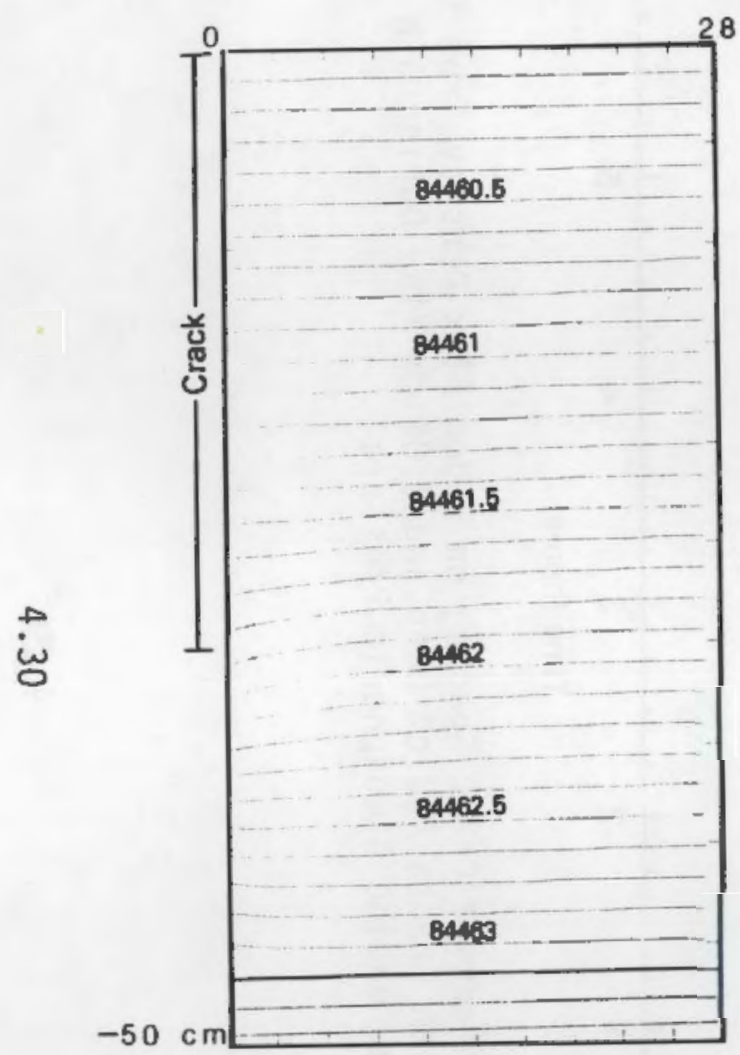

Width: $0.01 \mathrm{~cm}$

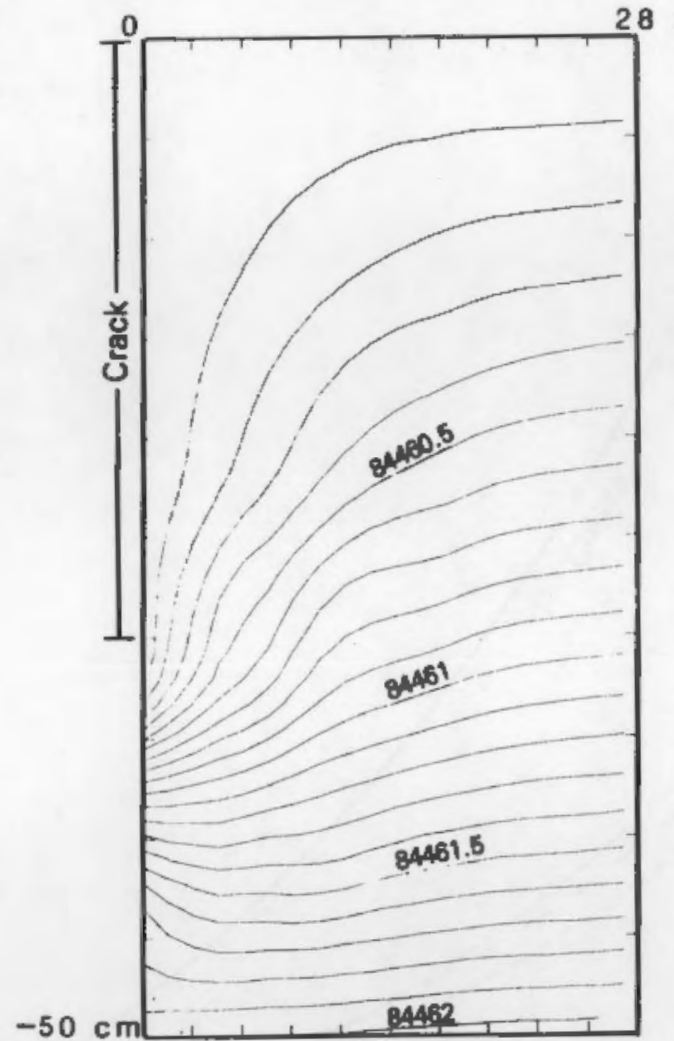

Width: $0.03 \mathrm{~cm}$

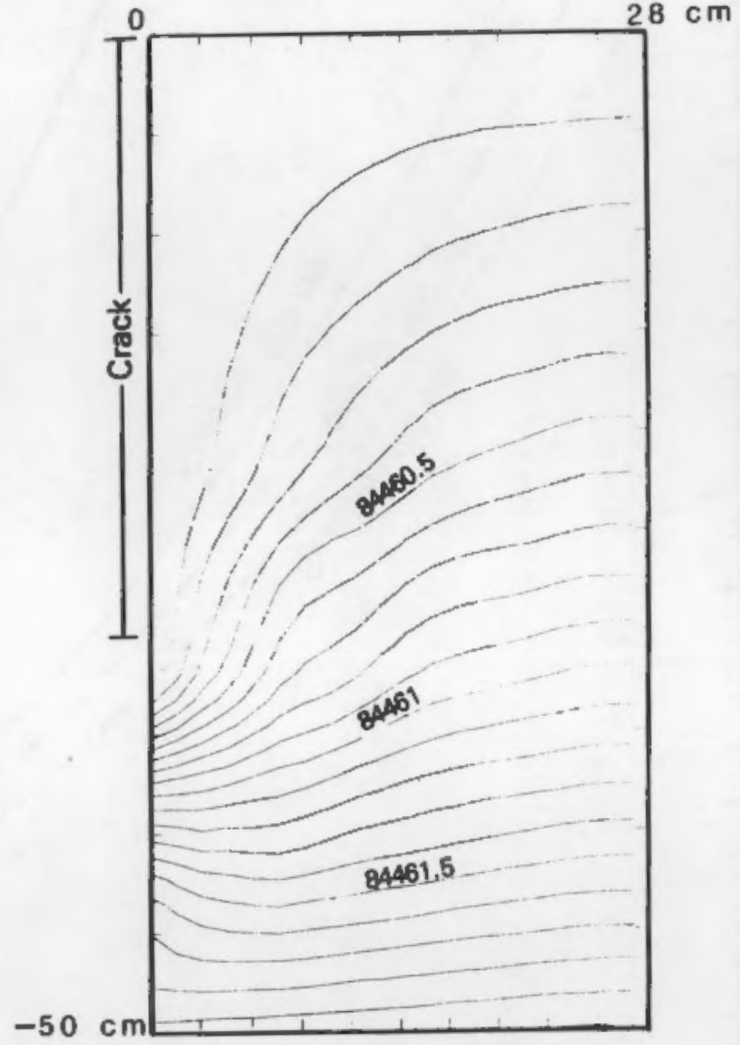

Width: $1.0 \mathrm{~cm}$

FIGURE 4.9a. Effect of Crack Width on Gas Pressures (Pascals) in Soil with Cracks $30 \mathrm{~cm}$ Deep and Spaced $56 \mathrm{~cm}$ Apart After $6 \mathrm{~h}$ of Decreasing Atmospheric Pressure 

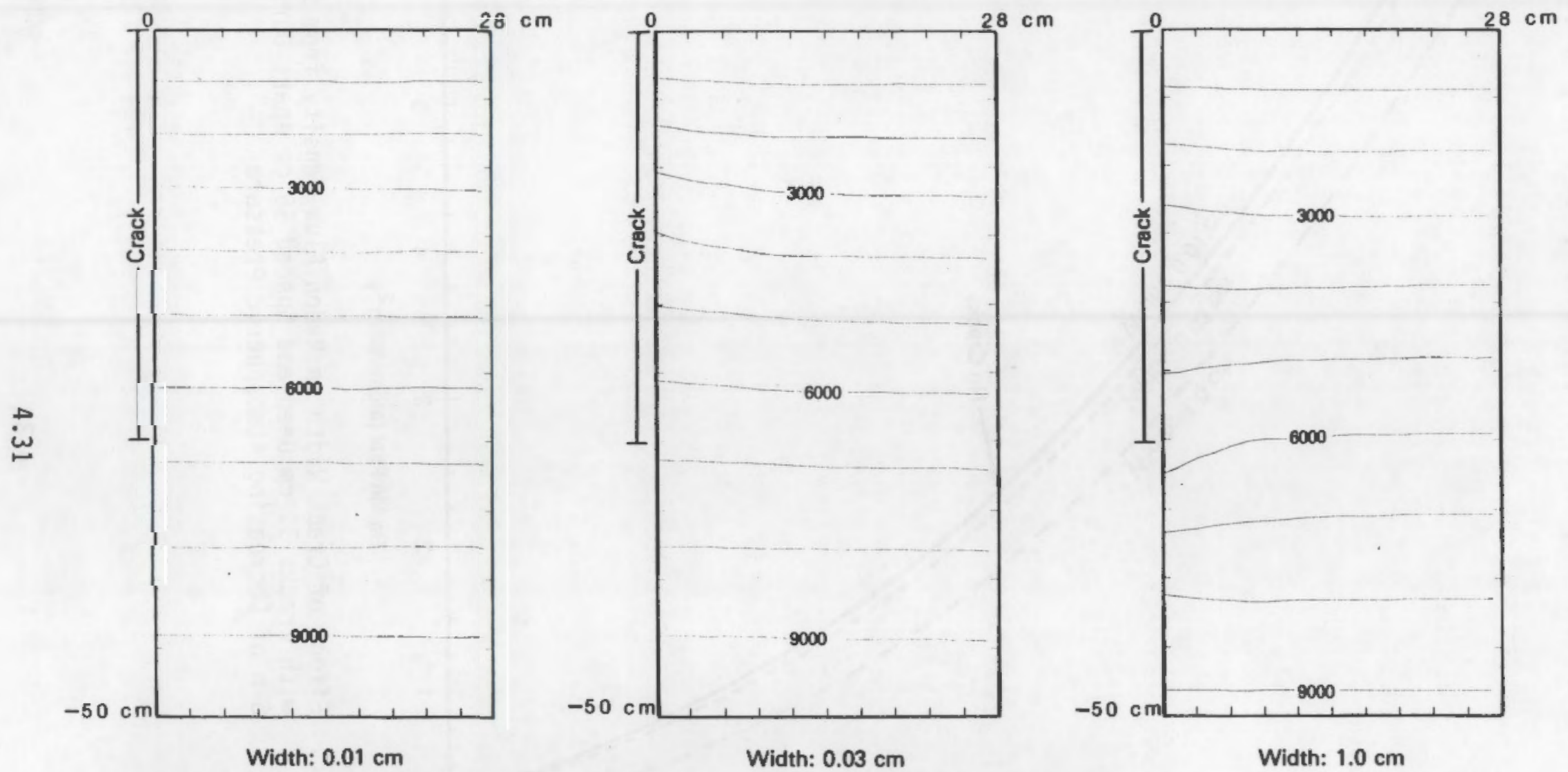

FIGURE 4.9b. Effect of Crack Width on Radon Concentrations (atoms $/ \mathrm{cm}^{3}$ ) in Soil with Cracks $30 \mathrm{~cm}$ Deep and Spaced $56 \mathrm{~cm}$ Apart After $6 \mathrm{~h}$ of Decreasing Atmospheric Pressure 


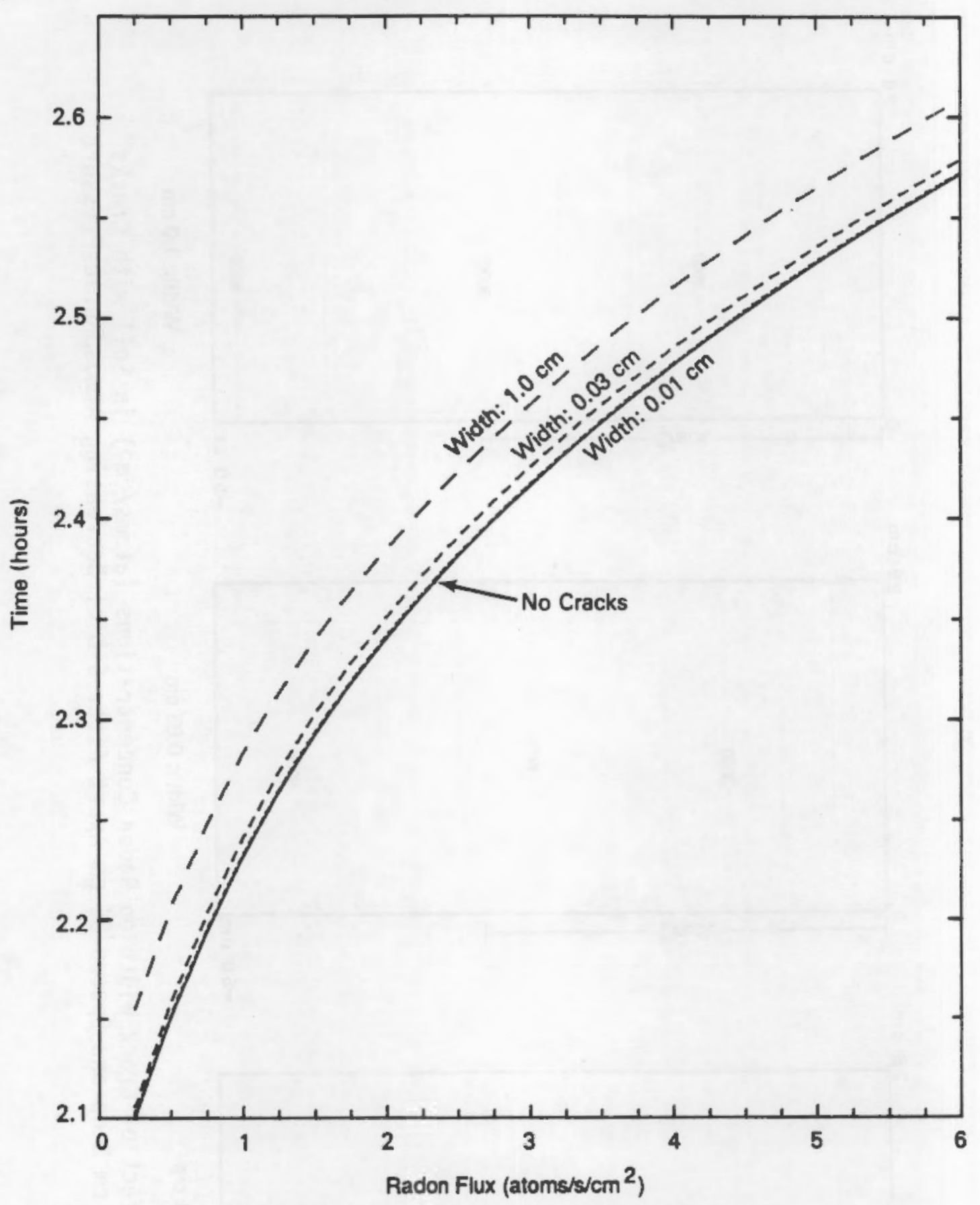

FIGURE 4.9c. Effect of Crack Width on Radon Flux Density from Soil with Cracks $30 \mathrm{~cm}$ Deep and Spaced $56 \mathrm{~cm}$ Apart During $6 \mathrm{~h}$ of Decreasing Atmospheric Pressure 


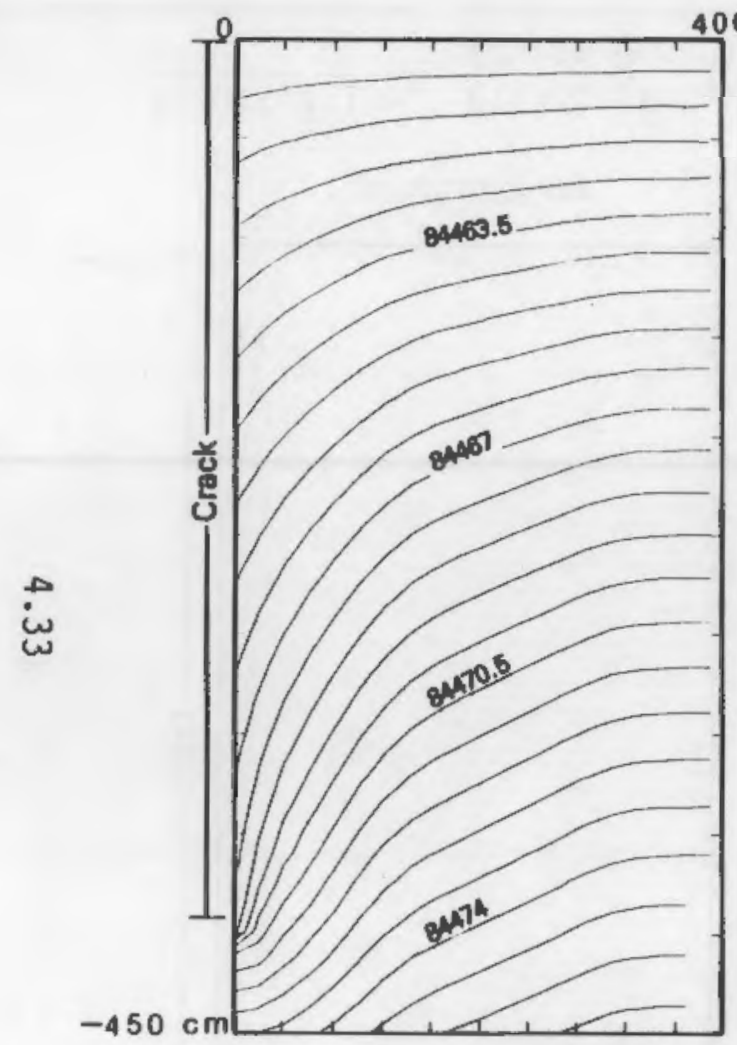

Width: $0.06 \mathrm{~cm}$

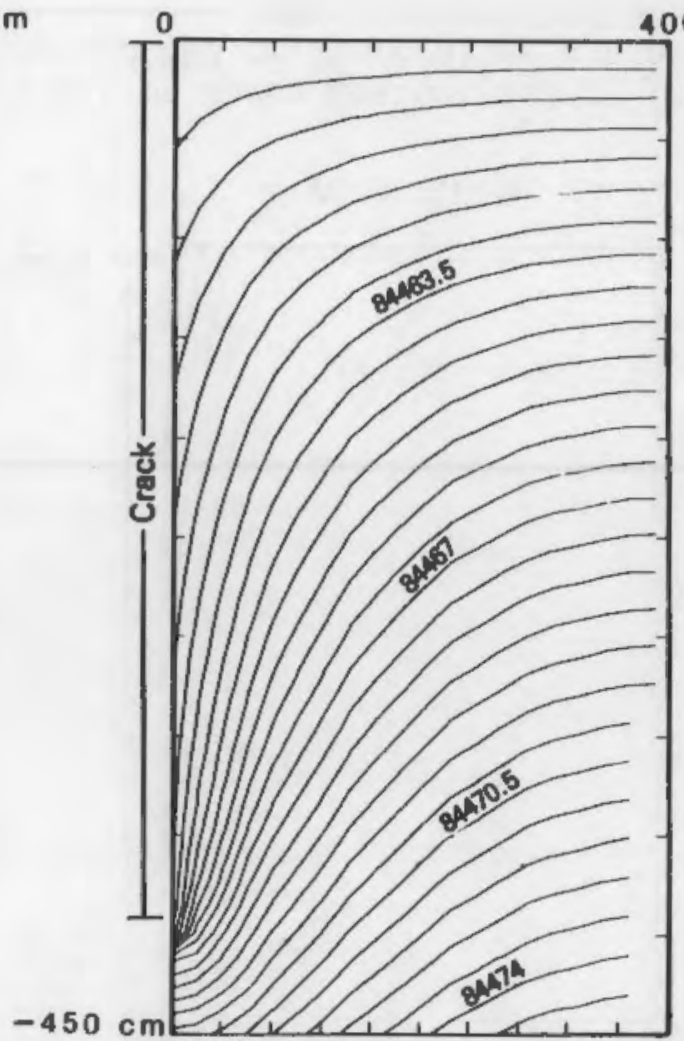

Width: $0.1 \mathrm{~cm}$

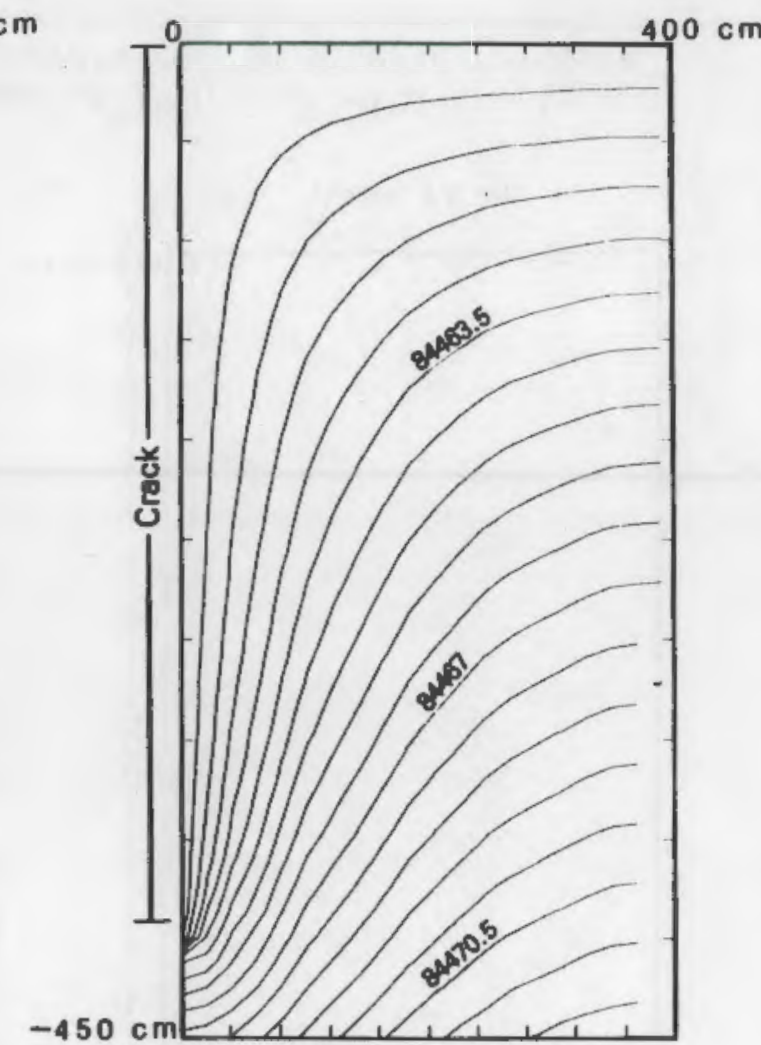

Width: $1.0 \mathrm{~cm}$

FIGURE 4.10a. Effect of Crack Width on Gas Pressures (Pascals) in Soil with Cracks $400 \mathrm{~cm}$ Deep and Spaced $800 \mathrm{~cm}$ Apart After $6 \mathrm{~h}$ of Decreasing Atmospheric Pressure 

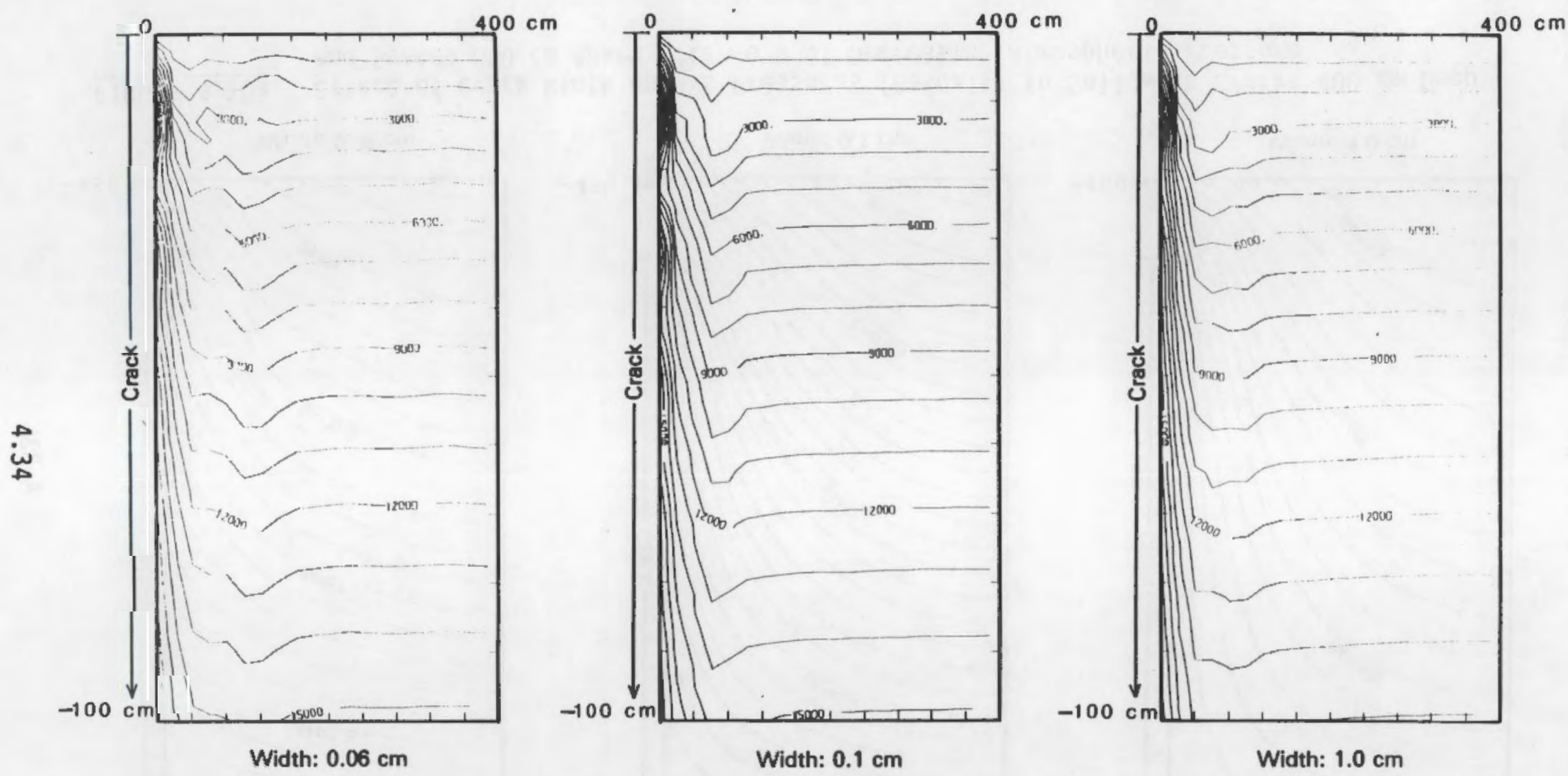

FIGURE 4.10b. Effect of Crack Width on Radon Concentrations (atoms $/ \mathrm{cm}^{3}$ ) in Soil with Cracks $400 \mathrm{~cm}$ Deep and Spaced $800 \mathrm{~cm}$ Apart After $6 \mathrm{~h}$ of Decreasing Atmospheric Pressure 


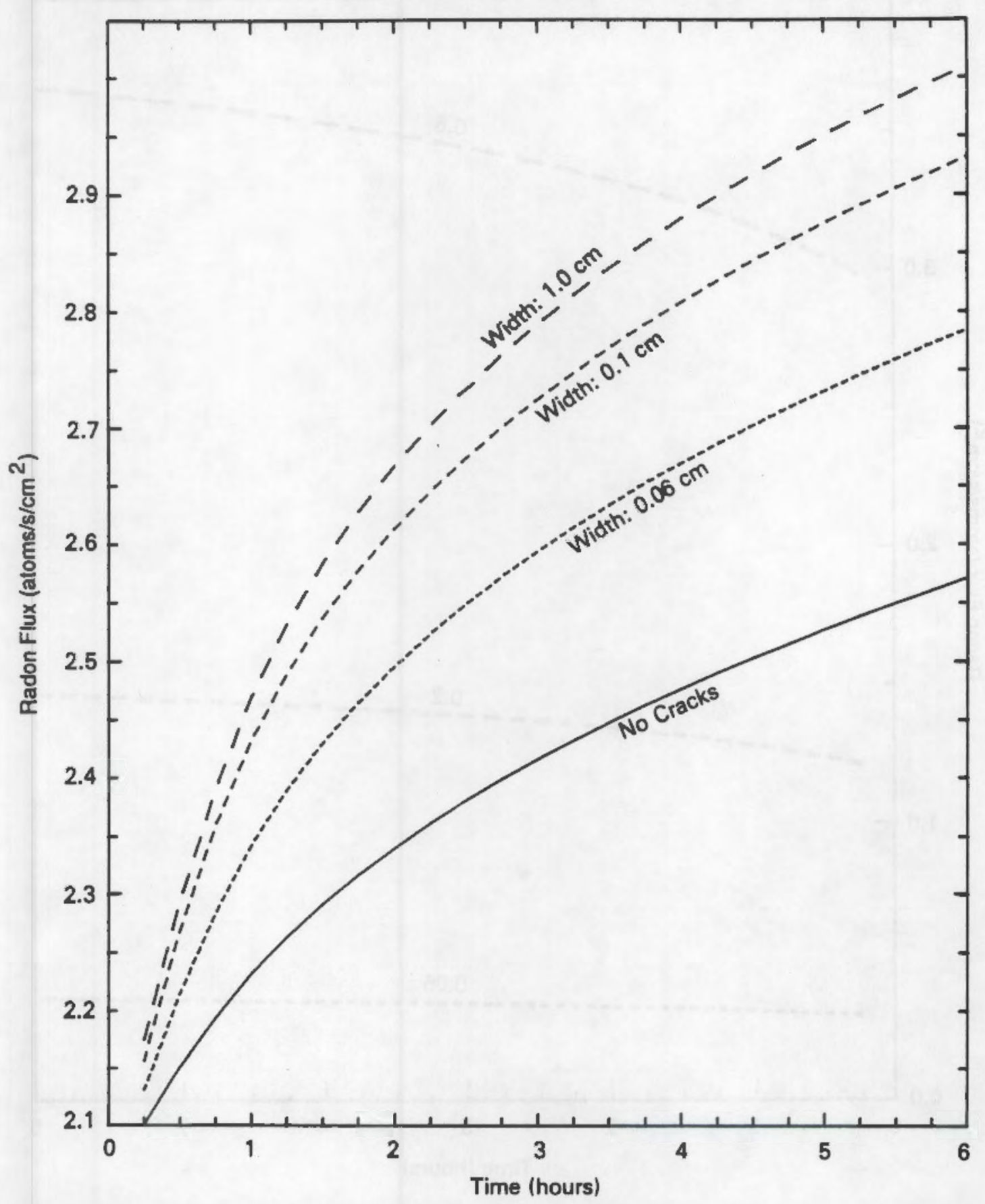

FIGURE 4.10c. Effect of Crack width on Radon Flux Density from Soil with Cracks $400 \mathrm{~cm}$ Deep and Spaced $800 \mathrm{~cm}$ Apart During $6 \mathrm{~h}$ of Decreasing Atmospheric Pressure 


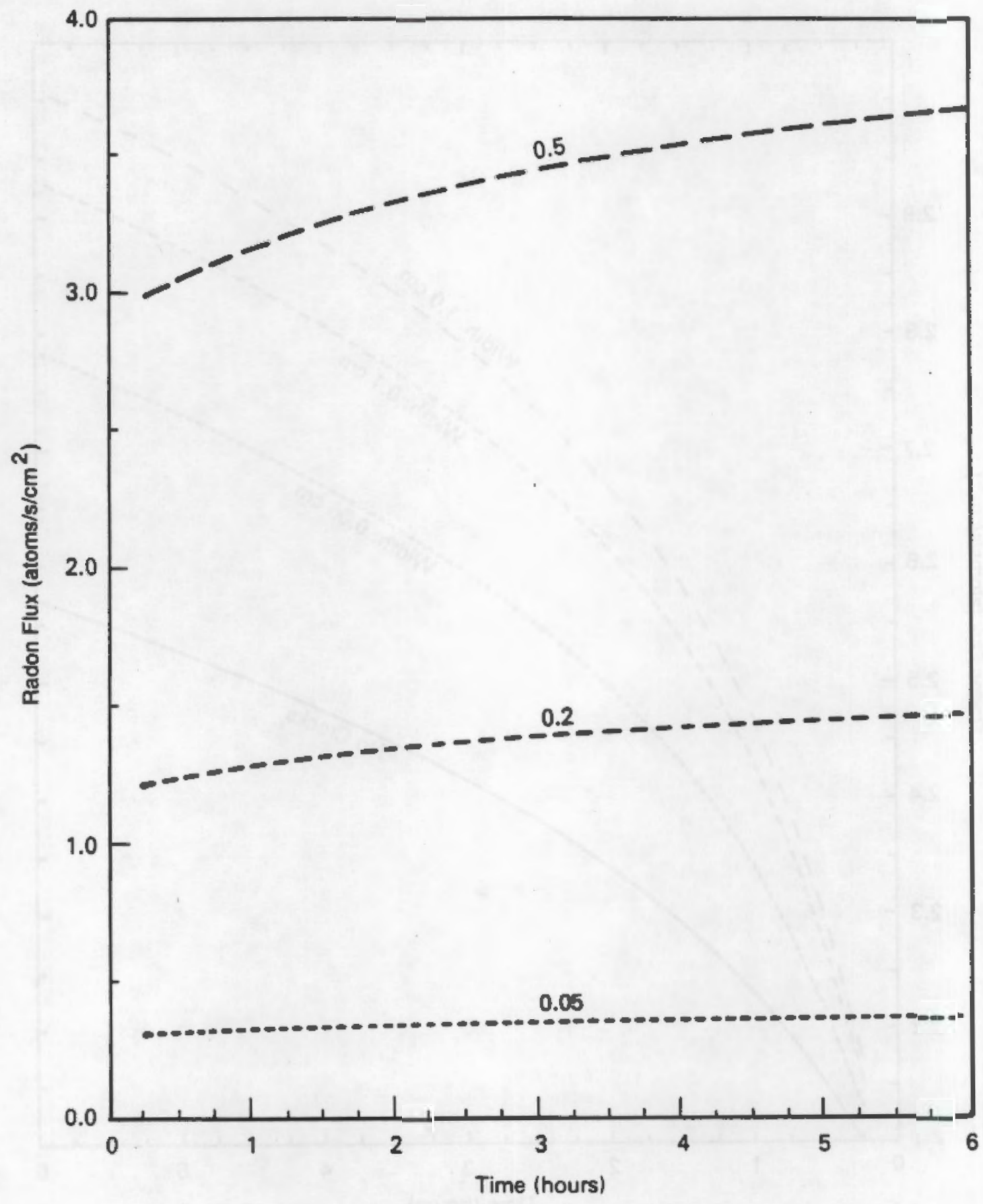

FIGURE 4.11a. Effect of Soil Porosity on Radon Flux Density from Homogeneous Soil During $6 \mathrm{~h}$ of Decreasing Atmospheric Pressure 


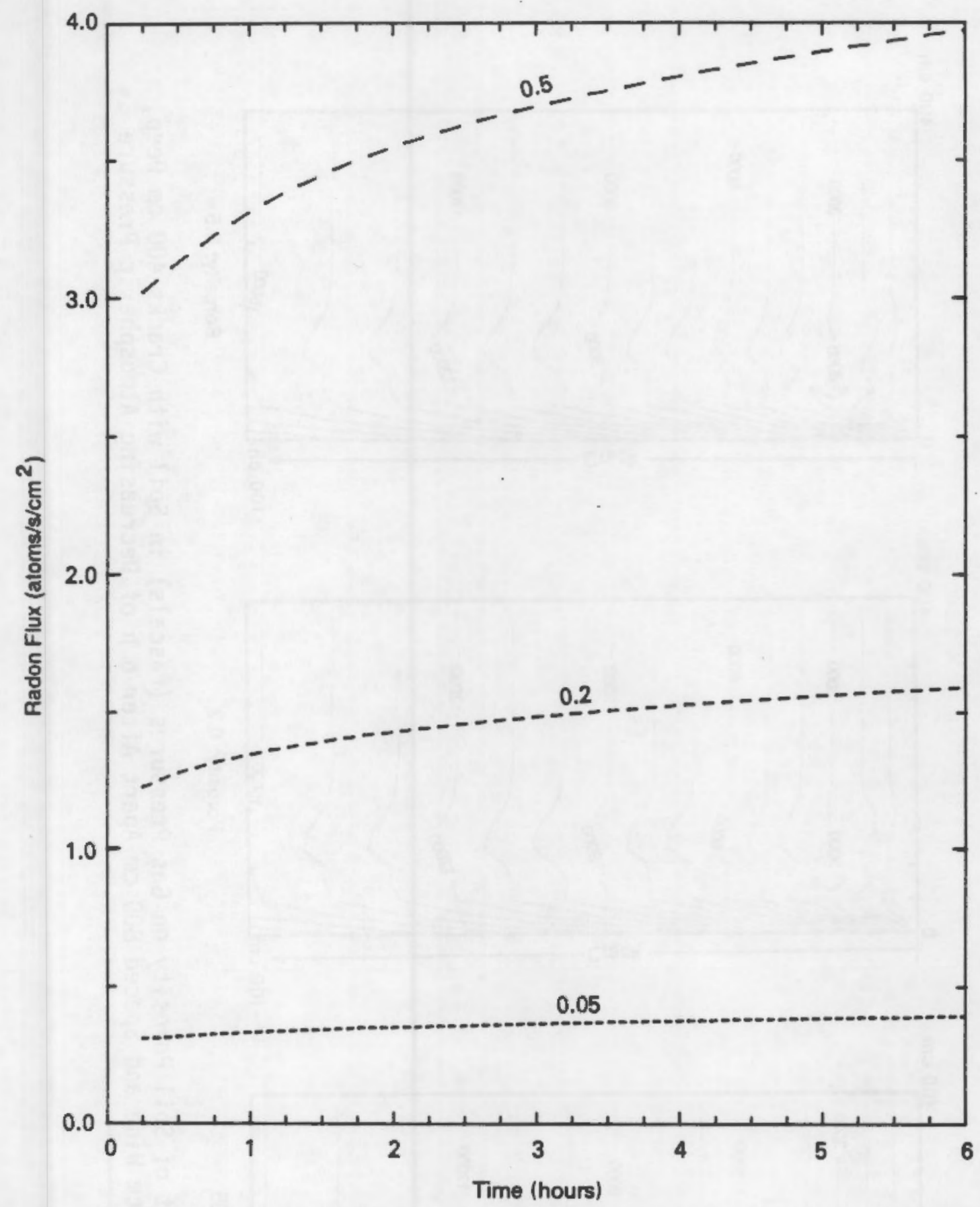

FIGURE 4.11b. Effect of Soil Porosity on Radon Flux Density from Soil with Cracks $400 \mathrm{~cm}$ Deep, $0.06 \mathrm{~cm}$ Wide and Spaced $800 \mathrm{~cm}$ Apart During $6 \mathrm{~h}$ of Decreasing Atmospheric Pressure 


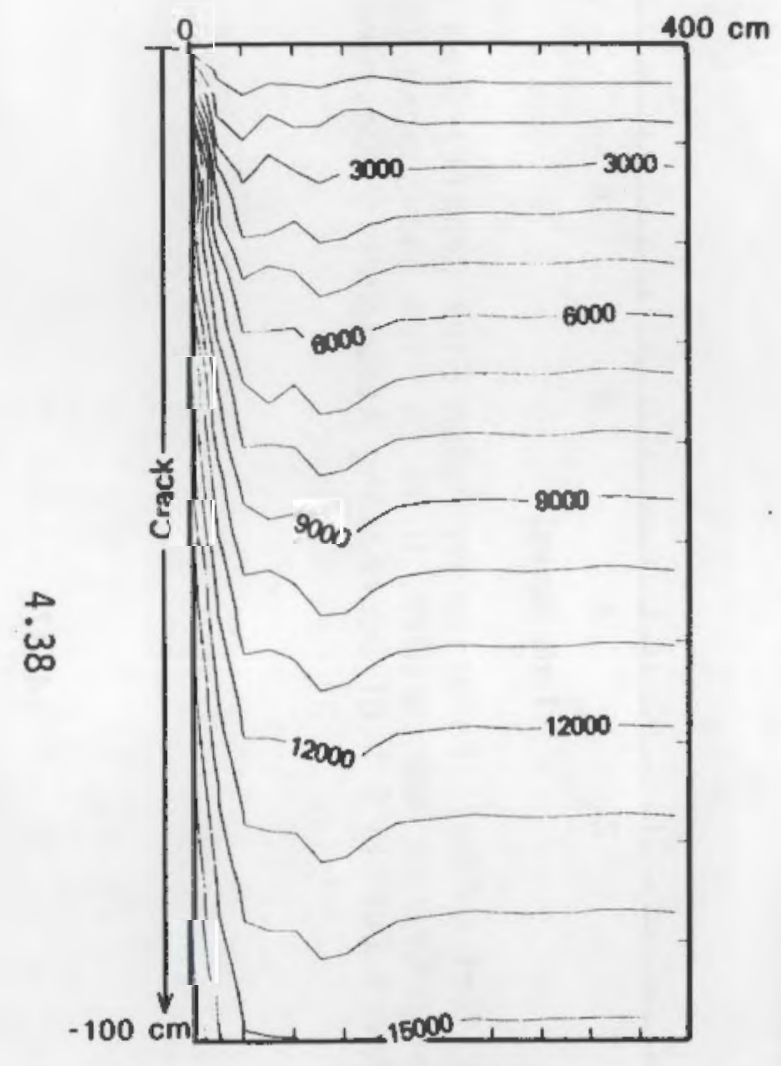

Porosity: 0.05
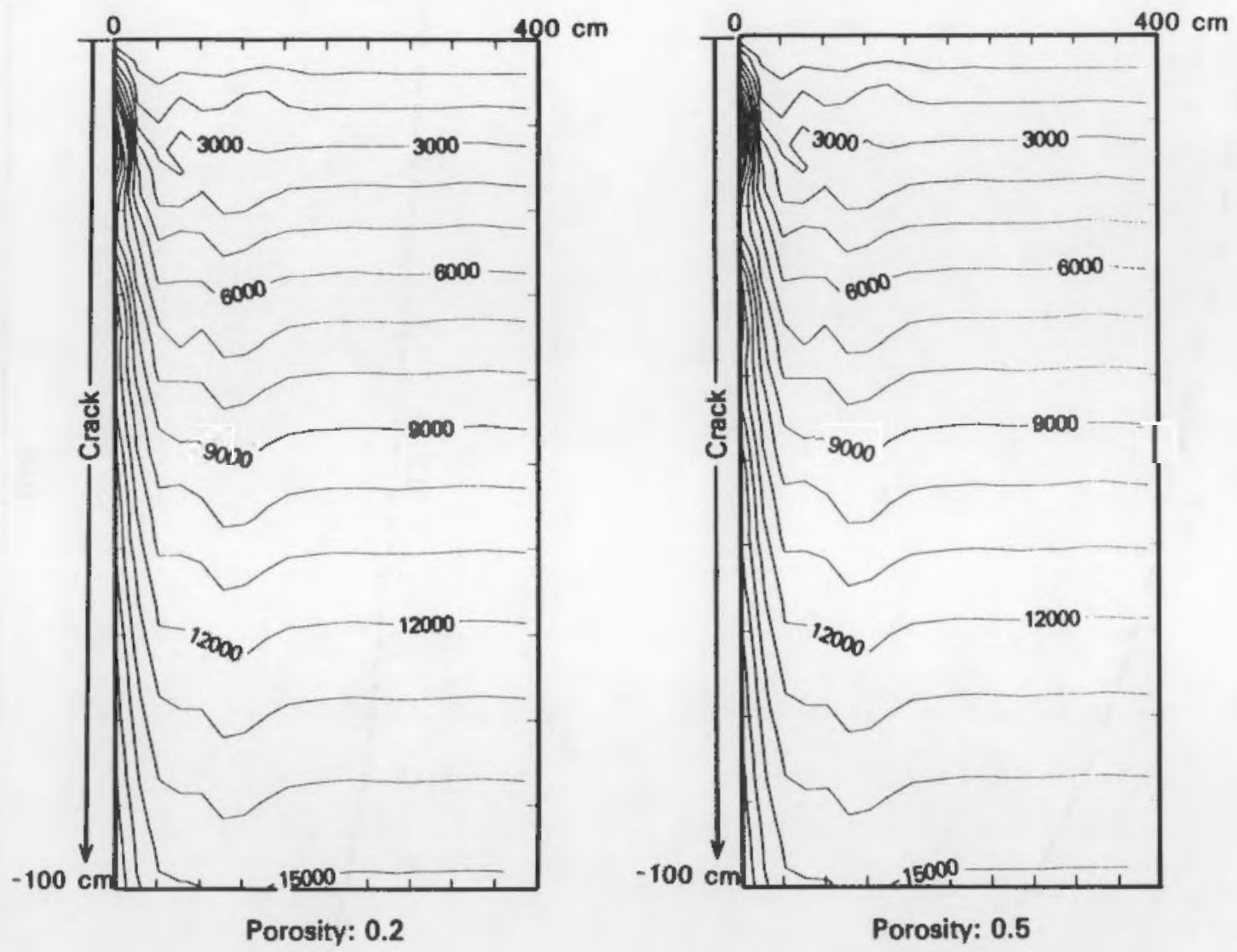

FIGURE 4.11c. Effect of Soil Porosity on Gas Pressures (Pascals) in Soil with Cracks $400 \mathrm{~cm}$ Deep, $0.06 \mathrm{~cm}$ Wide and Spaced $800 \mathrm{~cm}$ Apart After $6 \mathrm{~h}$ of Decreasing Atmospheric Pressure 

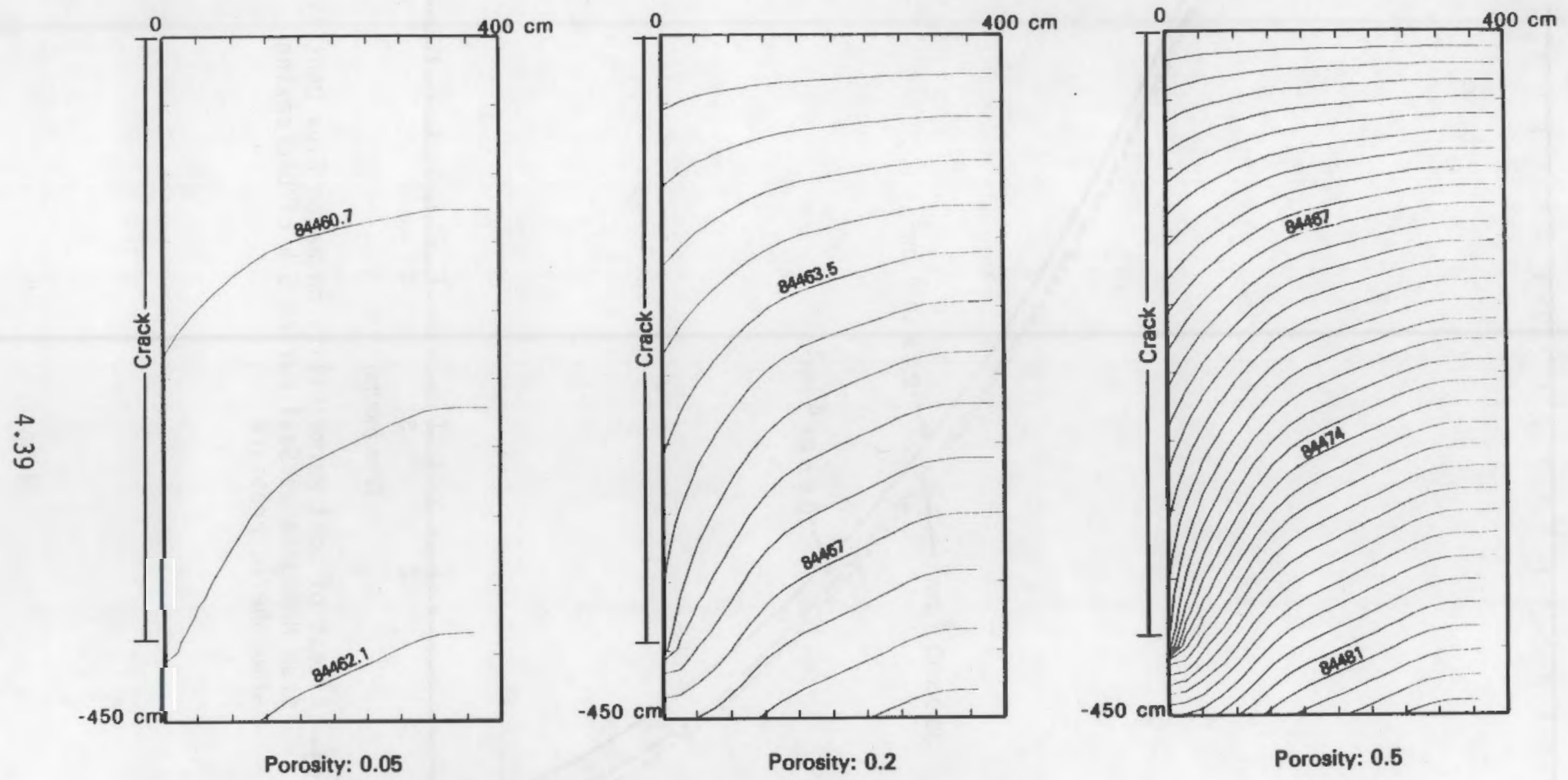

FIGURE 4.11d. Effect of Soil Porosity on Radon Concentrations (atoms $/ \mathrm{cm}^{3}$ ) in Soil with Cracks $400 \mathrm{~cm}$ Deep, $0.06 \mathrm{~cm}$ Wide and Spaced $800 \mathrm{~cm}$ Apart After $6 \mathrm{~h}$ of Decreasing Atmospheric Pressure 


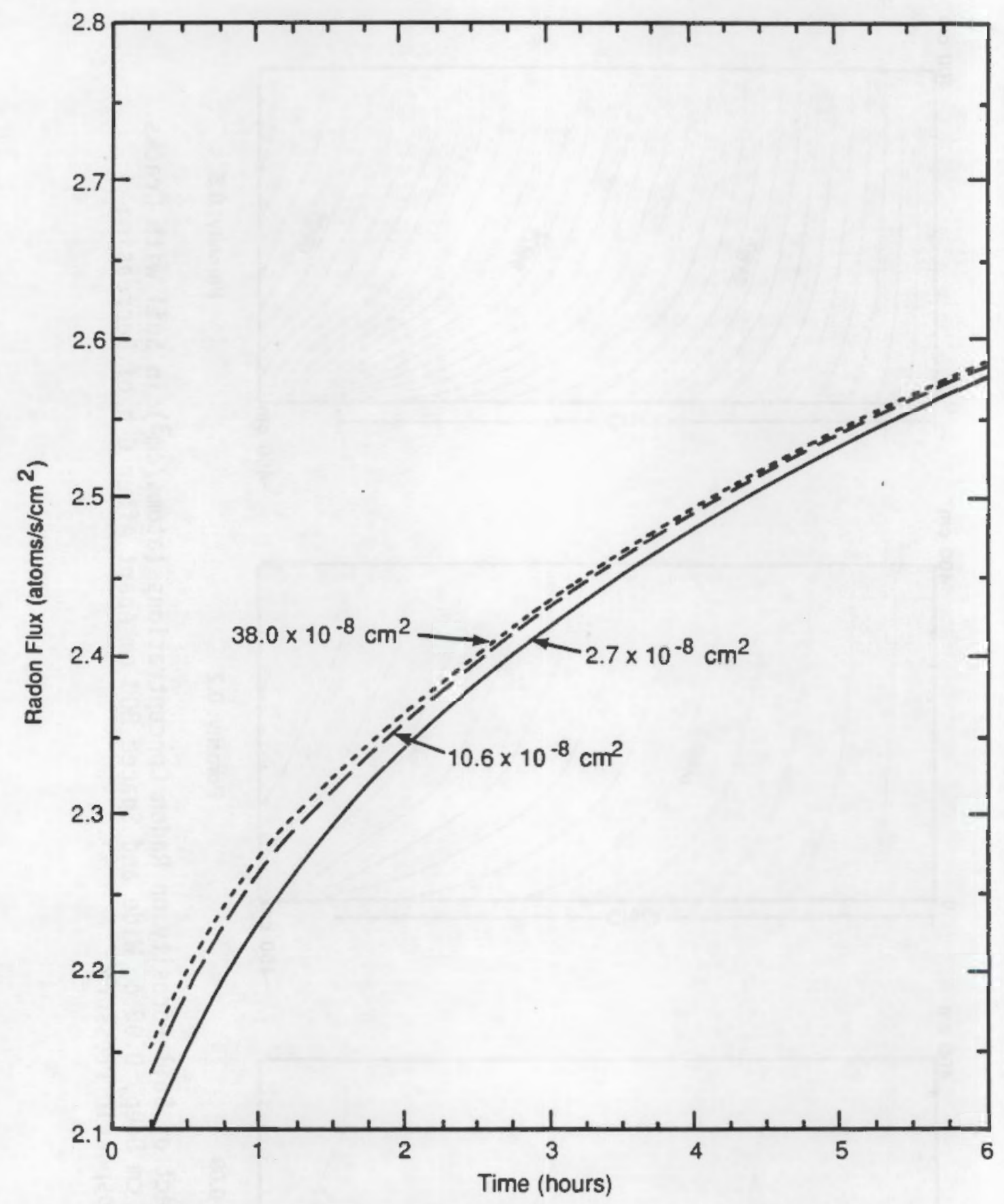

FIGURE 4.12a. Effect of Soil Permeability on Radon Flux Density from Homogeneous Soil During $6 \mathrm{~h}$ of Decreasing Atmospheric Pressure 


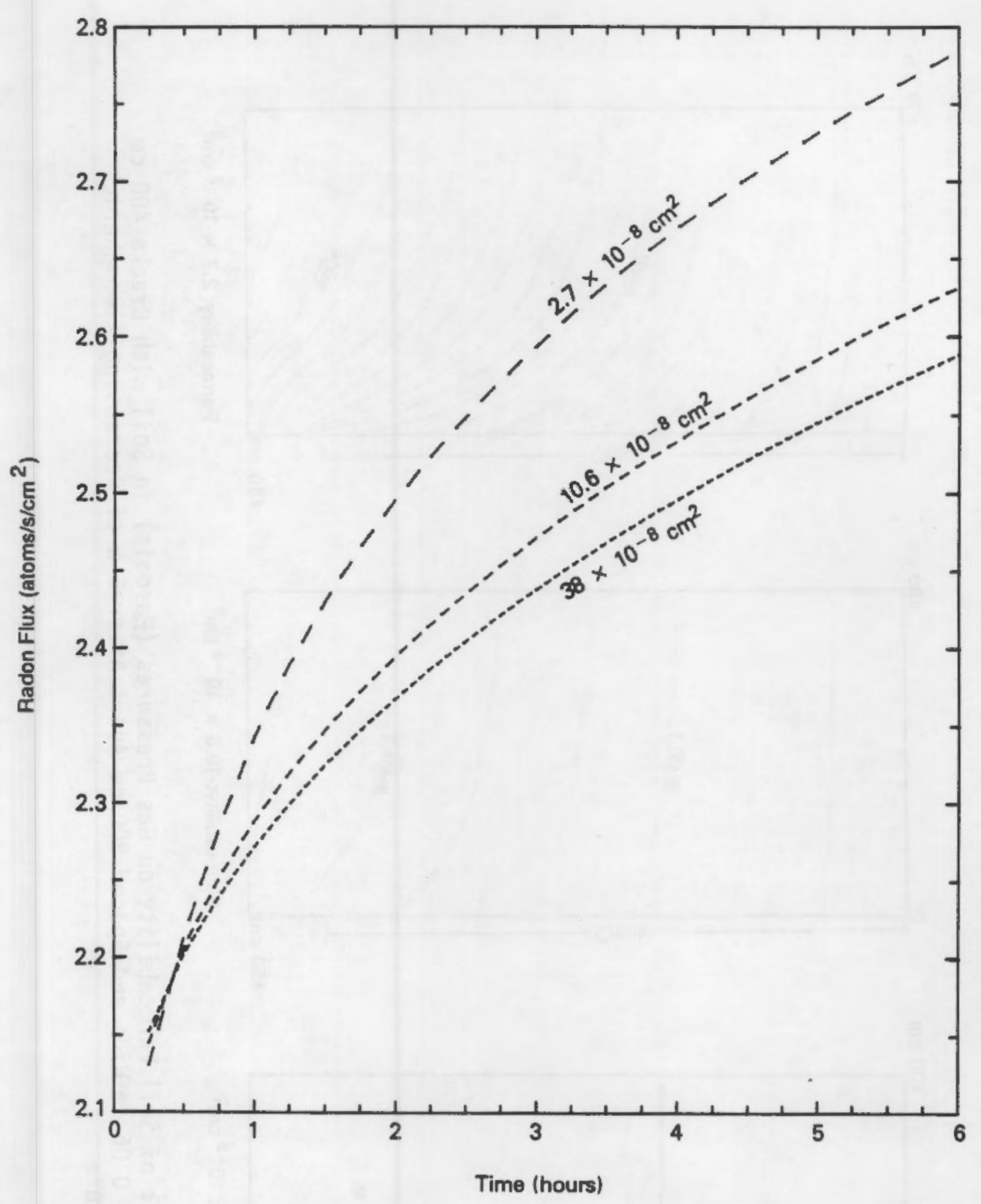

FIGURE 4.12b. Effect of Soil Permeability on Radon Flux Density from Soil with Cracks $400 \mathrm{~cm}$ Deep, $0.06 \mathrm{~cm}$ Wide and Spaced $800 \mathrm{~cm}$ Apart During $6 \mathrm{~h}$ of Decreasing Atmospheric Pressure 

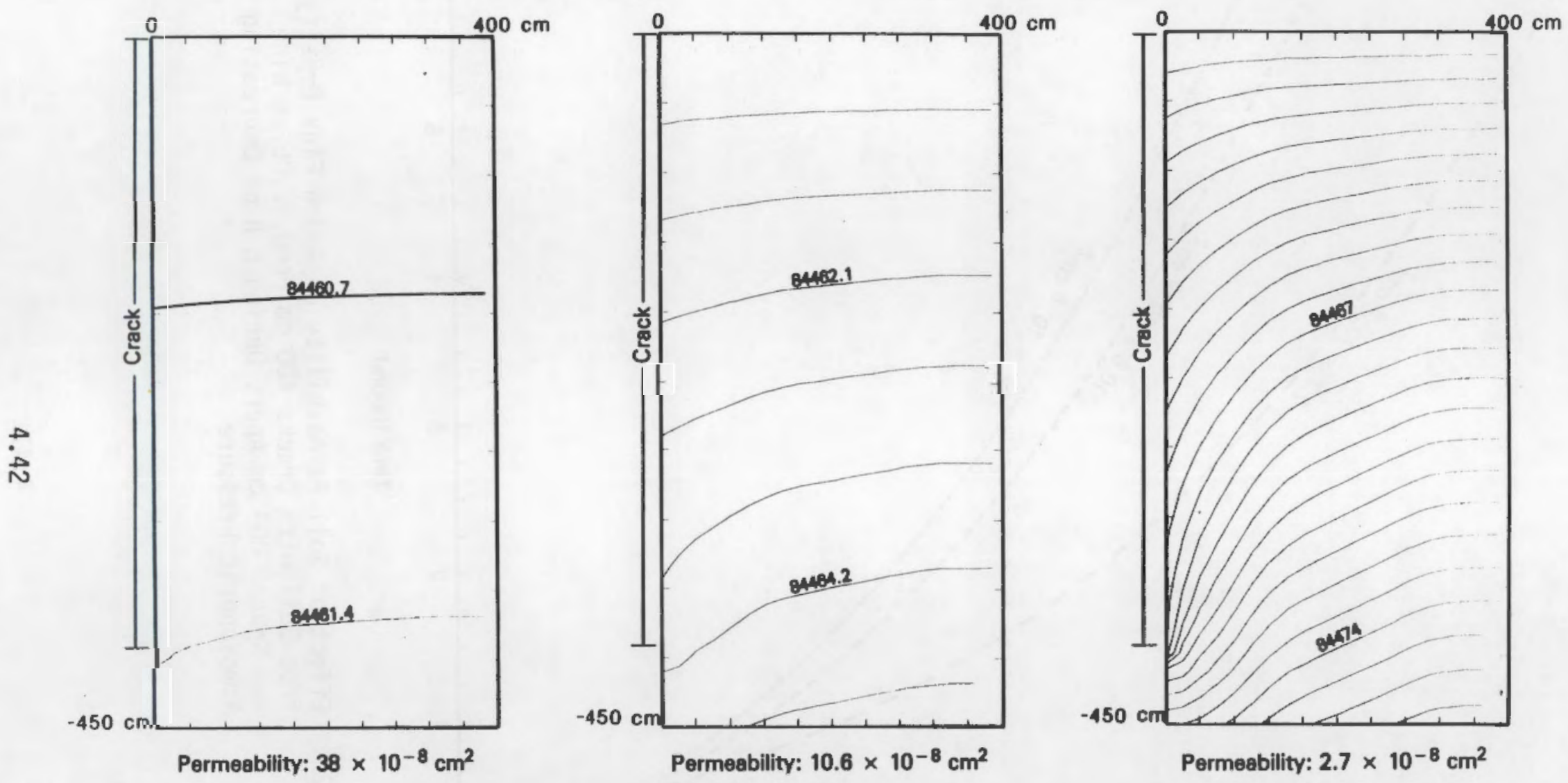

FIGURE 4.12c. Effect of Soil Permeability on Gas Pressures (Pascals) in Soil with Cracks $400 \mathrm{~cm}$ Deep, $0.06 \mathrm{~cm}$ Wide and Spaced $800 \mathrm{~cm}$ Apart After $6 \mathrm{~h}$ of Decreasing Atmospheric Pressure 

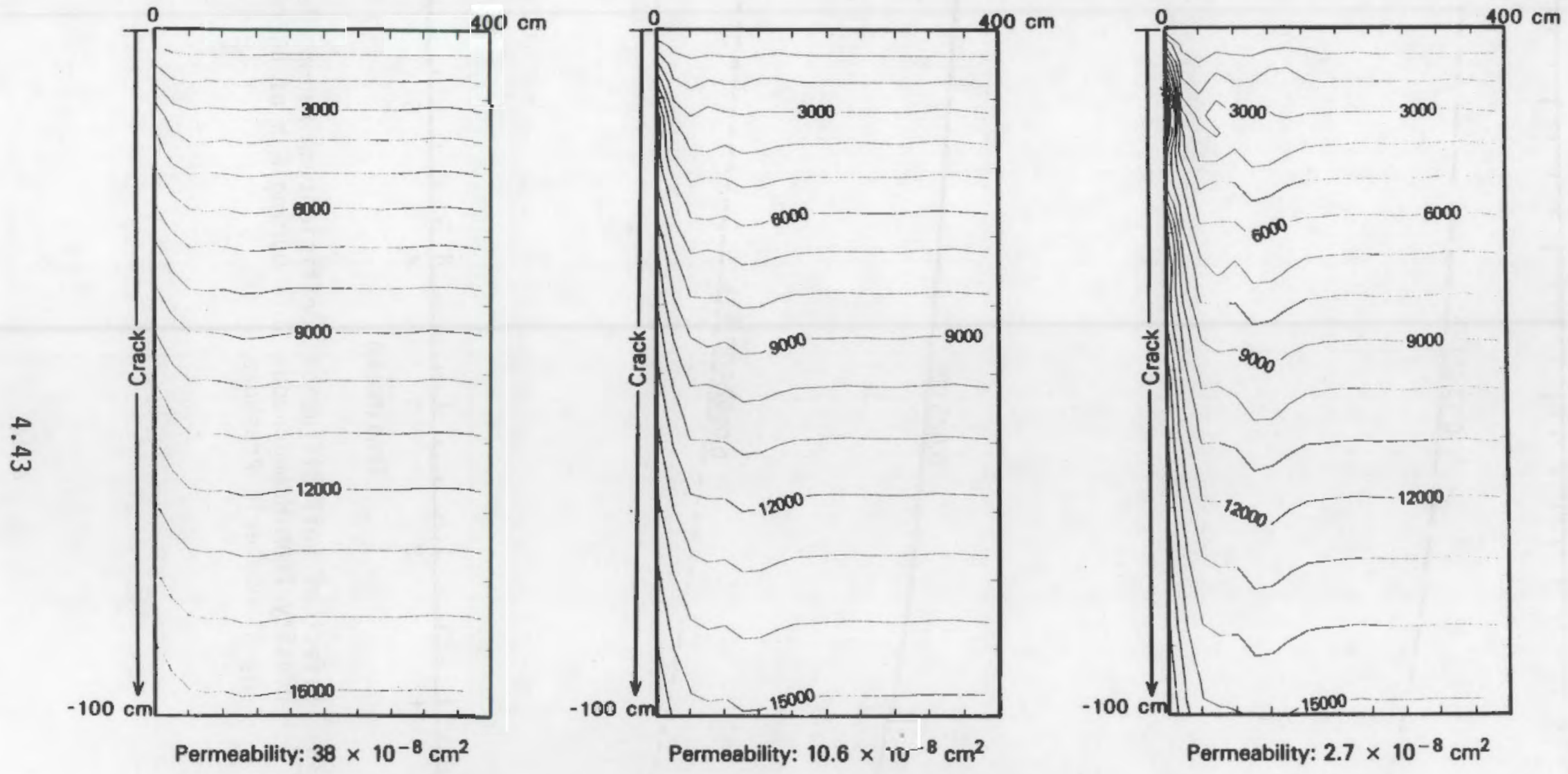

FIGURE 4.12d. Effect of Soil Permeability on Radon Concentrations (atoms $/ \mathrm{cm}^{3}$ ) in Soil with Cracks $400 \mathrm{~cm}$ Deep, $0.06 \mathrm{~cm}$ Wide and Spaced $800 \mathrm{~cm}$ Apart After $6 \mathrm{~h}$ of Decreasing Atmospheric Pressure 


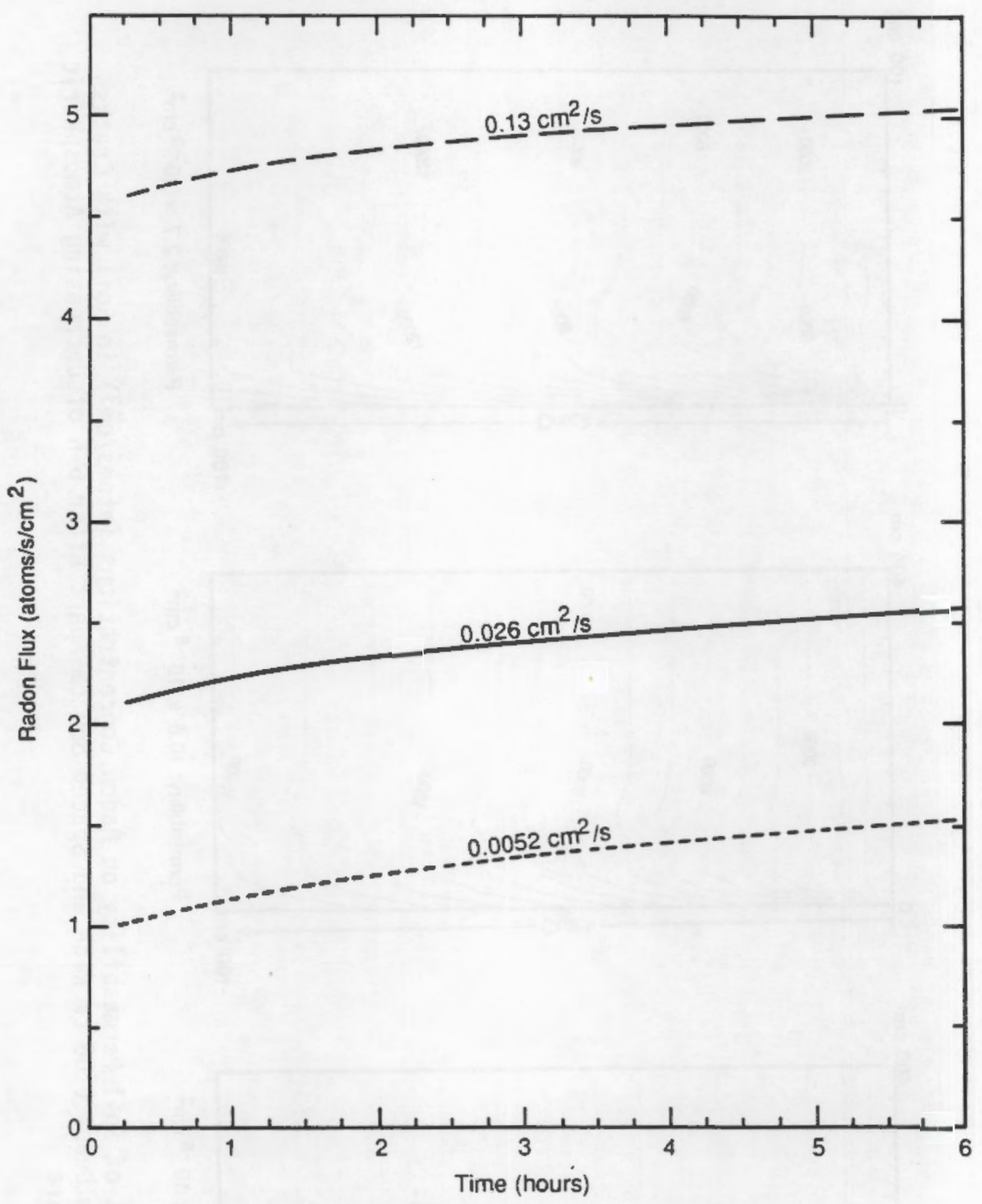

FIGURE 4.13a. Effect of Soil Diffusion Coefficient on Radon Flux Density from Homogeneous Soil During $6 \mathrm{~h}$ of Decreasing Atmospheric Pressure 


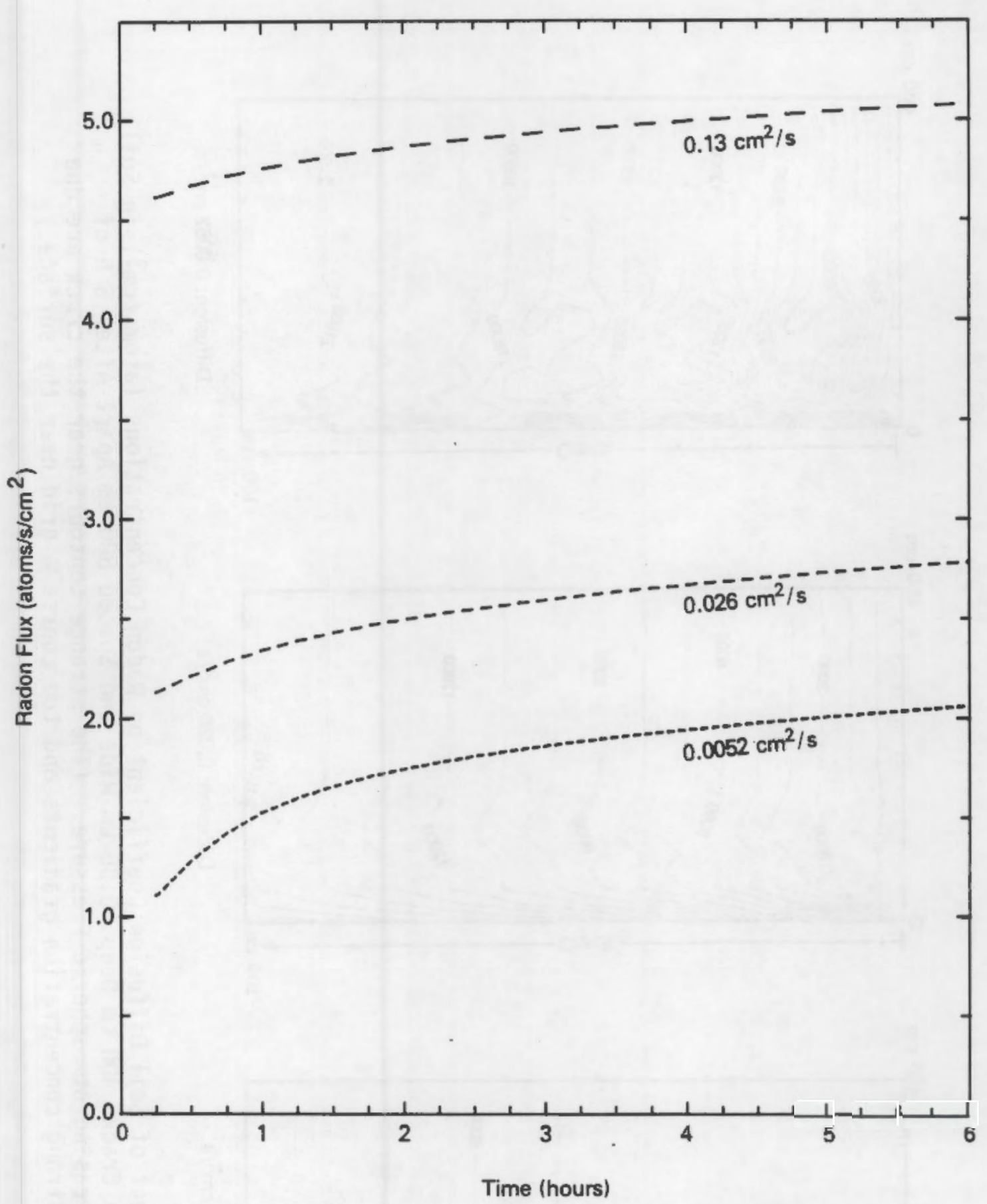

FIGURE 4.13b. Effect of Soil Diffusion Coefficient on Radon Flux Density from Soil with Cracks $400 \mathrm{~cm}$ Deep, $0.06 \mathrm{~cm}$ Wide and Spaced $800 \mathrm{~cm}$ Apart During $6 \mathrm{~h}$ of Decreasing Atmospheric Pressure 

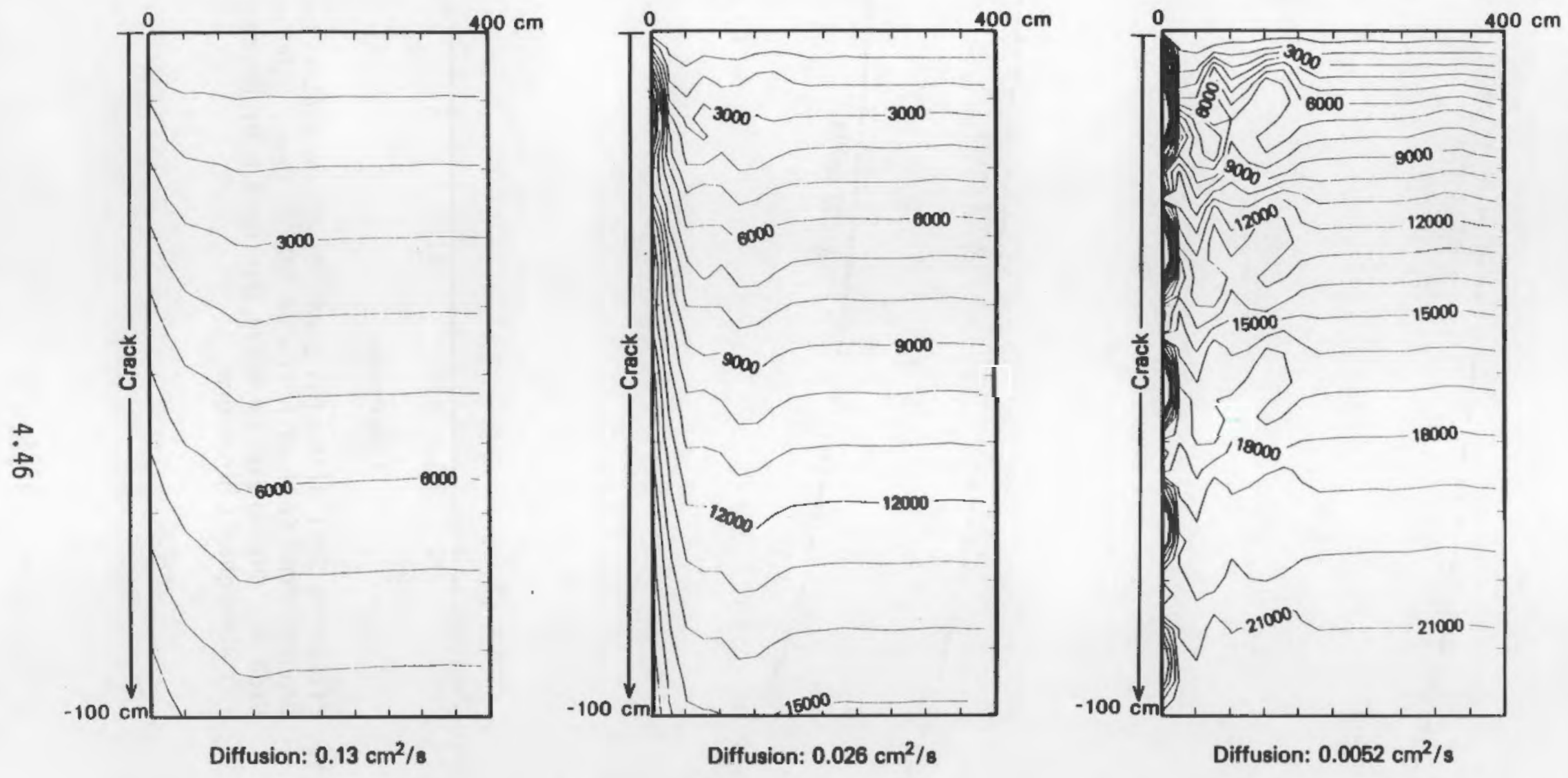

FIGURE 4.13c. Effect of Soil Diffusion Coefficient on Radon Concentrations (atoms $/ \mathrm{cm}^{3}$ ) in Soil with Cracks $400 \mathrm{~cm}$ Deep, $0.06 \mathrm{~cm}$ Wide and Spaced $800 \mathrm{~cm}$ Apart After $6 \mathrm{~h}$ of Decreasing Atmospheric Pressure. (The strange contours near the crack are due to strong concentration gradients and too coarse a grid near the surface.) 

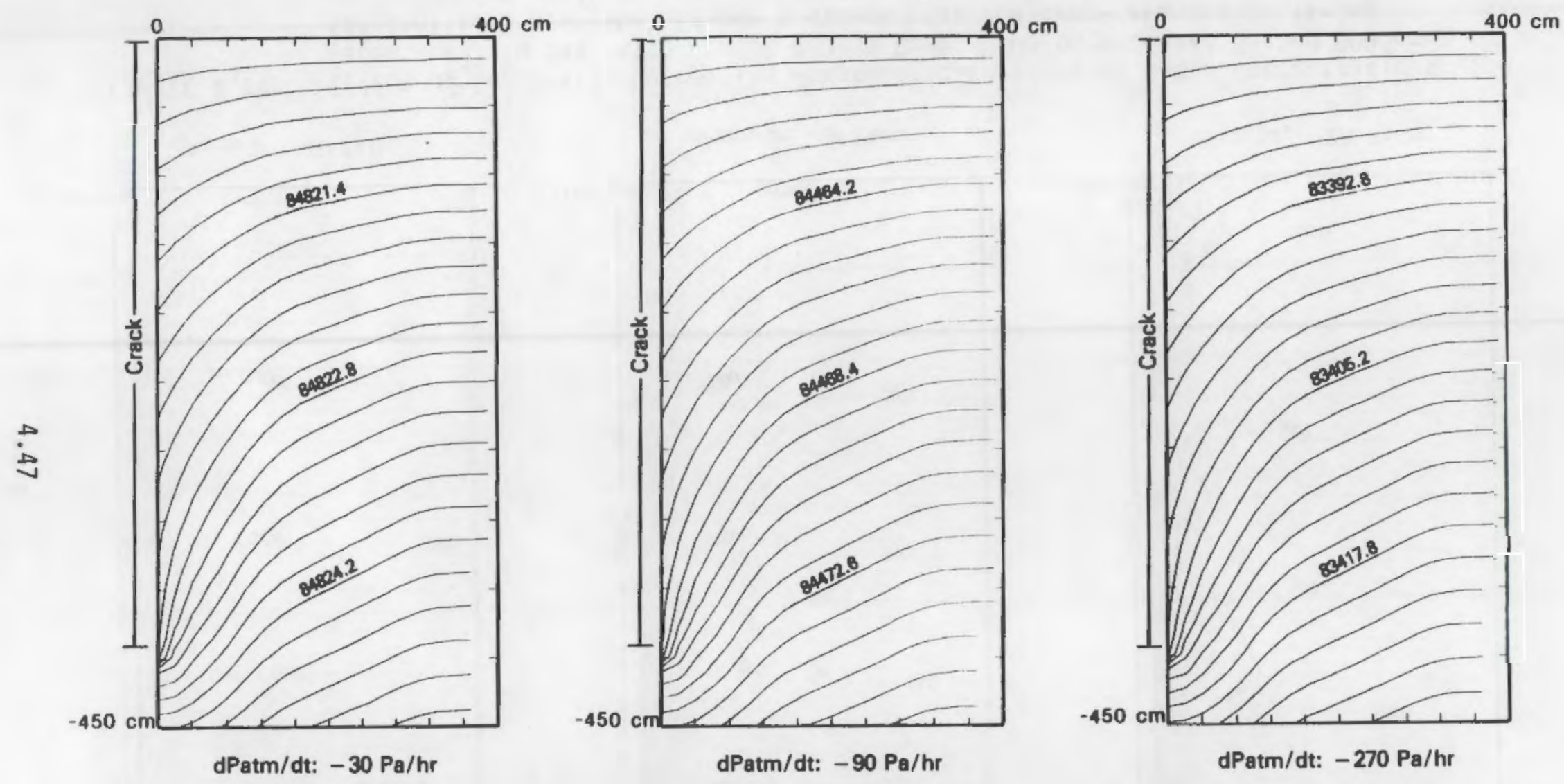

FIGURE 4.14a. Effect of Constantly Decreasing Atmospheric Pressure on Gas Pressures (Pascals) in Soil with Cracks $400 \mathrm{~cm}$ Deep, $0.06 \mathrm{~cm}$ Wide and Spaced $800 \mathrm{~cm}$ Apart After $6 \mathrm{~h}$ 

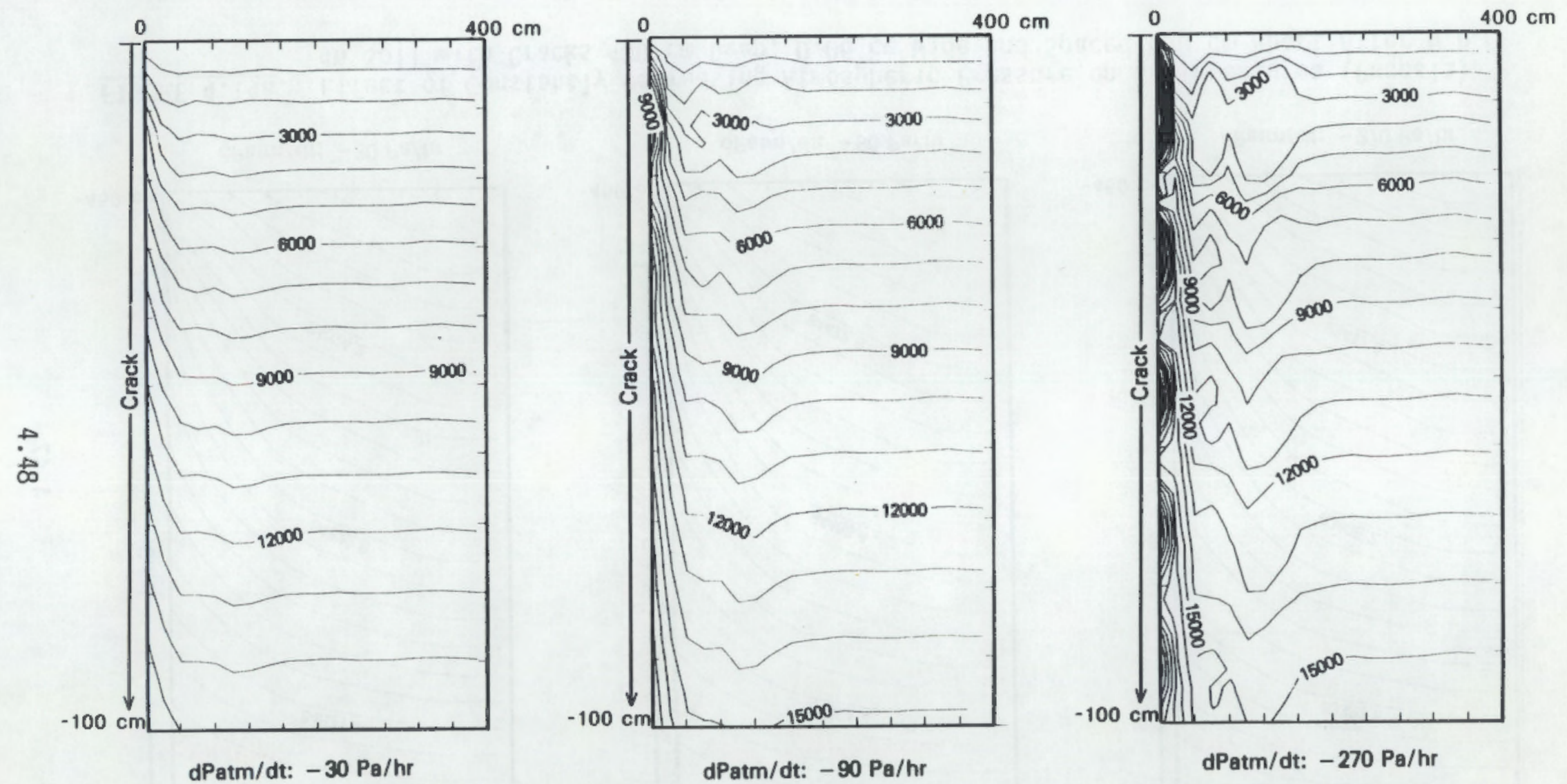

FIGURE 4.14b. Effect of Constantly Decreasing Atmospheric Pressure on Radon Concentrations (atoms $/ \mathrm{cm}^{3}$ ) in Soil with Cracks $400 \mathrm{~cm}$ Deep, $0.06 \mathrm{~cm}$ Wide and Spaced $800 \mathrm{~cm}$ Apart After $6 \mathrm{~h}$. (The strange contours near the crack are due to strong concentration gradients and too coarse a grid near the surface.) 

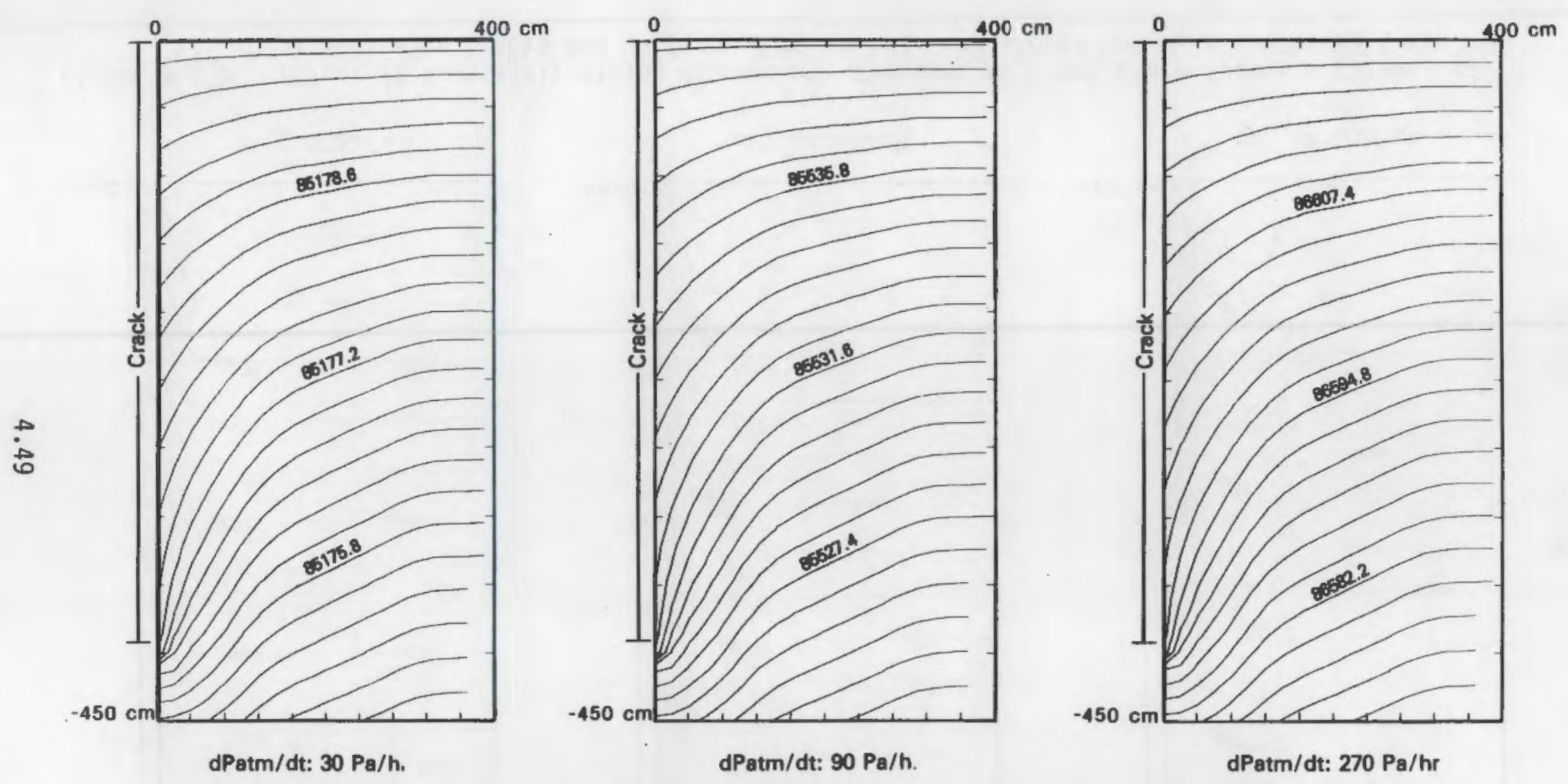

FIGURE 4.15a. Effect of Constantly Rising Atmospheric Pressure on Gas Pressures (Pascals) in Soil with Cracks $400 \mathrm{~cm}$ Deep, $0.06 \mathrm{~cm}$ Wide and Spaced $800 \mathrm{~cm}$ Apart After $6 \mathrm{~h}$ 

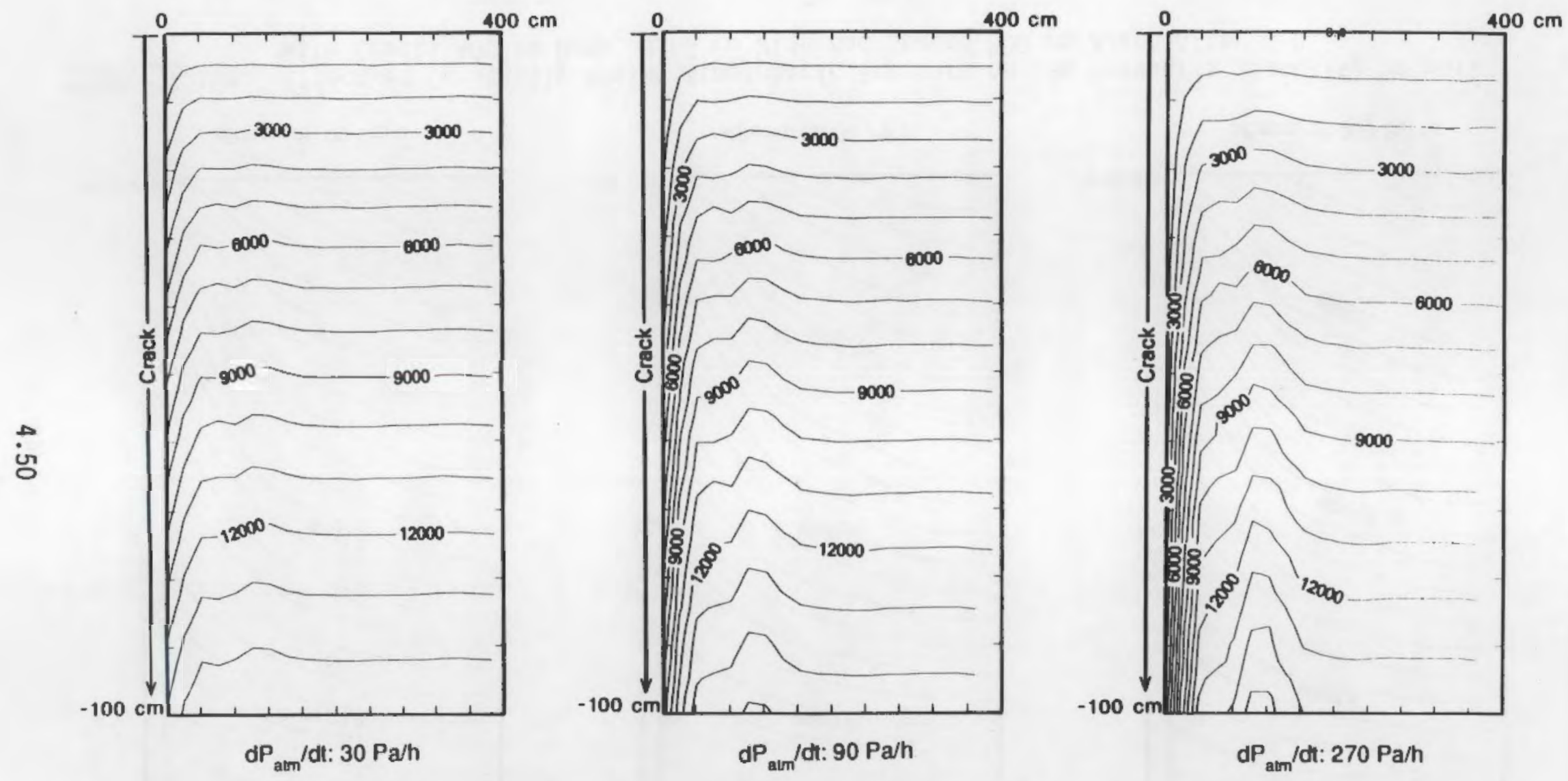

FIGURE 4.15b. Effect of Constantly Rising Atmospheric Pressure on Radon Concentrations (atoms $/ \mathrm{cm}^{3}$ ) in Soil with Cracks $400 \mathrm{~cm}$ Deep, $0.06 \mathrm{~cm}$ Wide and Spaced $800 \mathrm{~cm}$ Apart After $6 \mathrm{~h}$ 


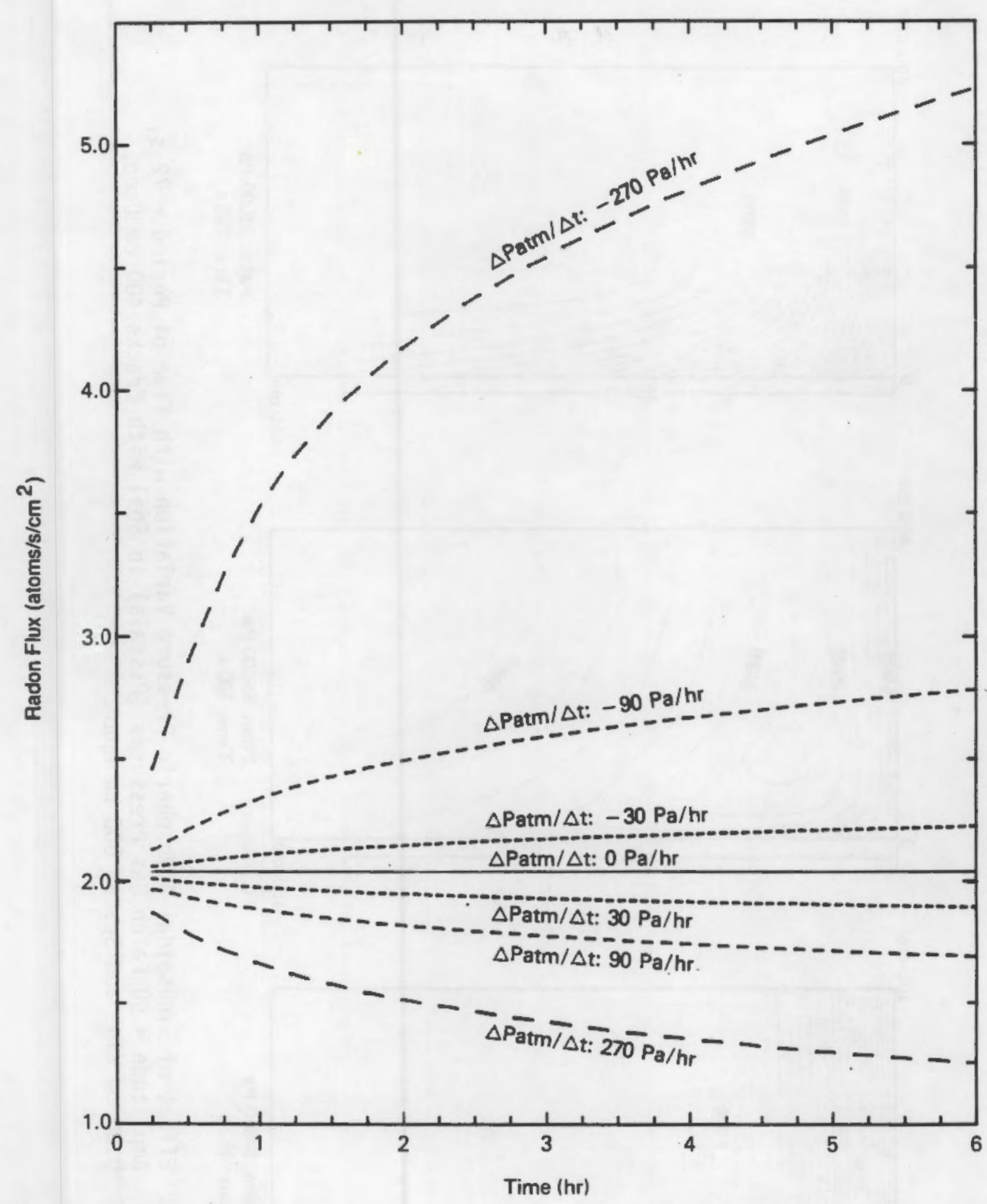

FIGURE 4.16. Effect of Constantly Changing Atmospheric Pressure on Radon Flux Density from Soil with Cracks $400 \mathrm{~cm}$ Deep, $0.06 \mathrm{~cm}$ Wide and Spaced $800 \mathrm{~cm}$ Apart During $6 \mathrm{~h}$ 

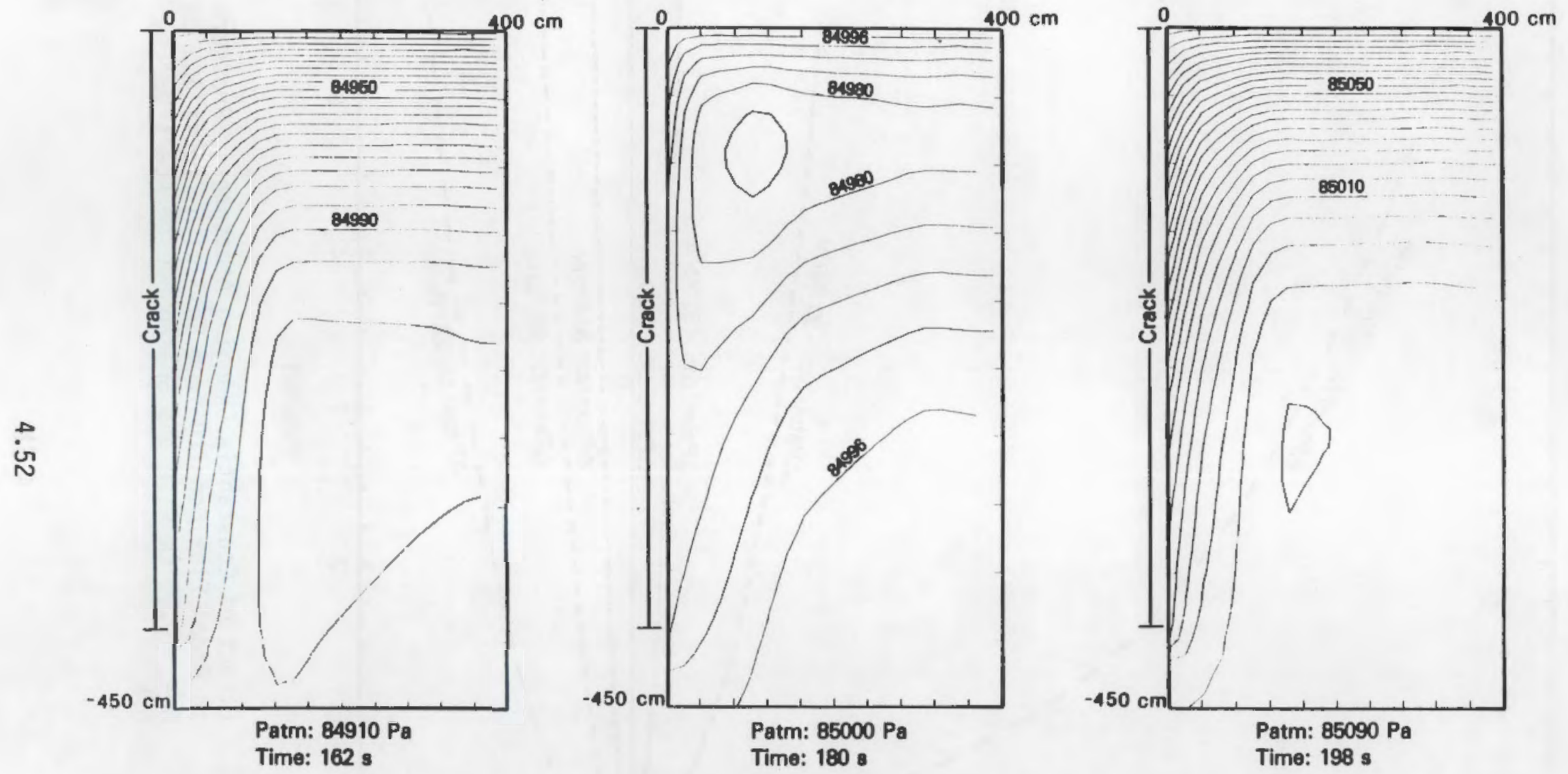

FIGURE 4.17a. Effect of Sinusoidal Atmospheric Pressure Variation with Time of Period = $72 \mathrm{~s}$, Amplitude $=90 \mathrm{~Pa}$ on Gas Pressures (Pascals) in Soil with Cracks $400 \mathrm{~cm}$ Deep, $0.06 \mathrm{~cm}$ Wide and Spaced $800 \mathrm{~cm}$ Apart 

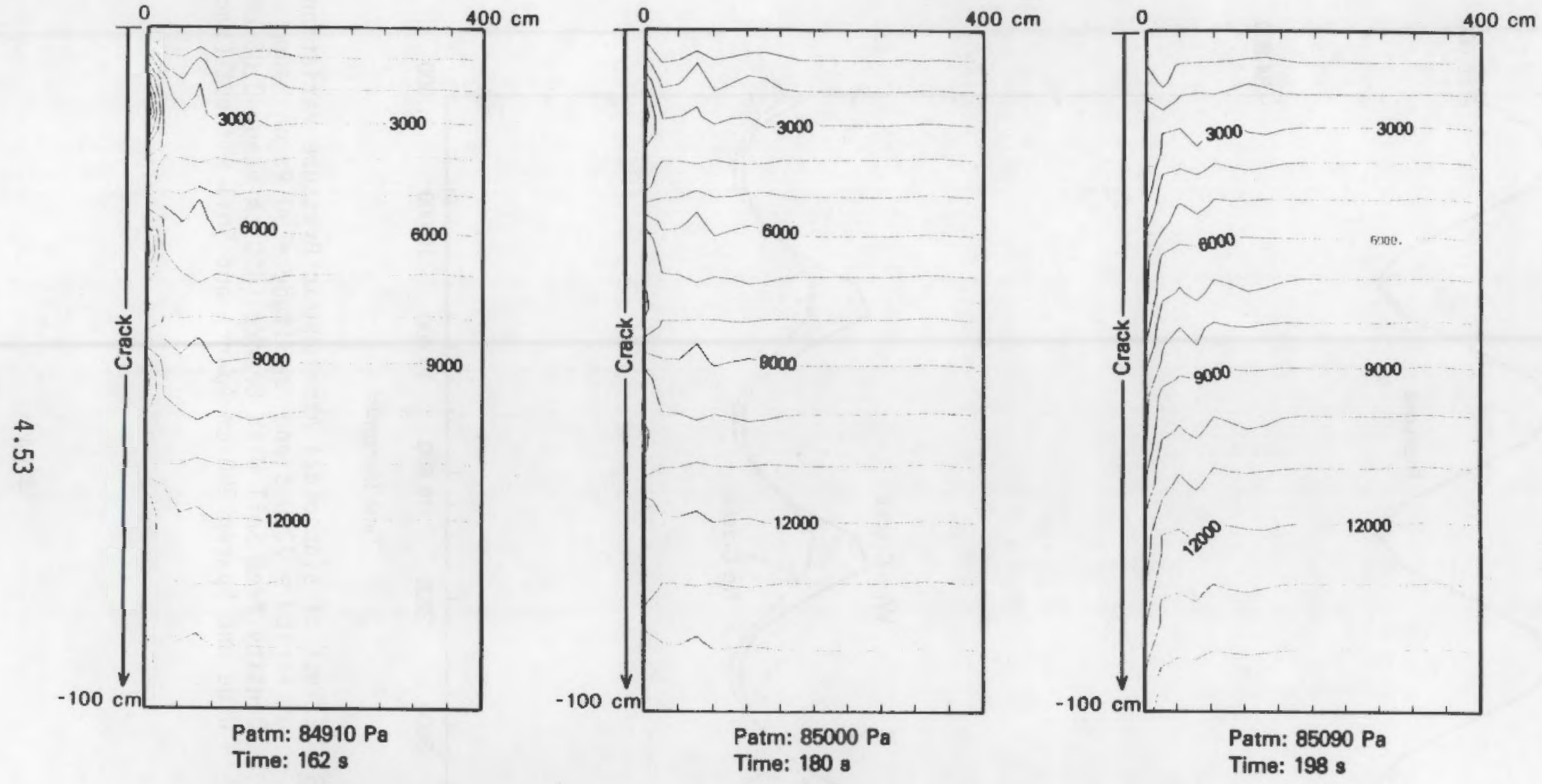

FIGURE 4.17b. Effect of Sinusoidal Atmospheric Pressure Variation with Time of Period $=72 \mathrm{~s}$, Amplitude $=90 \mathrm{~Pa}$ on Radon Concentrations (atoms $/ \mathrm{cm}^{3}$ ) in Soil with Cracks $400 \mathrm{~cm}$ Deep, $0.06 \mathrm{~cm}$ Wide and Spaced $800 \mathrm{~cm}$ Apart 


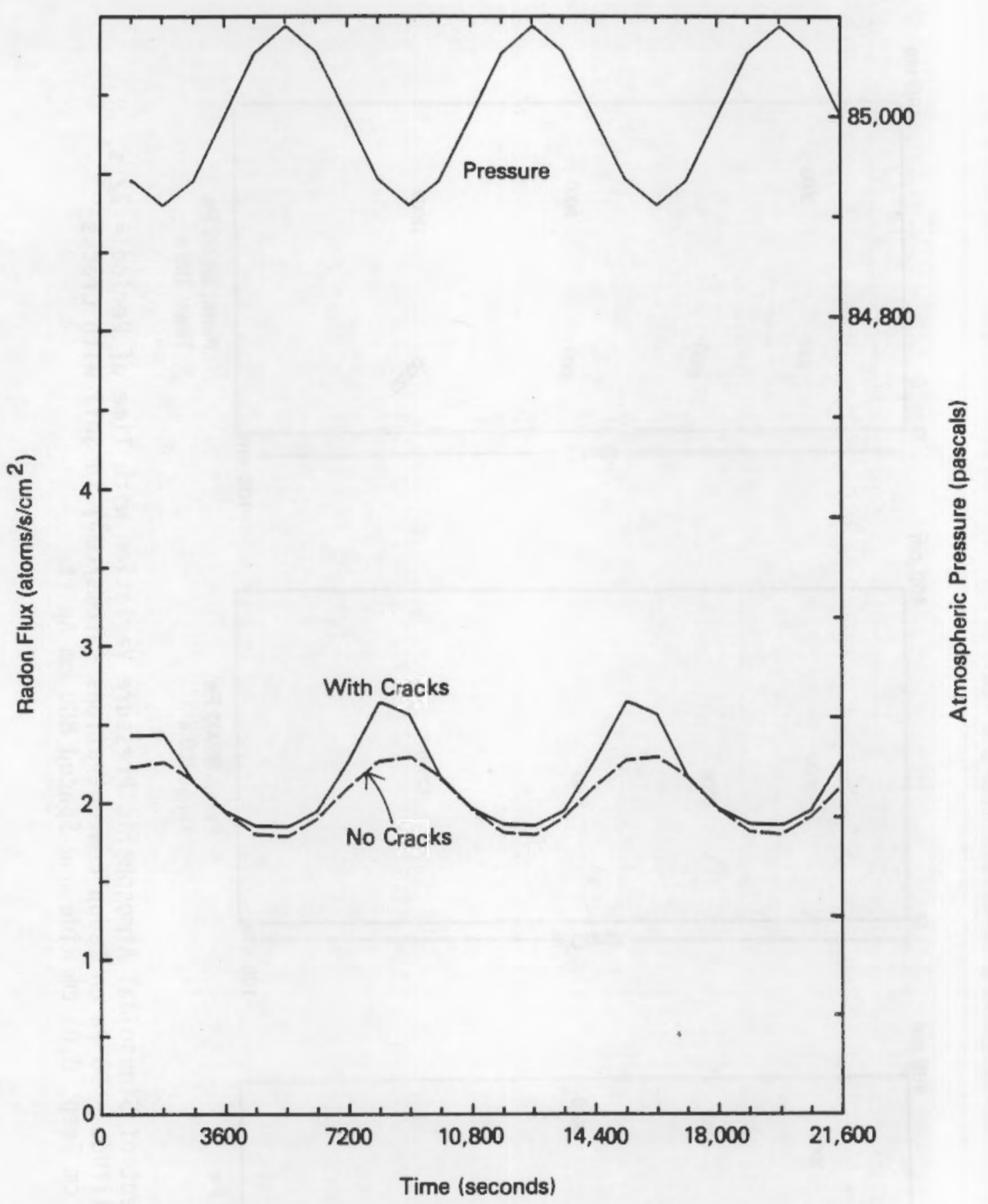

FIGURE 4.18. Effect of Sinusoidal Atmospheric Pressure Variation of Period $=7200 \mathrm{~s}$ and Amplitude $=90 \mathrm{~Pa}$ on Radon Flux Density from Soil With Cracks $(400 \mathrm{~cm}$ deep, $0.06 \mathrm{~cm}$ Wide and Spaced $800 \mathrm{~cm}$. Apart) and Soil Without Cracks 


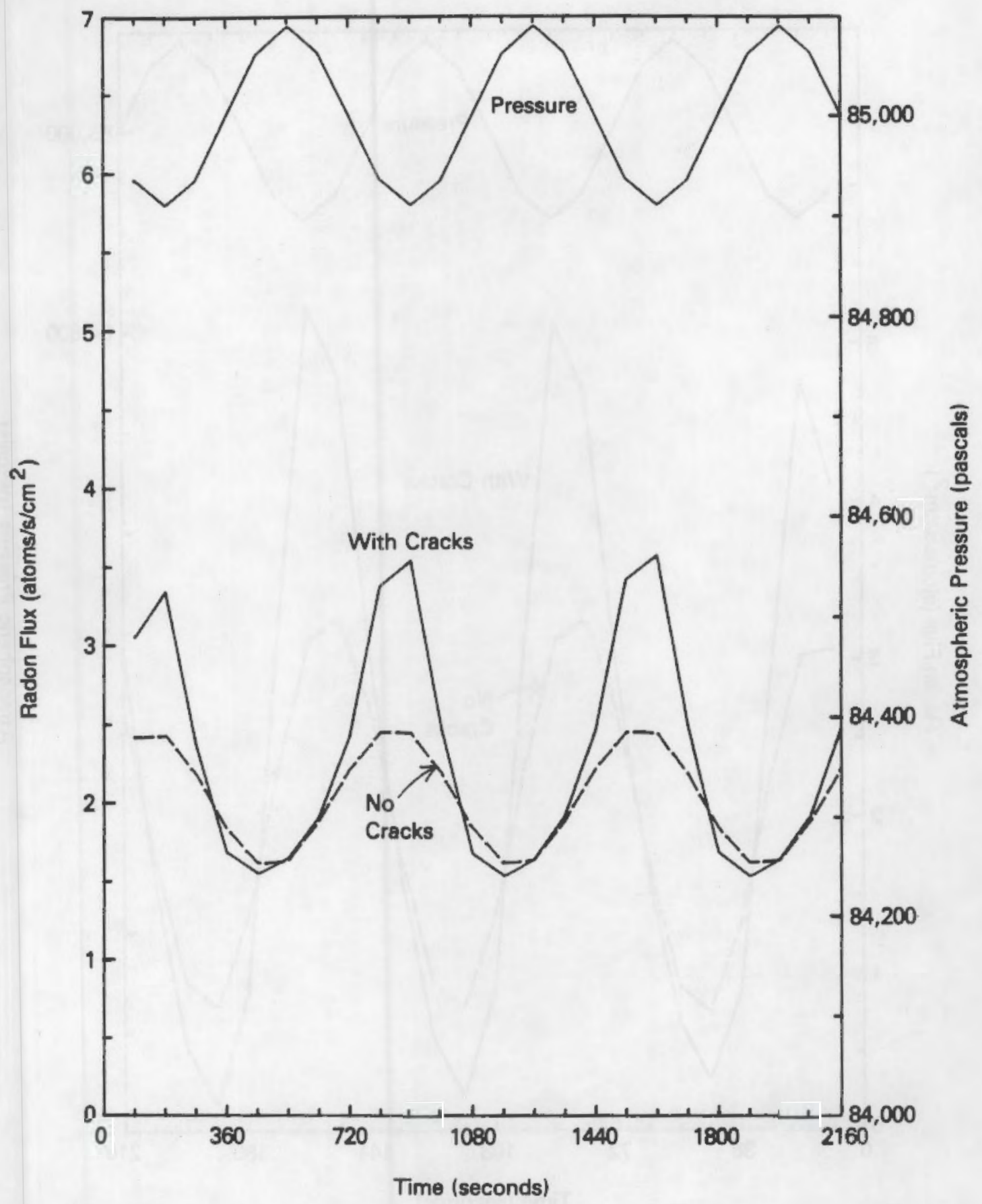

FIGURE 4.19. Effect of Sinusoidal Atmospheric Pressure Variation of Period $=720 \mathrm{~s}$ and Amplitude $=90 \mathrm{~Pa}$ on Radon Flux Density from Soil With Cracks $(400 \mathrm{~cm}$ deep, $0.06 \mathrm{~cm}$ wide and spaced $800 \mathrm{~cm}$ apart) and Soil Without Cracks 


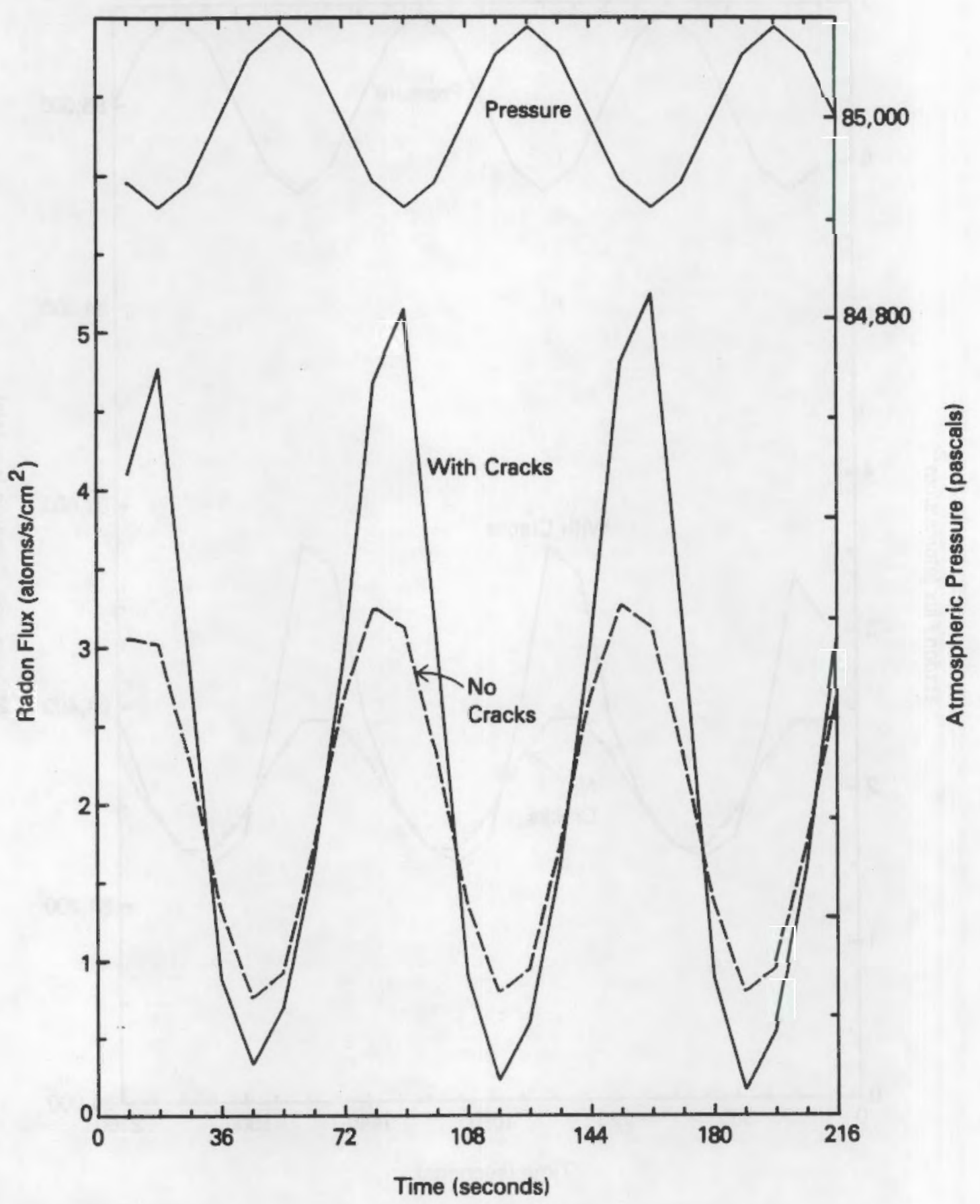

FIGURE 4.20. Effect of Sinusoidal Atmospheric Pressure Variation of Period $=72 \mathrm{~s}$ and Amplitude $=90 \mathrm{~Pa}$ on Radon Flux Density from Soil with Cracks $(400 \mathrm{~cm}$ Deep, $0.06 \mathrm{~cm}$ Wide and Spaced $800 \mathrm{~cm}$ Apart) and Soil Without Cracks 


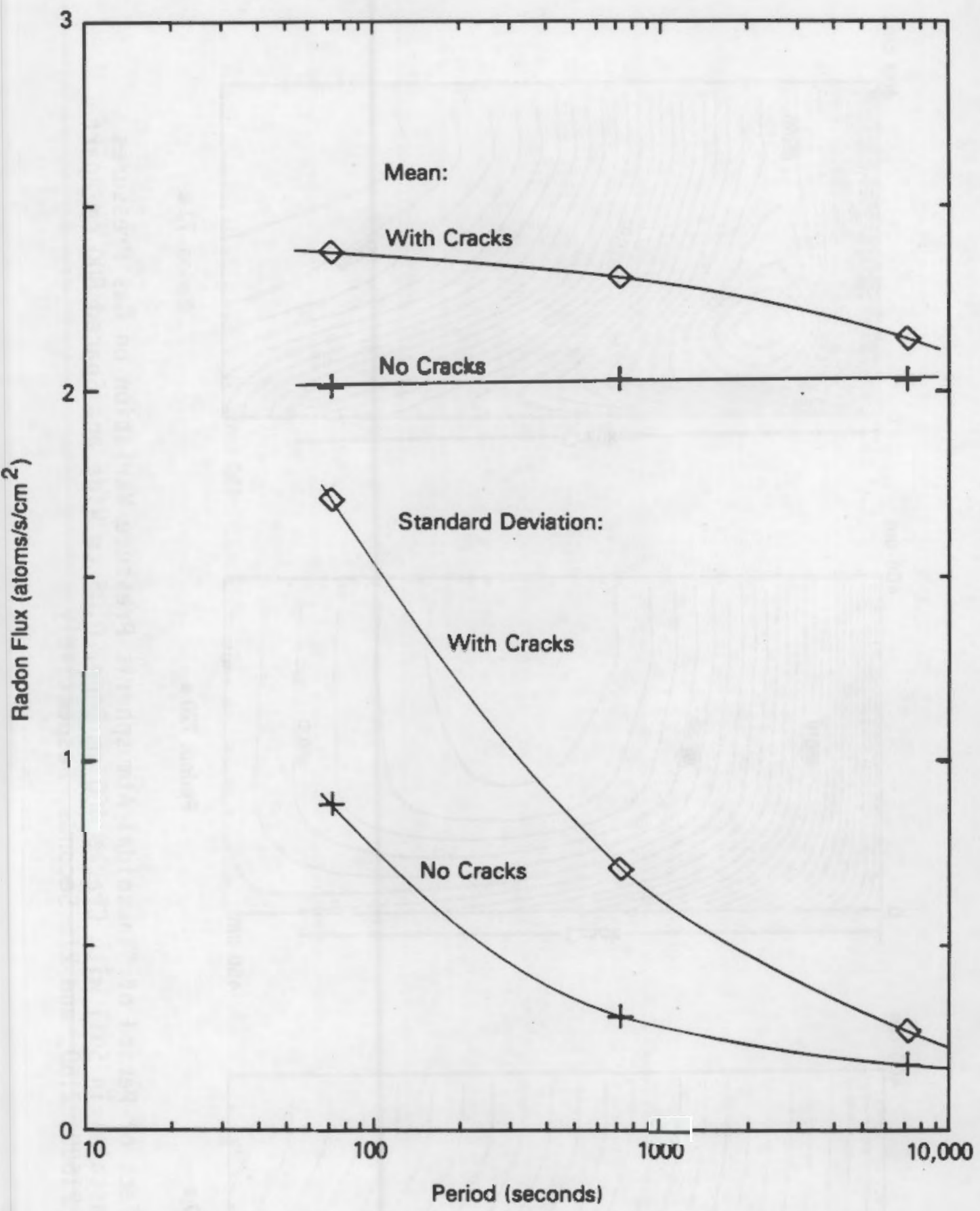

FIGURE 4.21. Effect of Period of Sinusoidal Atmospheric Pressure Variation on Mean and Standard Deviation of Radon Flux Density from Soil With Cracks (400 cm Deep, $0.06 \mathrm{~cm}$ Wide and Spaced $800 \mathrm{~cm}$ Apart) and Soil Without Cracks 


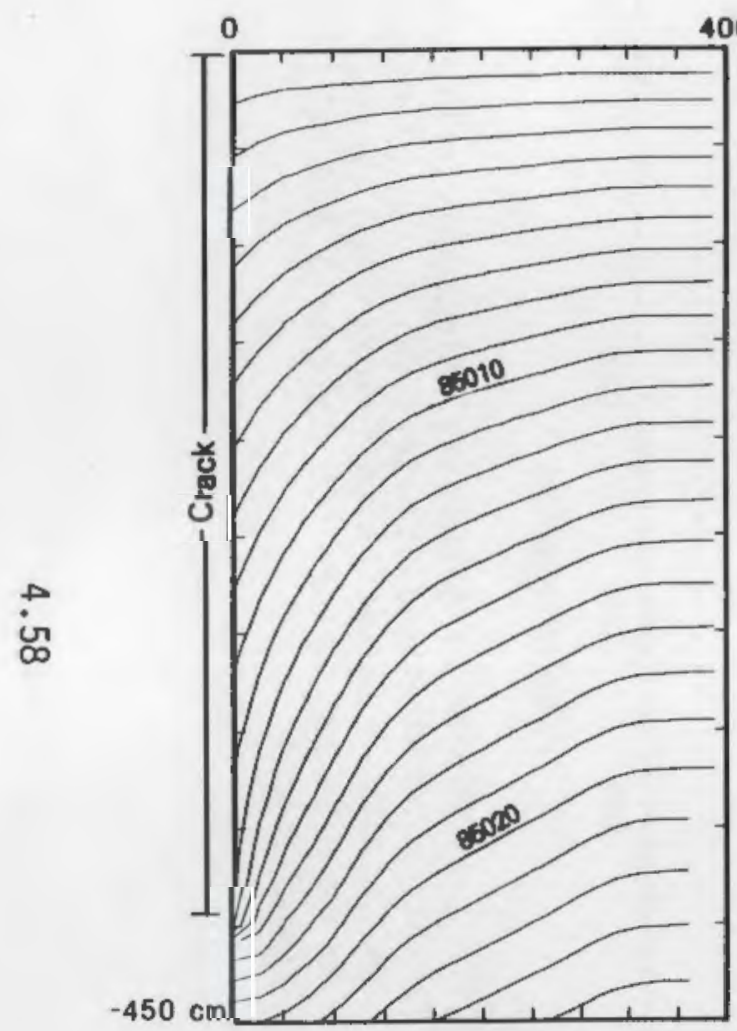

Period: $7200 \mathrm{~s}$

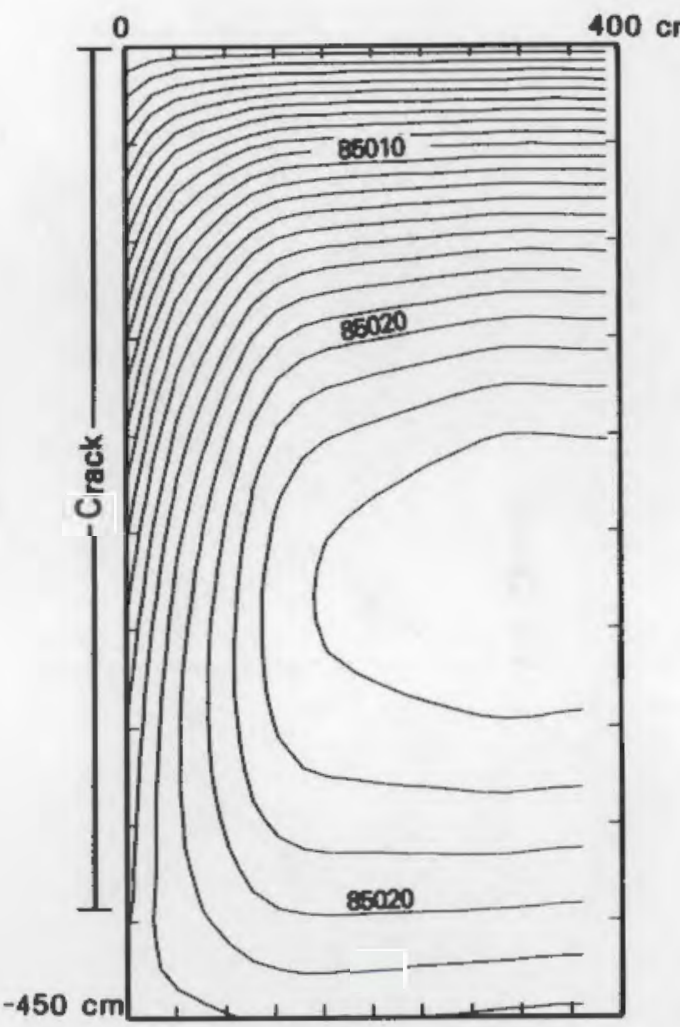

Period: $720 \mathrm{~s}$

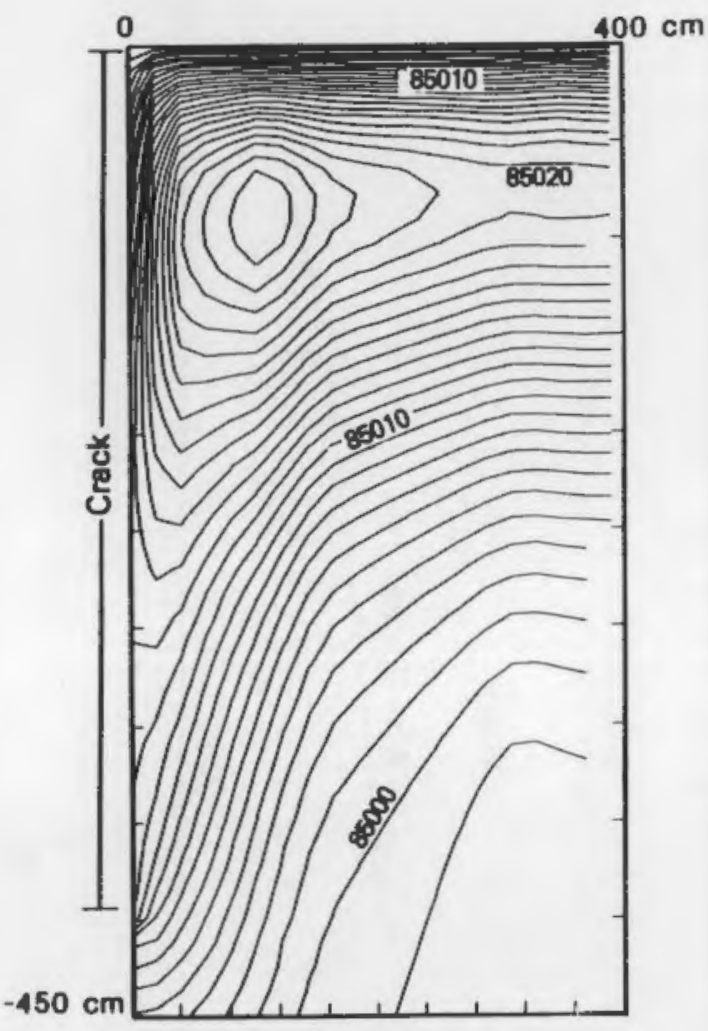

Period: 72 8

FIGURE 4.22a. Effect of Period of Sinusoidal Atmospheric Pressure Variation on Gas Pressures (Pascals) in Soil with Cracks $400 \mathrm{~cm}$ 0eep, $0.06 \mathrm{~cm}$ Wide and Spaced $800 \mathrm{~cm}$ Apart at 21600,2160 , and 216 Seconds, Respectively 


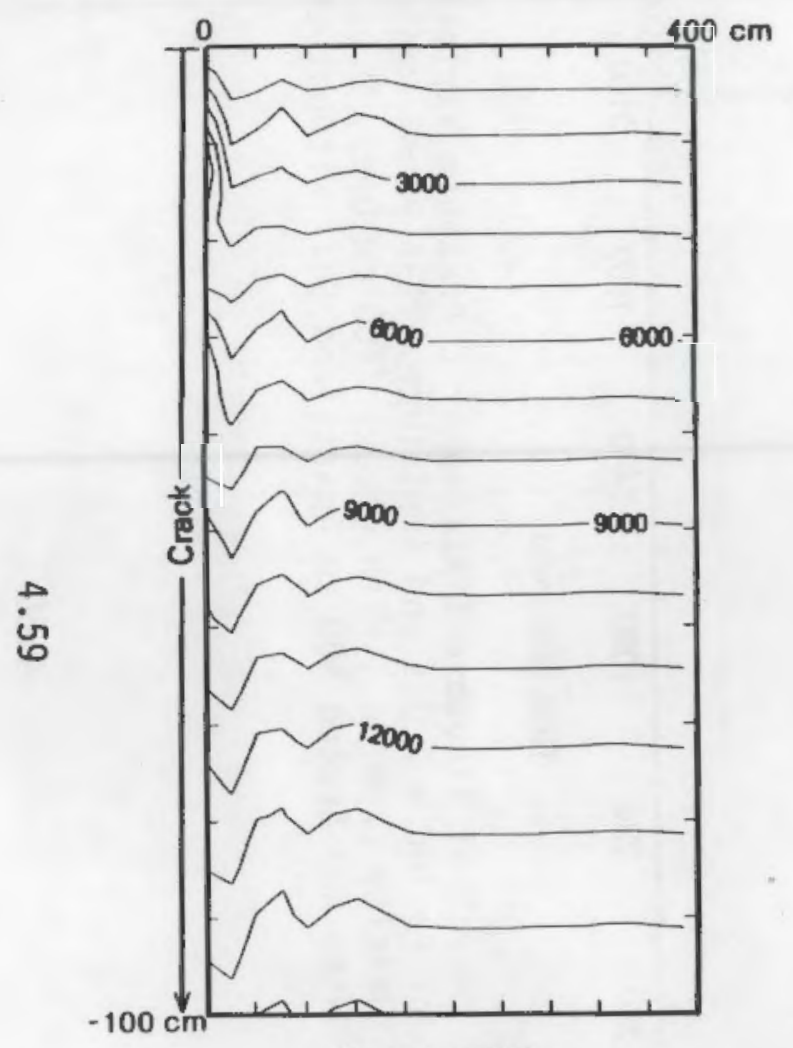

Period: $72000 \mathrm{~B}$
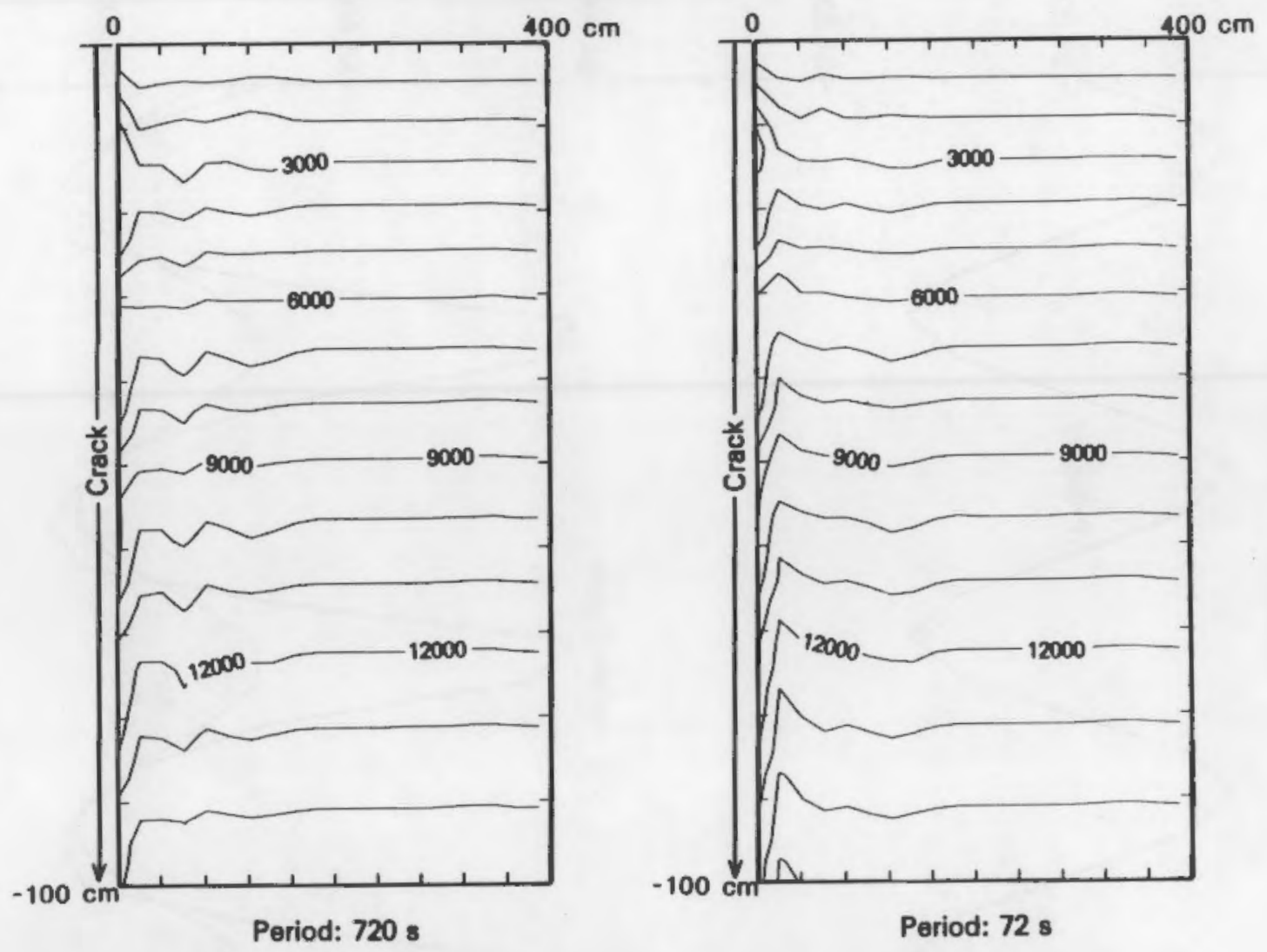

Period: $72 \mathrm{~s}$

FIGURE 4.22b. Effect of Period of Sinusoidal Atmospheric Pressure Variation on Radon Concentrations (atoms $/ \mathrm{cm}^{3}$ ) in Soil with Cracks $400 \mathrm{~cm}$ Deep, $0.06 \mathrm{~cm}$ Wide and Spaced $800 \mathrm{~cm}$ Apart at 21600, 2160, and 216 Seconds, Respectively 


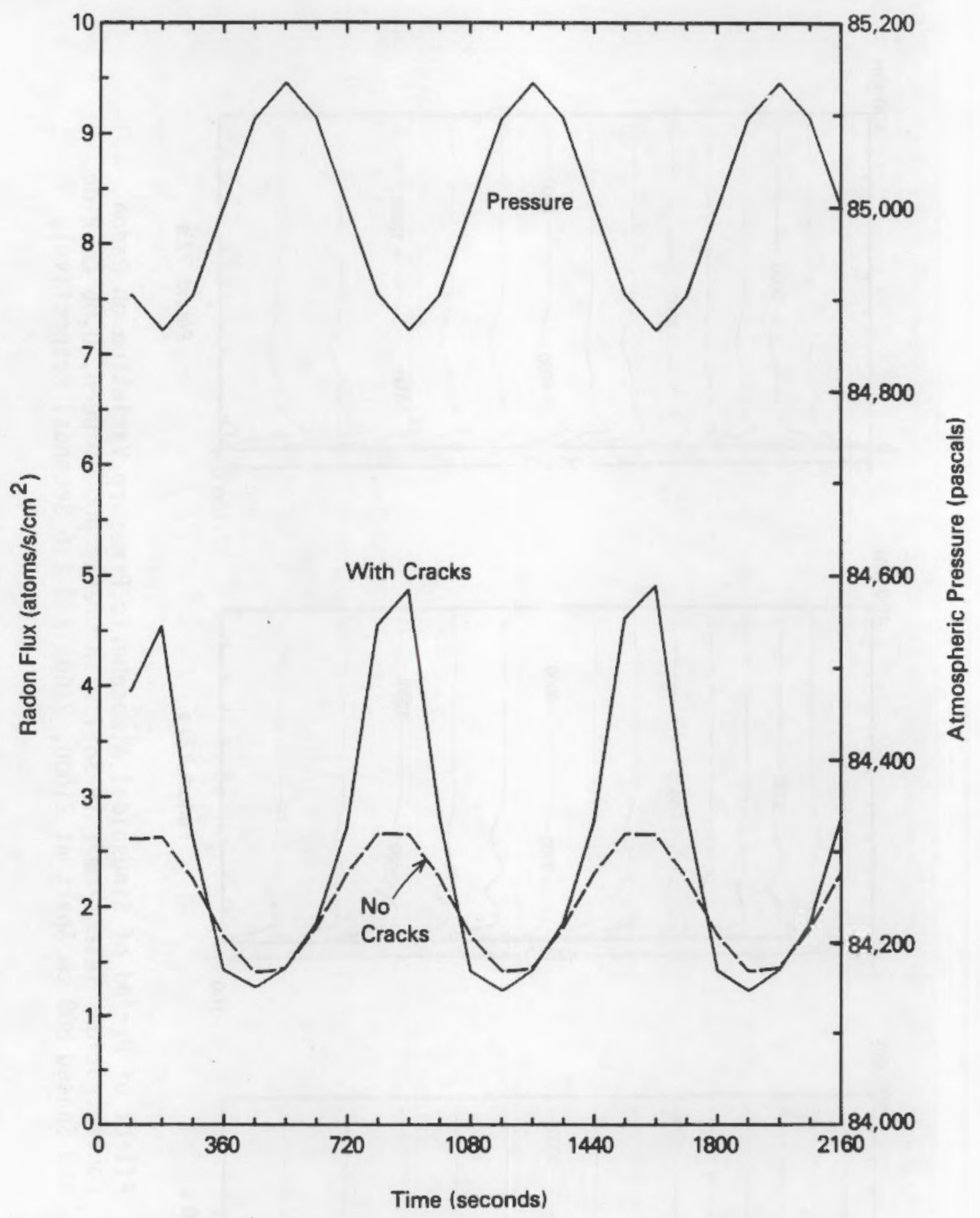

FIGURE 4.23. Effect of Sinusoidal Atmospheric Pressure Variation of Period $=720 \mathrm{~s}$ and Amplitude $=135 \mathrm{~Pa}$ on Radon Flux Density from Soil With Cracks (400 cm Deep, $0.06 \mathrm{~cm}$ Wide and Spaced $800 \mathrm{~cm}$ Apart) and Soil Without Cracks 


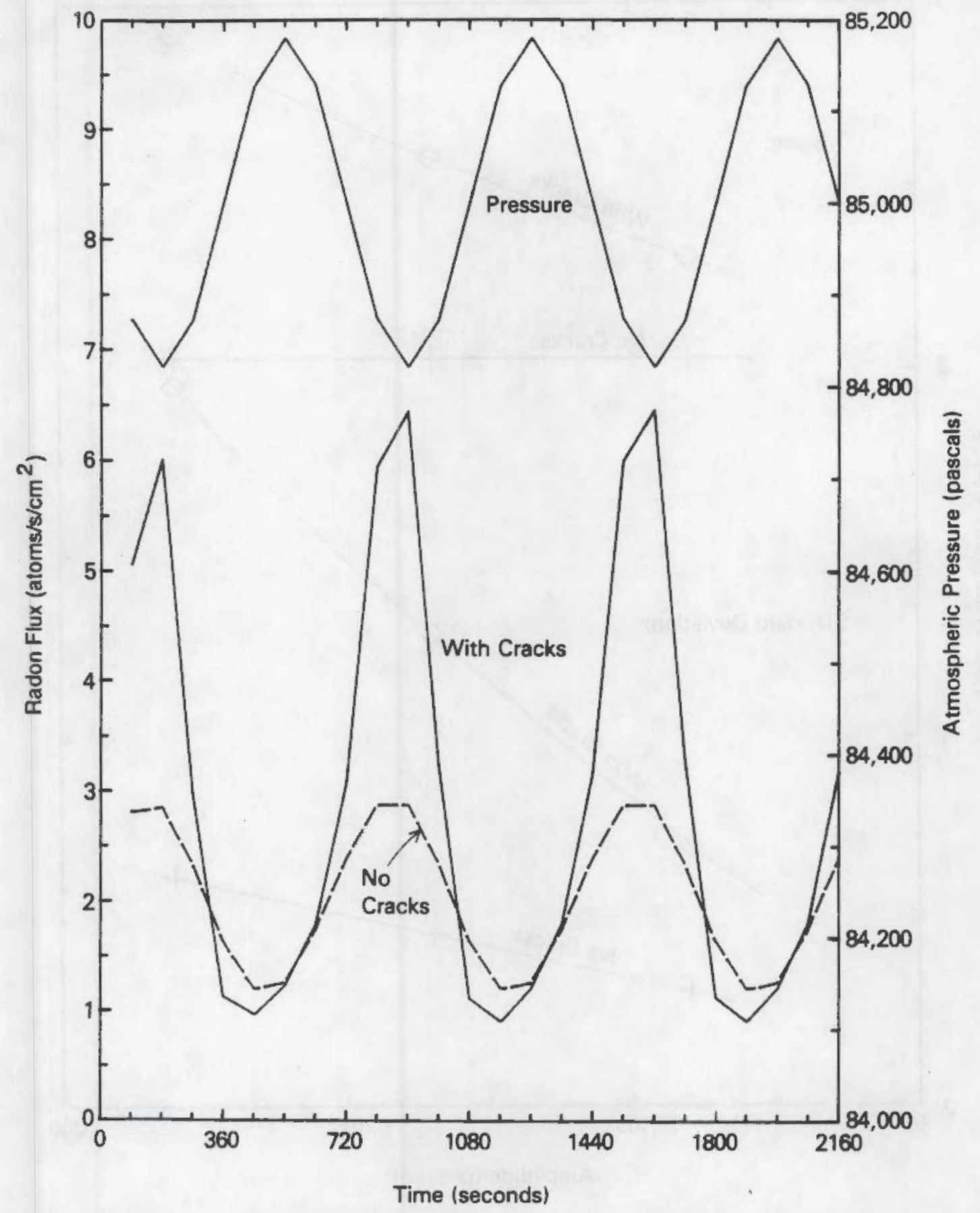

FIGURE 4.24. Effect of Sinusoidal Atmospheric Pressure Variation of of Period $=720 \mathrm{~s}$ and Amplitude $=180 \mathrm{~Pa}$ on Radon Flux Density from Soil With Cracks $(400 \mathrm{~cm}$ Deep, $0.06 \mathrm{~cm}$ Wide and Spaced $800 \mathrm{~cm}$ Apart) and Soil Without Cracks 


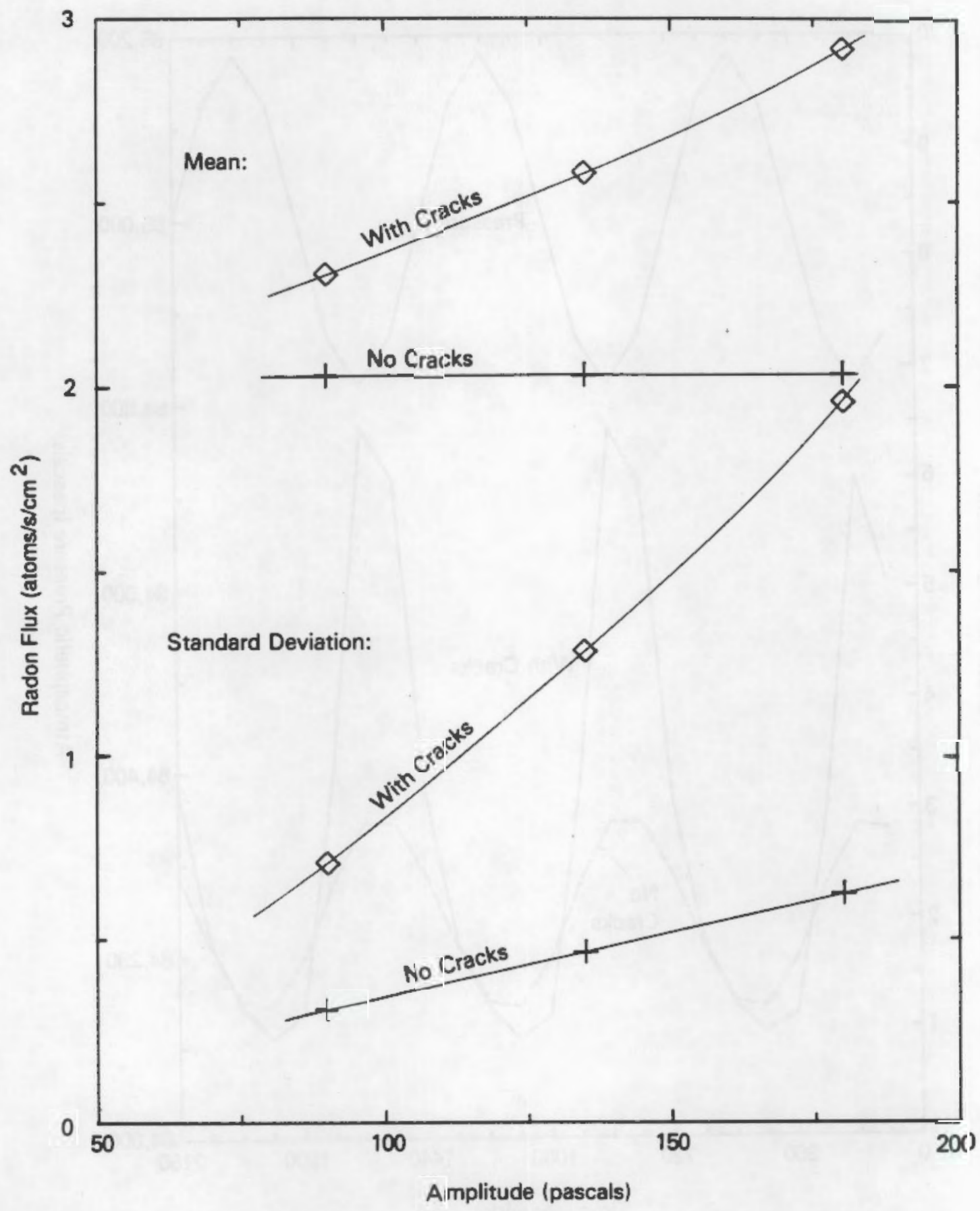

FIGURE 4.25. Effect of Amplitude of Sinusoidal Atmospheric Pressure Variation on Mean and Standard Deviation of Radon Flux Density from Soil With Cracks $(400 \mathrm{~cm}$ Deep, $0.06 \mathrm{~cm}$ Wide and Spaced $800 \mathrm{~cm}$ Apart) and Soil Without Cracks 


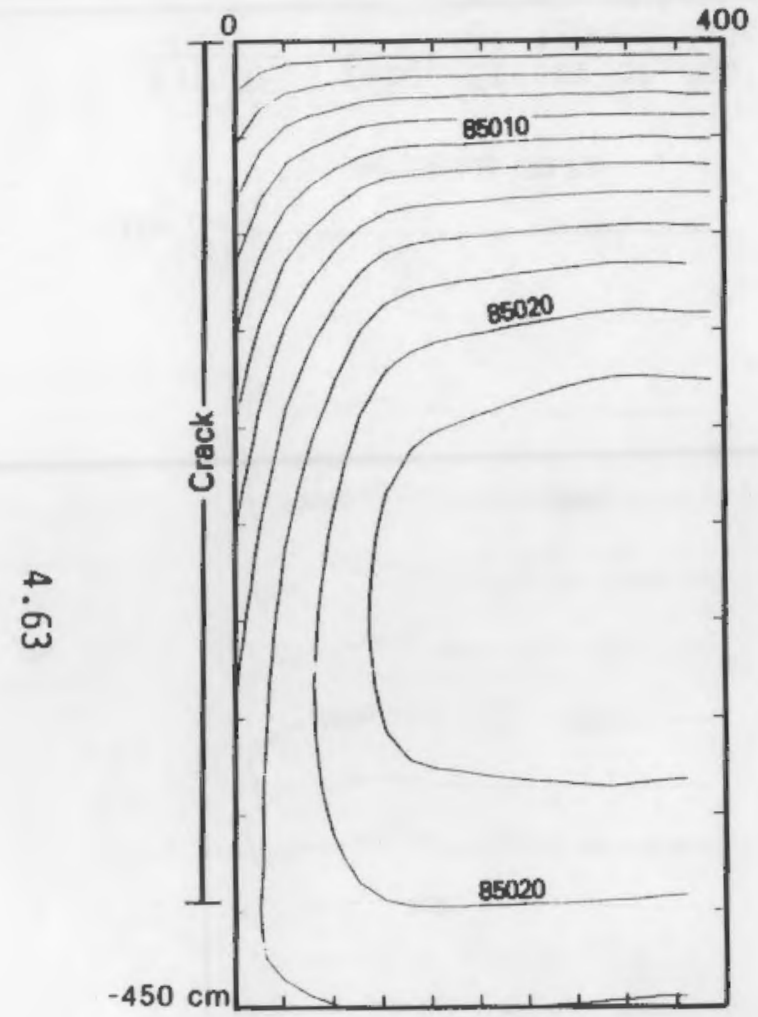

Amplitude: $90 \mathrm{~Pa}$
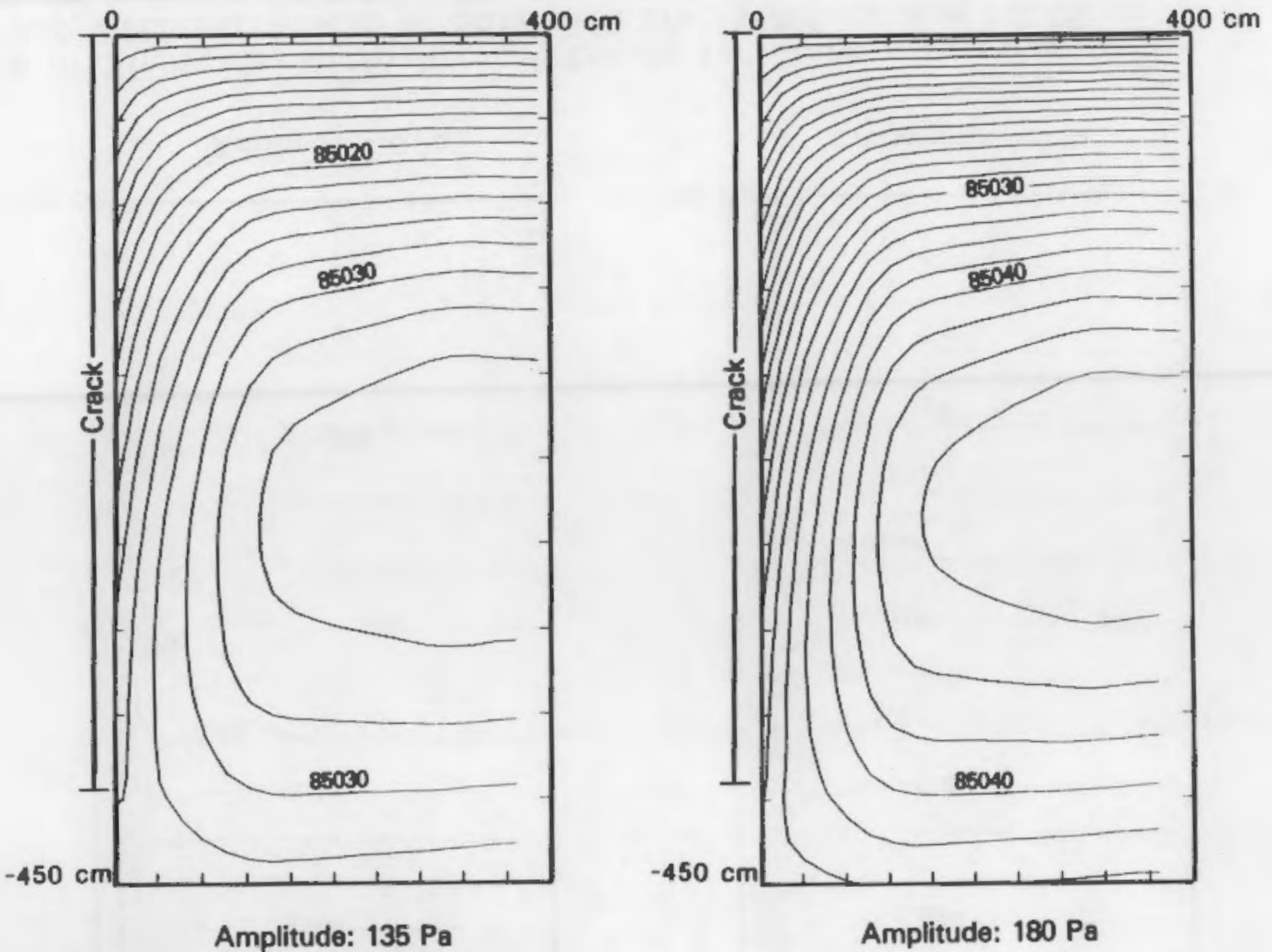

FIGURE 4.26a. Effect of Amplitude of Sinusoidal Atmospheric Pressure Variation with a Period of 720 Seconds on Gas Pressures in Soil with Cracks $400 \mathrm{~cm}$ Deep, $0.06 \mathrm{~cm}$ Wide and Spaced $800 \mathrm{~cm}$ Apart at 2160 Seconds 

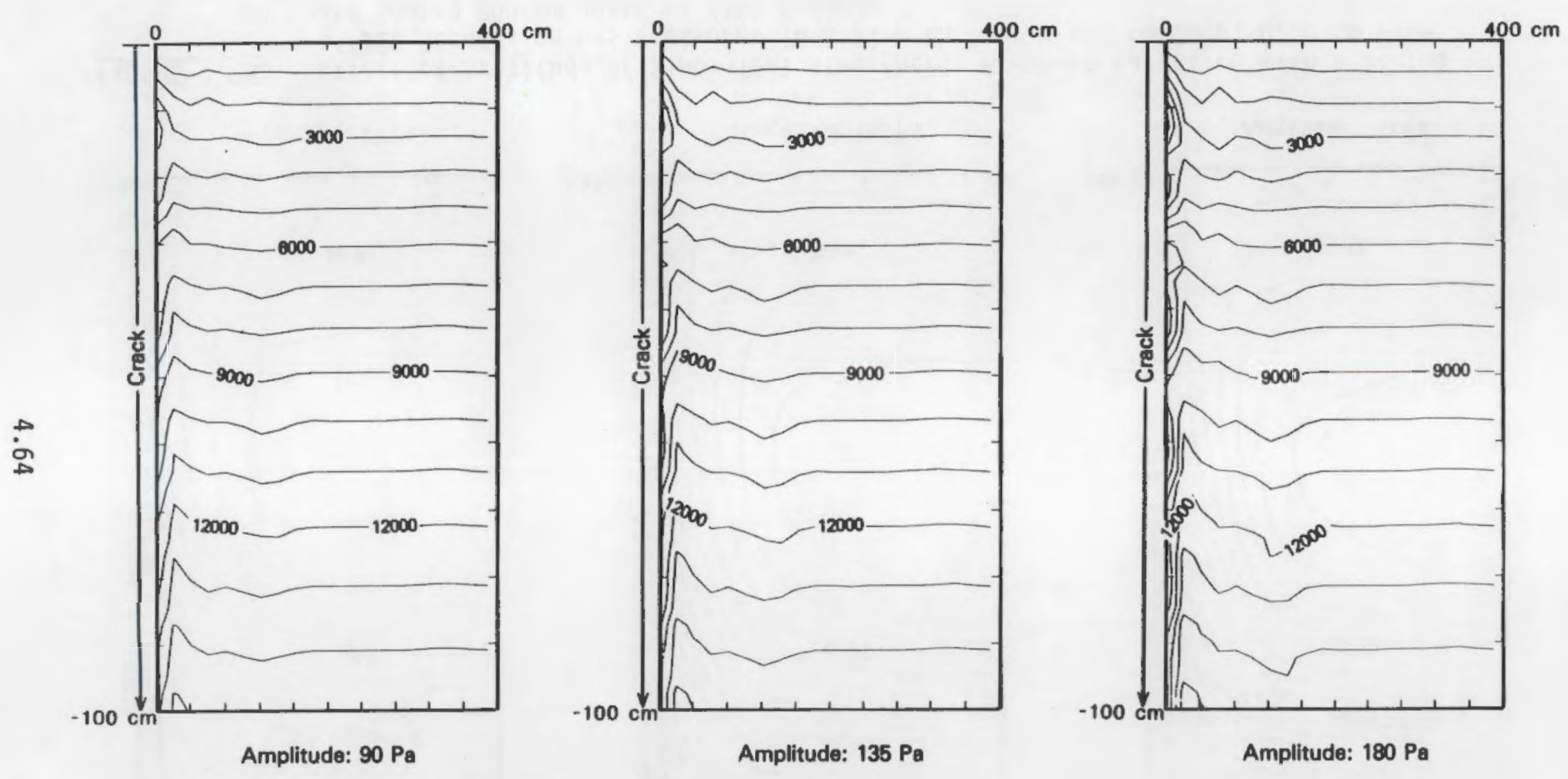

FIGURE 4.26b. Effect of Amplitude of Sinosoidal Atmospheric Pressure Variation with a Period of 720 Seconds on Radon Concentrations in Soil with Cracks $400 \mathrm{~cm}$ Deep, $0.06 \mathrm{~cm}$ Wide and Spaced $800 \mathrm{~cm}$ Apart at 2160 Seconds 


\subsection{COMPARISON OF MODEL RESULTS TO FIELD DATA}

This chapter compares the results of the sensitivity analysis to data collected in the field by Schery, Gaeddert and Wilkening (1984). The effects of long-term atmospheric pressure changes and of shorter-term wind speed fluctuations on radon fluxes from soil are considered.

Figure 5.1 shows atmospheric pressure and radon flux density measured at 2-h intervals. Figure 5.1 also shows the results of two model simulations: a transient, 1-D run and a transient, 2-D run with cracks $400 \mathrm{~cm}$ deep, $800 \mathrm{~cm}$ apart, and $0.06 \mathrm{~cm}$ wide. The one-dimensional model uses the same governing equations and boundary conditions developed in Chapter 2, except that no cracks are included in the soil. The atmospheric pressures in Figure 5.1 were used as the top boundary condition for both the $1-D$ and 2-D models. A typical pressure drop is between $30 \mathrm{~Pa} / \mathrm{h}$ and $90 \mathrm{~Pa} / \mathrm{h}$ with a few changes of up to 240 $\mathrm{Pa} / \mathrm{h}$. The soil parameters in Table 4.1 were used.

While the 2-D model matches some of the observed peaks in radon flux better than the 1-D model, some variations in the observed fluxes shown in Figure 5.1 do not correlate to the changes in atmospheric pressure. Something other than long-term atmospheric pressure fluctuations must be affecting radon flux density from the soil. Changes in wind velocity are a likely candidate. Figure 5.2 shows measurements of subsurface pressure gradients taken between $5 \mathrm{~cm}$ and $56 \mathrm{~cm}$ below the surface, atmospheric pressure, and wind speed recorded at Schery's field site. The subsurface pressure gradients clearly show morecorrelation to wind speed than atmospheric pressure. Pressure gradients of $0.1 \mathrm{~Pa} / \mathrm{cm}$ are typical, while a few are as high as $0.5 \mathrm{~Pa} / \mathrm{cm}$.

In Section 4.3, sinusoidal variations in surface pressure were applied with periods of from $1 \mathrm{~min}$ to $2 \mathrm{~h}$. The predicted pressure gradients in the top $50 \mathrm{~cm}$ of soil (Figures $4.16 \mathrm{a}, 4.21 \mathrm{a}$, and $4.25 \mathrm{a}$ ) range from of $0.1 \mathrm{~Pa} / \mathrm{cm}$ to $0.5 \mathrm{~Pa} / \mathrm{cm}$. As mentioned above, similar pressure gradients were measured in the field and may be attributed to changes in wind speed at the surface. Sinusoidal variations in surface pressure with periods between $2 \mathrm{~h}$ and $72 \mathrm{~s}$ and amplitude of $90 \mathrm{~Pa}$ show deviations in flux of up to $70 \%$ greater than a 1-D model, and mean fluxes up to $25 \%$ greater than a 1-D model (Figure 4.20 ). 

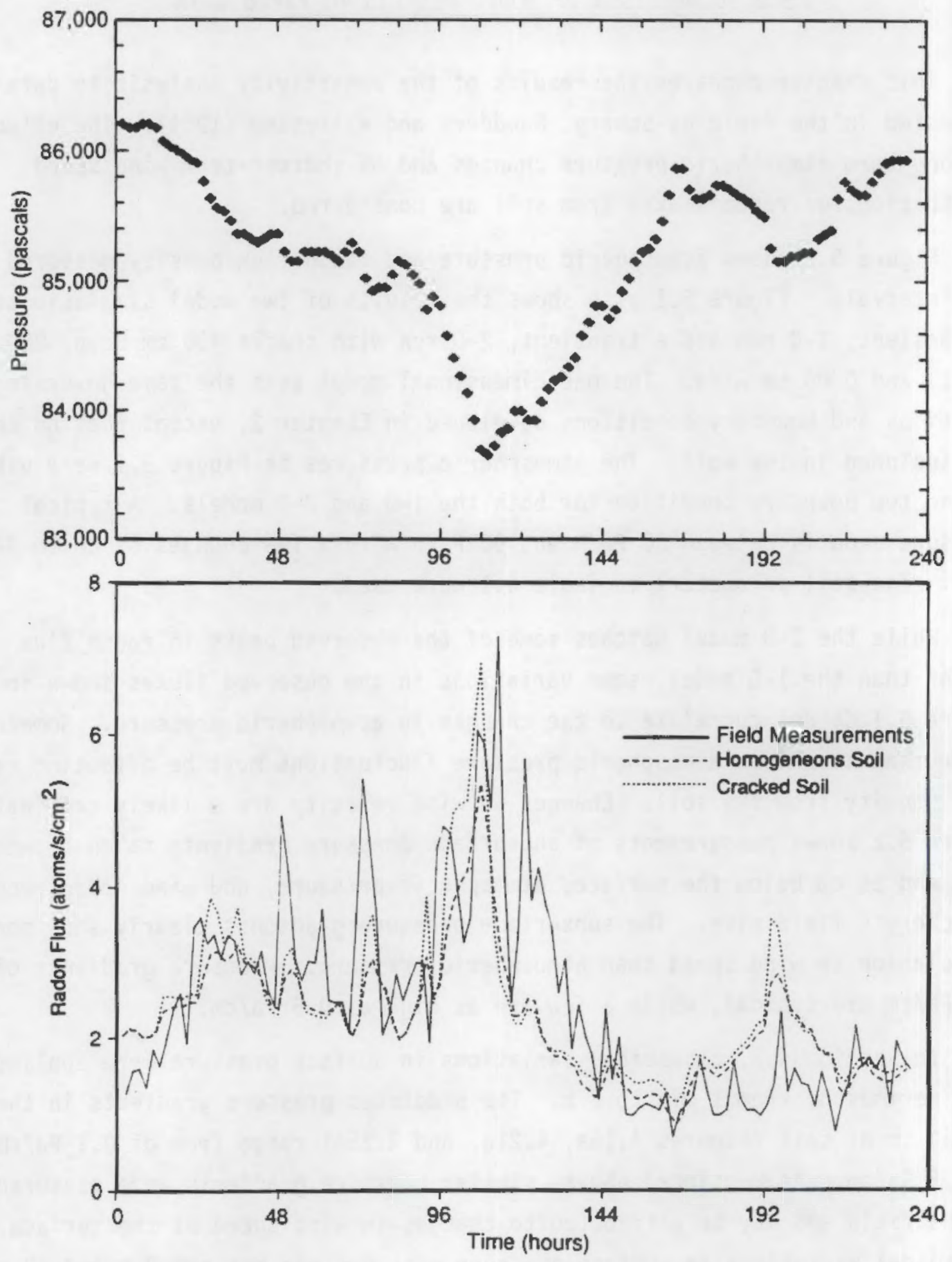

FIGURE 5.1. Atmospheric Pressure and Radon Flux Density Measurements at Field Site of Schery et al. (1984). One-dimensional soil model used pressures and soil parameters from same article. 



FIGURE 5.2. Measurements of Subsurface Pressure Gradients, Barometric Pressure, and Wind Speed Taken at Field Site of Schery and Siegel (1986) Over a 32-h Period 
Sinusoidal variations in atmospheric pressure with amplitudes between 90 and $180 \mathrm{~Pa}$ and a period of $720 \mathrm{~s}$ (12 min) show deviations in flux of up to $100 \%$ greater than a 1-D model, and mean fluxes up to 50 percent greater than a 1-D model (Figure 4.24). Even the deviation of flux densities predicted by the $1-D$ model is as great as $45 \%$, but there is effectively no change in mean flux (Figure 4.19). High-frequency pressure changes, attributable to wind at the surface of cracked soil, could cause an increase in mean flux of radon from the soil and also large deviations in flux.

Soil cracks and short-term variations in pressure attributed to wind might be sufficient to explain the difference between a 1-D radon transport model driven by barometric pressure changes and observed radon fluxes. The variation in observed fluxes seen in Figure 5.1 that do not correlate to atmospheric pressure changes might best explained by changes in wind speed.

The fact that rather large, widely spaced cracks are needed in the model to show a significant enhancement of flux suggests that the shallow cracks observed on the soil surface at the site may be of negligible importance in increasing the radon flux densities. Holes left by decayed plant roots, which are observed to be deep and widely spaced in an arid environment, might be a more significant factor than soil cracks in affecting radon fluxes. 


\subsection{CONCLUSIONS AND RECOMMENDATIONS}

Based on the results of the sensitivity analysis, radon flux appears to be sensitive to the values of the soil properties selected, with the diffusion coefficient being most important, followed by the permeability and porosity. Radon flux is also very sensitive to changes in barometric pressure, both long-term (e.g., $2000 \mathrm{~Pa}$ over 4 days) and short-term (e.g., 200 Pa over several minutes). For the relatively high-permeability soil examined herein, the predicted radon fluxes seem least sensitive to the crack dimensions. The limited sensitivity analys is of soil permeabilities suggests that cracks may play an important role in enhancing radon flux from low permeability, and high porosity soils (e.g., days) under transient pressure conditions.

The diffusion coefficient of radon in soil has been proven to be correlated to the water content of the soil (Rogers, Overmeier and Nielson 1979). For the soil considered in this study, Schery, Gaeddert and wilkening 1984 reported a water saturation of 0.06 . This value indicates that only $17 \%$ of the soil porosity (which is equal to 0.35 ) is filled with water, and this water content would have a small effect on the diffusion coefficient. However, in soils with higher water contents, the transport of radon could be significantly affected by the reduction in air-filled void space. Also, movement of soil water could enhance or diminish the flux of radon from the soil surface. For these reasons, the effects of water content on radon transport should be included in future modeling studies of radon transport in soils. 


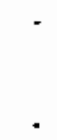

. 


\subsection{REFERENCES}

Bear, J. 1979. Hydraulics of Groundwater. McGraw-Hill, New York.

Brebbia, C. A. and A. J. Ferrante. 1978. Computational Methods for the Solution of Engineering Problems. Crane-Russak, New York.

Carslaw H. S. and J. C. Jaeger. 1959. Conduction of Heat in Solids. 2nd edition, Oxford University Press, London.

Clements, W. E. 1974. The Effect of Atmospheric Pressure Variation on the Transport of 222Radon from Soil to the Atmosphere. Ph.D. Dissertation, New Mexico Institute of Mining and Technology, Socorro, New Mexico.

Freeze, R. A. and J. A. Cherry. 1979. Groundwater. Prentice-Hall, Inc., Englewood Cliffs, New Jersey.

Grisak, G. E. and J. F. Pickens. 1980a. "Solute Transport Through Fractured Media: 1. The Effect of Matrix Diffusion." Water Resour. Res. 16(4):719-730.

Grisak, G. E. and J. F. Pickens. 1980b. "Solute Transport Through Fractured Media: 2. Column Study of Fractured Ti11." Water Resour. Res. 16(4):731-739.

Huyakorn, P. S. B. H. Lester and J. W. Mercer. 1983. "An Efficient Finite Element Technique for Modeling Transport in Fractured Porous Media: 1. Single Species Transport." Water Resour. Res. 19(3):841-854.

Huyakorn, P. S., B. H. Lester and C. R. Faust. 1983. "Finite Element Techniques for Modeling Groundwater Flow in Fractured Aquifers." Water Resour. Res. $19(4): 1019-1035$.

Huyakorn, P. S. and G. F. Pinder. 1983. Computational Methods in Subsurface Flow. Academic Press, New York.

INTERA Environmental Consultants, Inc. 1983. FTRANS: A Two-Dimensional Code for Simulating Fluid Flow and Transport of Radioactive Nuclides in Fractured $\overline{R o c k}$ for Repository Performance Assessment. ONWI-426, prepared for Battelle Memorial Institute, Office of Nuclear Waste Isolation, Columbus, Ohio.

Lohman, S. W. 1979. Ground-Water Hydraulics. U.S. Geological Survey Professional Paper No. 708, U.S. Government Printing Office, Washington, D.C.

Neretnieks, I. 1980. "Diffusion in the Rock Matrix: An Important Factor in Radionuclide Retardation?" J. Geophys. Res. 85(B8):4379-4397.

Rogers, V. C., R. F. Overmyer and K. K. Nielson. 1979. "Radon Attenuation Through Covers Materials." In Uranium Mill Tailings Management-II, pp. 145-156, Colorado State University, Fort Collins, Colorado. 
Schery, S. D., D. H. Gaeddert and M. H. Wilkening. 1984. "Factors Affecting Exhalation of Radon from a Gravelly Sandy Loam." J. Geophys. Res. 89 (D5): 7299-7309.

Schery, S. D. and D. Siegel. 1986. "The Role of Channels in the Transport of Radon from the Soil." J. Geophys. Res. 91(B12):12366-12374.

Sudicky, E. A. and E. 0. Frind. 1982. "Contaminant Transport in Fractured Porous Media: Analytical Solutions for a System of Parallel Fractures." Water Resour. Res. 18(6):1634-1642.

Wilson, J. L., L. R. Townley and A. Sa da Costa. 1979. Mathematical Development of a Finite Element Aquifer Flow Model, AQUIFEM-1. Ralph M. Parsons Laboratory for Water Resources and Hydrodynamics Report Number 248. Massachusetts Institute of Technology, Cambridge, Massachusetts. 


\section{DISTRIBUTION}

No. of

Copies

OFFSITE

12 DOE Office of Scientific and Technical Information

T. B. Borak

Department of Radiology and Radiation Biology Colorado State University

Fort Collins, CO 80523

J. Cotter

Hawaii Institute of Geophysics

University of Hawaji

2525 Correa Road

Honolulu, HI 96822

P. Doyle

5-1939 Carling Ave. Ottawa, Ontario

CANADA K2A 1 E9

W. Fisk

90-3058

Lawrence Berkeley Lab

Berkeley, CA 94720

R. B. Gammage

Martin Marietta Energy Systems, Inc.

P.0. Box 2001

Oak Ridge, TN 37831-6383

D. Genereux

Ralph M. Parsons Laboratory for Water Resources and Hydrodynamics

Dept. of Civil Engineering

Massachusetts Institute of Technology

Cambridge, MA 02138
No. of

Copies

R. Grasty

Energy, Mines and Resources

Canada

601 Booth St.

Ottawa, Ontario

CANADA K1A 0E8

W. Graustein

Dept. of Geology \& Geophysics

Yale University

P.0. 6666

New Haven, CT 06511-8130

R. E. Green

Department of Agronomy

\& Soil Science

University of Hawai $i$

1910 East-West Rd.

Honolulu, HI 96822

B. Howell

Environmental Science Division

Lawrence Livermore National Labs L524

P.0. Box 5510

Livermore, CA 94550

B. S. Levy

Camp Dresser \& McKee Inc.

One Center Plaza

Boston, MA 02108

C. Mendoza

Waterloo Centre for Groundwater

Research

University of Waterioo

Waterloo, Ontario

CANADA N2L 3GI

K. K. Nielson

Rogers \& Assoc. Engineering Corp. Box 330

Salt Lake City, UT 84110 
No. of

Copies

C. R. 01 sen

Environmental Sciences Division

Oak Ridge National Laboratory

0ak Ridge, TN 37831-6036

R. T. Peake

U.S. Environmental Protection Agency

Office of Radiation Programs

401 M St. SW

Washington, DC 20460

F. M. Phillips

New Mexico Institute of

Mining and Technology

Socorro, NM 87801

M. Reimer

U.S. Geological Survey

MS 963

Denver Federal Center

Denver, C0 80225

S. D. Schery

New Mexico Institute of

Mining and Technology

Socorro, NM 87801

J. P. Schubert

Argonne National Laboratory

9700 South Cass Avenue

Argonne, 1L 60439

R. R. Schumann

U.S. Department of the Interior P.0. Box 25046, MS 939, DFC Denver, CO 80225

A. B. Tanner

U.S. Department of Interior

Geological Survey

990 National Center

Reston, VA 22092
No. of

Copies

$\mathrm{J}$. Washington

318 Deike Bldg.

University Park, PA 16802

J. L. Wilson

New Mexico Institute of

Mining and Technology

Socorro, NM 87801

C. Hray

G. K. Yuill \& Assoc., Ltd.

1441 Pembina Hwy

Winnepeg, Manitoba

CANADA R3T 2C4

ONSITE

DOE Richland Operations Office

E. C. Norman

40 Pacific Northwest Laboratory

C. E. Elderkin

J. W. Falco

D. J. Holford (10)

H. D. Freeman (5)

G. W. Gee (5)

J. M. Hales

J. N. Hartley

P. C. Hays

E. L. Owczarski

P. C. Owczarski (5)

R. L. Skaggs

J. A. Stottlemyre

R. E. Wildung

Publishing Coordination

Technical Report Files 